Florida International University FIU Digital Commons

$11-14-2013$

\title{
XPSWMM Analysis of the ORNL Stormwater Collection System Up to Outfall 211
}

Heidi Belle Henderson

heidi1_@hotmail.com

DOI: 10.25148 /etd.FI13120606

Follow this and additional works at: https://digitalcommons.fiu.edu/etd

Part of the Civil Engineering Commons, and the Environmental Engineering Commons

\section{Recommended Citation}

Henderson, Heidi Belle, "XPSWMM Analysis of the ORNL Stormwater Collection System Up to Outfall 211" (2013). FIU Electronic Theses and Dissertations. 1020.

https://digitalcommons.fiu.edu/etd/1020

This work is brought to you for free and open access by the University Graduate School at FIU Digital Commons. It has been accepted for inclusion in FIU Electronic Theses and Dissertations by an authorized administrator of FIU Digital Commons. For more information, please contact dcc@fiu.edu. 


\title{
FLORIDA INTERNATIONAL UNIVERSITY \\ Miami, Florida
}

\section{XPSWMM ANALYSIS OF THE ORNL STORMWATER COLLECTION SYSTEM UP TO OUTFALL 211}

\author{
A thesis submitted in partial fulfillment of \\ the requirements for the degree of \\ MASTER OF SCIENCE \\ in \\ ENVIRONMENTAL ENGINEERING \\ by
}

Heidi Belle Henderson 
To: Dean Amir Mirmiran

College of Engineering and Computing

This thesis, written by Heidi Belle Henderson, and entitled XPSWMM Analysis of the ORNL Stormwater Collection System up to Outfall 211, having been approved in respect to style and intellectual content, is referred to you for judgment.

We have read this thesis and recommend that it be approved.

Georgio Tachiev

Omar I. Abdul-Aziz

Hector R. Fuentes, Major Professor

Date of Defense: November 14, 2013

The thesis of Heidi Belle Henderson is approved.

$\begin{array}{r}\text { Dean Amir Mirmiran } \\ \text { College of Engineering and Computing } \\ \hline \begin{array}{r}\text { Dean Lakshmi N. Reddi } \\ \text { University Graduate School }\end{array}\end{array}$

Florida International University, 2013 


\section{ACKNOWLEDGMENTS}

First, I would like to thank Florida International University for accepting me into their Civil and Environmental Engineering Master of Science program. In addition, I thank Dr. Leonel Lagos, the Director of the DOE Fellows Program at the Applied Research Center, for giving me the opportunity to work on this project that developed into a thesis, and to my committee members - Dr. Hector R. Fuentes, Dr. Georgio Tachiev, and Dr. Omar I. Abdul-Aziz - for their guidance through the development of the thesis. Special thanks go to Adrian Arbide for his assistance in the analysis of the data and to Catherine Wadley for her assistance in the finishing touches. I am also grateful to Dr. Eric Pierce for his mentorship during my summer internship at the Oak Ridge National Laboratory while collecting the data for my thesis. Additional thanks to Angelique Lawrence and Peggy Shoffner for always making themselves available for discussion and review of my thesis during their busy schedule. Last, but never least, thanks goes to my wonderful mother, father, and fiancé for their continual love and support day in and day out, and to Jesus Christ, my Lord and Savior. 


\section{ABSTRACT OF THE THESIS \\ XPSWMM ANALYSIS OF THE ORNL STORMWATER COLLECTION SYSTEM UP \\ TO OUTFALL 211}

by

Heidi Belle Henderson

Florida International University, 2013

Miami, Florida

\section{Professor Hector R. Fuentes, Major Professor}

The Oak Ridge National Laboratory, Tennessee, was the site for a number of US Government projects during the 1940s and 1950s including the development of thermonuclear weapons. Chemical processes conducted at the site as part of these projects resulted in contamination of certain building areas at the ORNL. The purpose of this study is to develop a hydraulic-hydrologic computer model via XPSWMM to determine surface water flow rates and water stages within the drainage system during rainfall events and introduce a conservative contaminant into the system to trace peak concentrations of contaminants.

The model was calibrated by simulating actual rainfall events over the area of interest. The model results were compared to that of Outfall 211's monitored data. Trial 1 was most successful, where the cumulative flow rates produced by the model and the monitored data varied only by $0.5 \mathrm{cfs}$. A sensitivity analysis was completed by varying Manning's coefficient and infiltration parameters within the area of interest. The sensitivity analysis concluded that the model was responsive to the variations presented; 
however, only minor differences were determined for the selected range of parameters, indicating robustness of model predictions.

A hypothetical conservative contaminant was entered into the system as constant and varied timeseries. The resulting pollutographs produced by XPSWMM aid in the assessment for potential mobilization of contaminants and provide insight to where peak concentrations and loads occur under present conditions.

Probability exceedance and probability distribution methods were used to analyze the timeseries of flow and pollutant concentrations collected during this study. Probability exceedance curves determined the percentage of time flooding occurred within the system under various conditions. The flow rates and concentrations produced by the transport analysis were best described by the Generalized Extreme Value, while the loading rates were best described by Log-logistic distribution. 


\section{TABLE OF CONTENTS}

CHAPTER PAGE

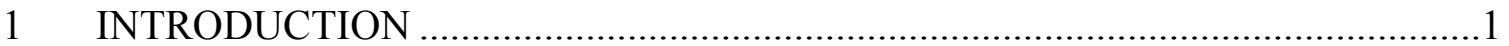

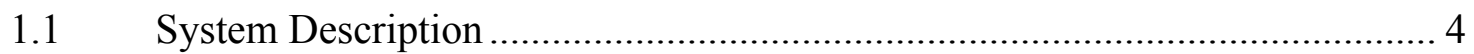

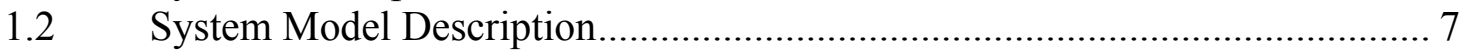

2 RESEARCH OBJECTIVES ......................................................................11

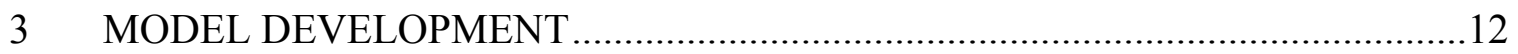

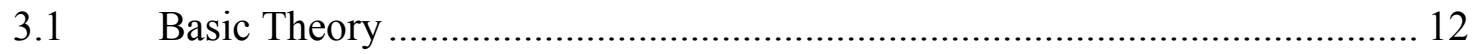

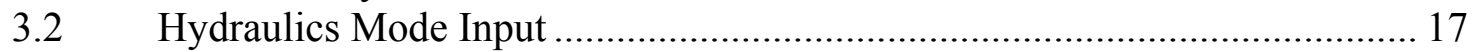

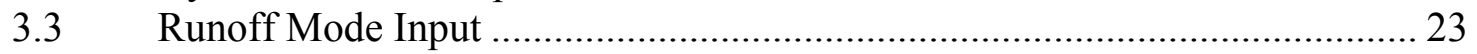

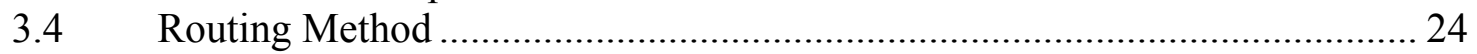

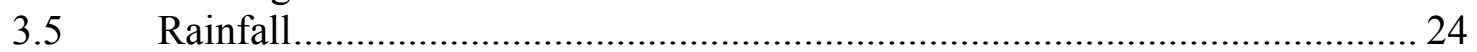

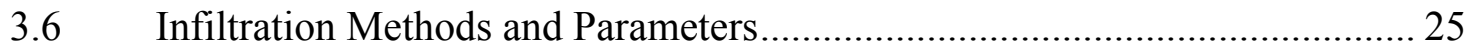

3.6.1 Green Ampt Infiltration Method .......................................................... 26

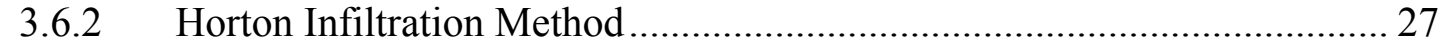

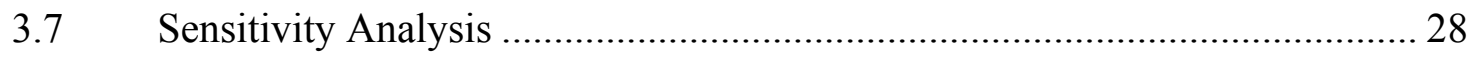

3.7.1 Manning's Roughness Sensitivity Analysis Results .................................. 31

3.7.2 Infiltration Sensitivity Analysis Results .................................................. 33

3.8 Design Storm Simulations ..................................................................... 35

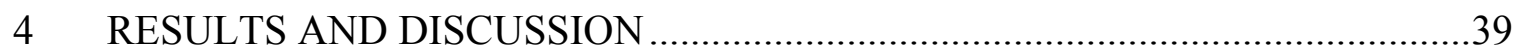

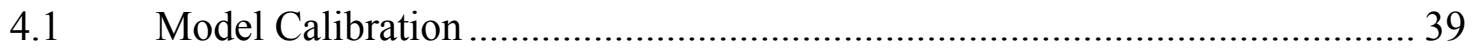

4.1.1 Calibration of Steady Uniform Flow Conditions ....................................... 39

4.1.2 Unsteady Non-Uniform Flow Calibrations ................................................ 45

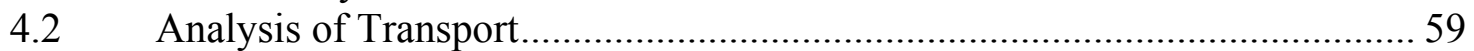

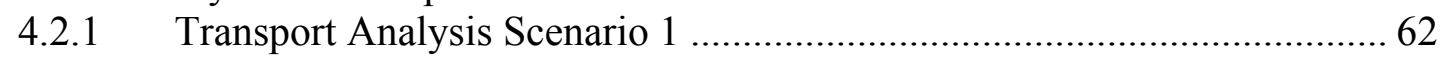

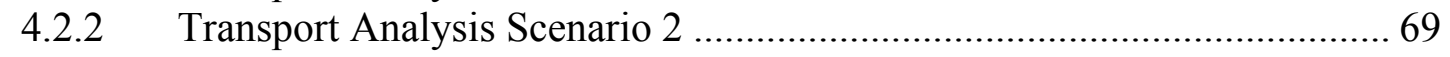

4.2.3 Transport Analysis Scenario 3 ............................................................ 75

4.2.4 Transport Analysis Scenario 4 ................................................................ 78

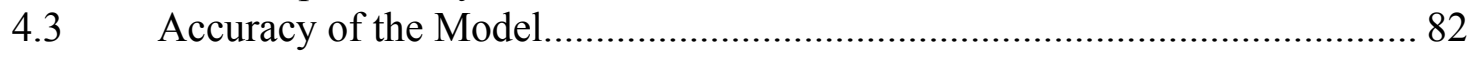

4.4 Probability Exceedance Analysis of Hydrologic Events ............................... 83

4.4 Probability Distribution of Hydrologic and Transport Data ............................ 86

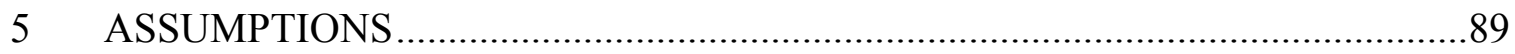

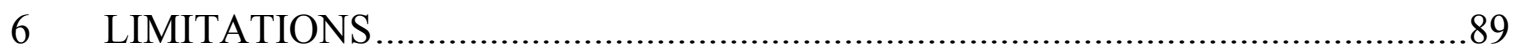

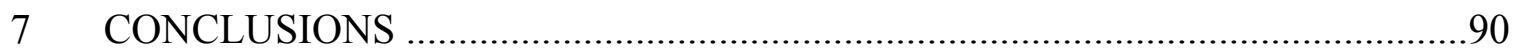

7.1 Calibration of Surface Water Model............................................................ 91

7.1.1 Sensitivity Analysis ............................................................................. 91

7.1.2 Design Storms Conclusions................................................................... 91 


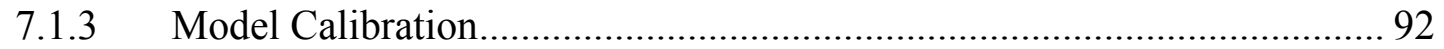

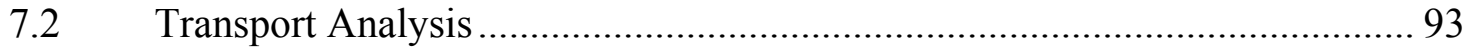

7.3 Characterize Transport Data and Show Trends .......................................... 93

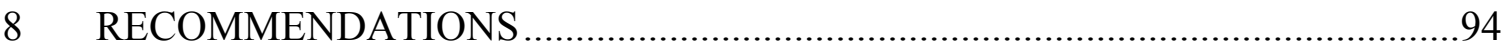

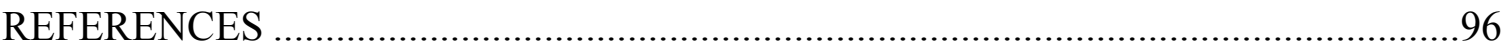




\section{LIST OF TABLES}

TABLE

PAGE

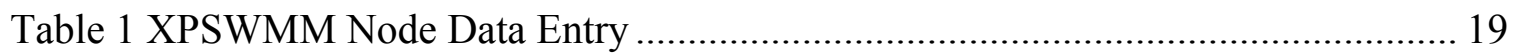

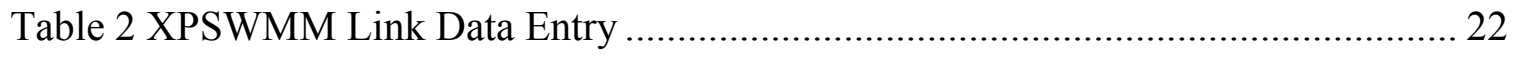

Table 3 Manning's Values for Concrete Pipe ……………………………………….... 33

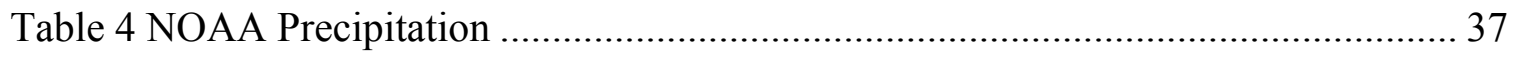

Table 5 Design Storm Stage and Flow Rate Results ........................................................ 38

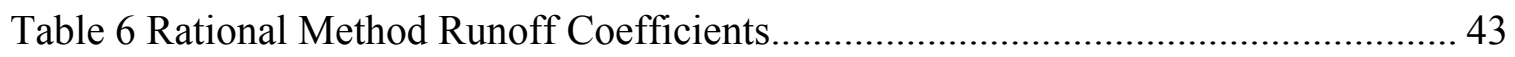

Table 7 Rainfall Data for Calibration Trial 1................................................................ 47

Table 8 Rainfall Data for Calibration Trial 2.............................................................. 50

Table 9 Rainfall Data for Calibration Trial 3.............................................................. 53

Table 10 Rainfall Data for Calibration Trial 4........................................................... 56

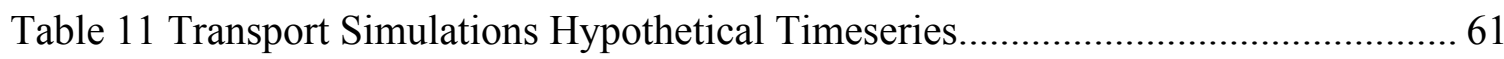

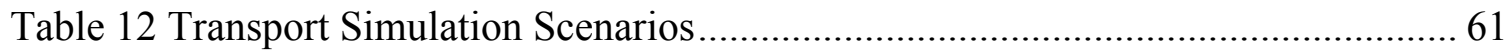

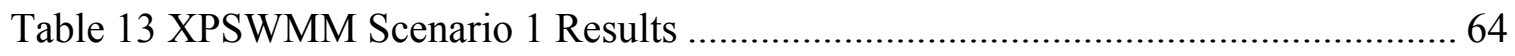

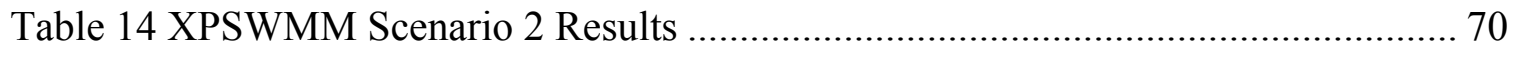

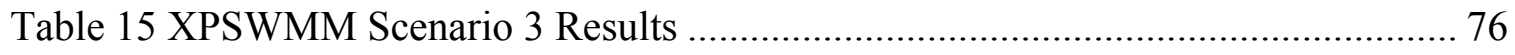

Table 16 XPSWMM CC4 Scenario 4 Results .............................................................. 79

Table 17 Continuity Results.................................................................................. 82

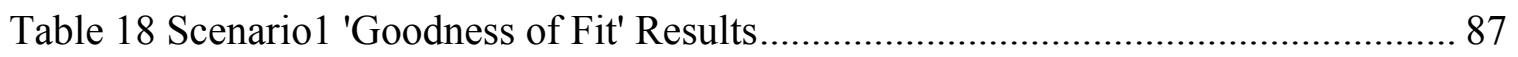

Table 19 Scenario 2 'Goodness of Fit’ Results ............................................................. 87

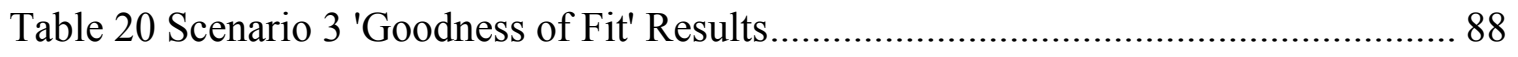

Table 21 Scenario 4 'Goodness of Fit' Results ............................................................ 88 


\section{LIST OF FIGURES}

FIGURE

PAGE

Figure 1 Oak Ridge Reservation (USEPA, 2004) ................................................... 2

Figure 2 Location of ORNL in ORR Showing Drainage Basin (ChemRisk, 1999)......... 3

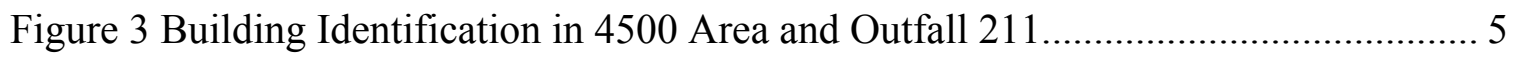

Figure 4 Area of Interest Boundary Marked in Red .............................................. 5

Figure 5 XPSWMM Digital Terrain Model of 4500 Area created with XPSWMM......... 6

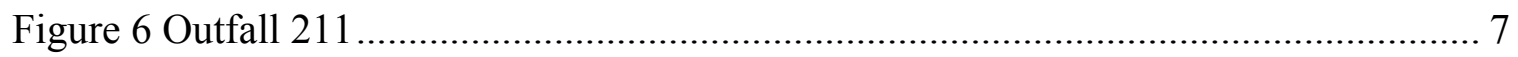

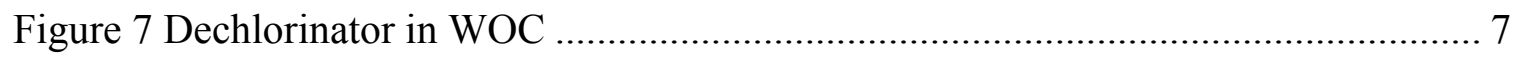

Figure 8 Sub-catchment Delineation of System ................................................... 9

Figure 9 Stormwater Collection System diagram in XPSWMM.............................. 10

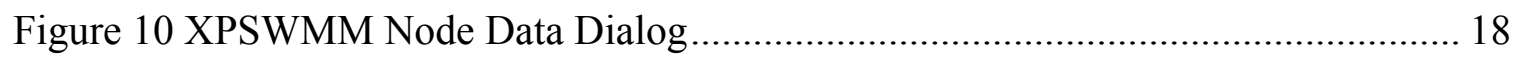

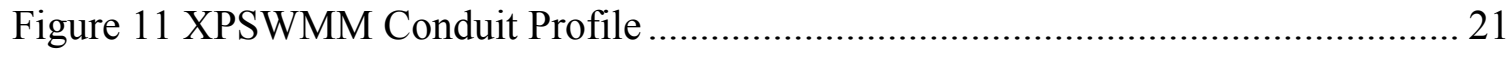

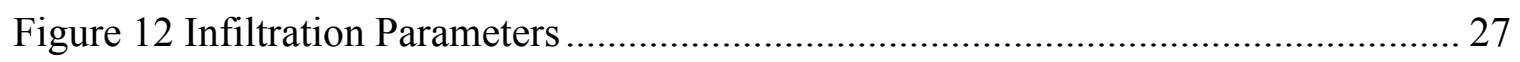

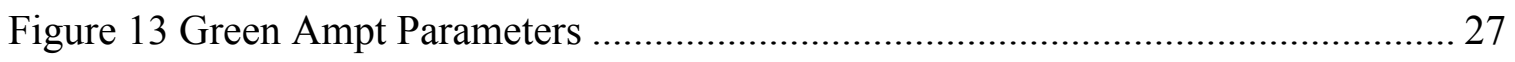

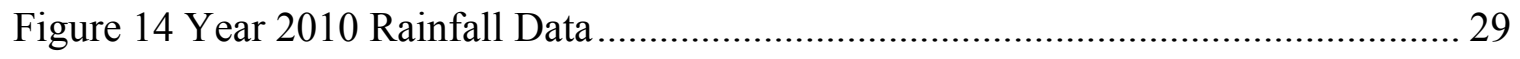

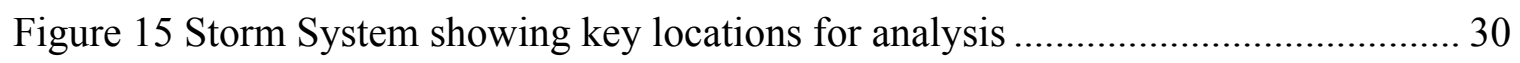

Figure 16 MH211-3 Hydrograph and PE Curves for Manning's Roughness Coefficient Sensitivity Analysis ...................................................................... 32

Figure 17 OF-211 Hydrograph and PE Curves for Manning's Roughness Coefficient Sensitivity Analysis ........................................................................... 33

Figure 18 MH211-3 PE Curves for Infiltration Sensitivity Analysis ............................ 34

Figure 19 OF-211 PE Curves for Infiltration Sensitivity Analysis................................ 34 


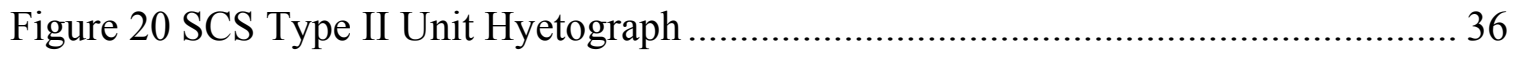

Figure 22 Rainfall Hyetograph for Steady Uniform Flow.............................................. 40

Figure 23 Stormwater Collection System for Steady Uniform Flow ………………….... 41

Figure 24 Conduit P-20 Results for Steady Uniform Flow ............................................. 44

Figure 25 Conduit P-26 Results for Steady Uniform Flow ............................................. 45

Figure 26 Rainfall Hyetograph for Calibration Trial 1 ............................................... 48

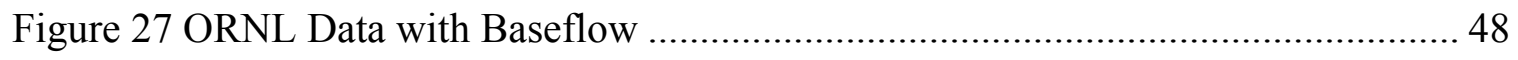

Figure 28 ORNL Data and XPSWMM Results Hydrograph.......................................... 49

Figure 29 ORNL Data and XPSWMM Results Cumulative Flow Rates ......................... 49

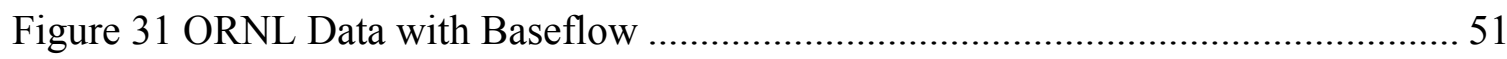

Figure 32 ORNL Data and XPSWMM Results Hydrograph............................................ 52

Figure 33 ORNL Data and XPSWMM Results Cumulative Flow Rates ......................... 52

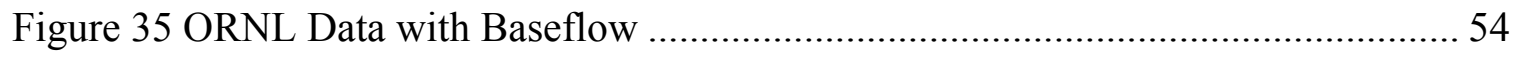

Figure 36 ORNL Data and XPSWMM Results Hydrograph............................................ 55

Figure 37 ORNL Data and XPSWMM Results Cumulative Flow Rates .......................... 55

Figure 39 ORNL Data with Baseflow ………………….......................................... 57

Figure 40 ORNL Data and XPSWMM Results Hydrograph............................................ 58

Figure 41 ORNL Data and XPSWMM Results Cumulative Flow Rates ......................... 58

Figure 42 Transport Scenario 1 Entrance of Pollutant Location ...................................... 62

Figure 43 XPSWMM Scenario 1 P-10 Hydrograph and Pollutograph.............................. 65

Figure 44 XPSWMM Scenario 1 P-11 Hydrograph and Pollutograph............................... 66

Figure 45 XPSWMM Scenario 1 P-15 Hydrograph and Pollutograph.............................. 67

Figure 46 XPSWMM Scenario 1 P-26 Hydrograph and Pollutograph............................. 68 
Figure 47 XPSWMM Scenario 1 P-27 Hydrograph and Pollutograph.............................. 68

Figure 48 Transport Analysis Scenario 2 Pollutant Entrance Locations .......................... 69

Figure 49 XPSWMM Scenario 2 P-10 Hydrograph and Pollutograph.............................. 71

Figure 50 XPSWMM Scenario 2 P-11 Hydrograph and Pollutograph............................. 72

Figure 51 XPSWMM Scenario 2 P-15 Hydrograph and Pollutograph............................. 73

Figure 52 XPSWMM Scenario 2 P-26 Hydrograph and Pollutograph............................. 74

Figure 53 XPSWMM Scenario 2 P-27 Hydrograph and Pollutograph............................. 74

Figure 54 Transport Analysis Scenario 3 Entrance of Pollutant...................................... 75

Figure 56 XPSWMM Scenario 3 P-26 Hydrograph and Pollutograph............................. 77

Figure 57 XPSWMM Scenario 3 P-27 Hydrograph and Pollutograph.............................. 78

Figure 58 Transport Analysis Scenario 4 Pollutant Entrance Locations .......................... 79

Figure 59 XPSWMM Scenario 4 P-15 Hydrograph and Pollutograph.............................. 80

Figure 60 XPSWMM Scenario 4 P-26 Hydrograph and Pollutograph............................. 81

Figure 61 XPSWMM Scenario 4 P-27 Hydrograph and Pollutograph.............................. 81

Figure 62 P-10 Hydrographs Indicating Scenarios 1-4 and their PE Curves ................... 85

Figure 63 P-26 Hydrographs Indicating Scenarios 1-4 and their PE Curves .................. 85 


\section{ABBREVIATIONS AND ACRONYMS}

$\mathrm{AC}$

CAD

cfs

$\mathrm{CP}$

DTM

EGL

$\mathrm{ft}$

GEV

GIS

HGL

$\mathrm{Hg}$

in

Li-6

$\mathrm{lb}$

MATLAB

$\mathrm{mg} / \mathrm{L}$

$\mathrm{MH}$

NAD

NOAA

NRCS

OF-211

ORNL
Air conditioning

Computer-aided Design

Cubic Feet per Second

Concrete pipe

Digital Terrain Model

Energy Grade Line

feet

Generalized Extreme Value

Geographic Information Systems

Hydraulic Grade Line

Mercury

inch

Lithium 6

pound

Matrix Laboratory, Numerical Computing

Milligram per Liter

Manhole

North American Datum

National Oceanic and Atmospheric Administration

Natural Resources Conservation Service

Outfall 211

Oak Ridge National Laboratory 


$\begin{array}{ll}\text { ORR } & \text { Oak Ridge Reservation } \\ \text { PE } & \text { Probability Exceedance } \\ \text { PEC } & \text { Probability Exceedance Curve } \\ \text { PD } & \text { Probability Distribution } \\ \text { PDF } & \text { Probability Distribution Function } \\ \text { PVC } & \text { Polyvinyl Chloride } \\ \text { Q } & \text { Volumetric flow rate measured in cubic feet per second } \\ \text { RCP } & \text { Reinforced Concrete Pipe } \\ \text { SCS } & \text { Soil Conservation Service } \\ \text { SWMM } & \text { Stormwater Management Model } \\ \text { VP } & \text { Vitrified Pipe } \\ \text { WI } & \text { Wrought Iron } \\ \text { WOC } & \text { White Oak Creek } \\ \text { XPSWMM } & \text { Windows based Stormwater Management Model }\end{array}$




\section{INTRODUCTION}

The Oak Ridge National Laboratory (ORNL) in the Oak Ridge Reservation (ORR), Tennessee, was the site for a number of US Government projects during the 1940s and 1950s including the development of the atomic bomb and thermonuclear weapons. Chemical processes conducted at the site as part of these projects resulted in contamination of certain building areas at the ORNL. Because contaminants attach to dissolved and suspended solids within an aquatic system (Ravichandran, 2003 and Yang, 2006) when rainfall occurs these contaminants may be transported from the ORNL site through stormwater drainage systems. The possibility of contamination in surrounding waterways is a cause for concern as the chemicals being transported are dangerous pollutants and can be carried through the stormwater system and then further through adjacent, connected creeks and rivers.

The purpose of this study is to develop a robust computer model that can determine surface water flow rates and water stages during rainfall events at the ORNL

4500 Area stormwater drainage system. The study will also examine the potential of tracking the transport of peak concentrations of any contaminants within the stormwater system using this model. 


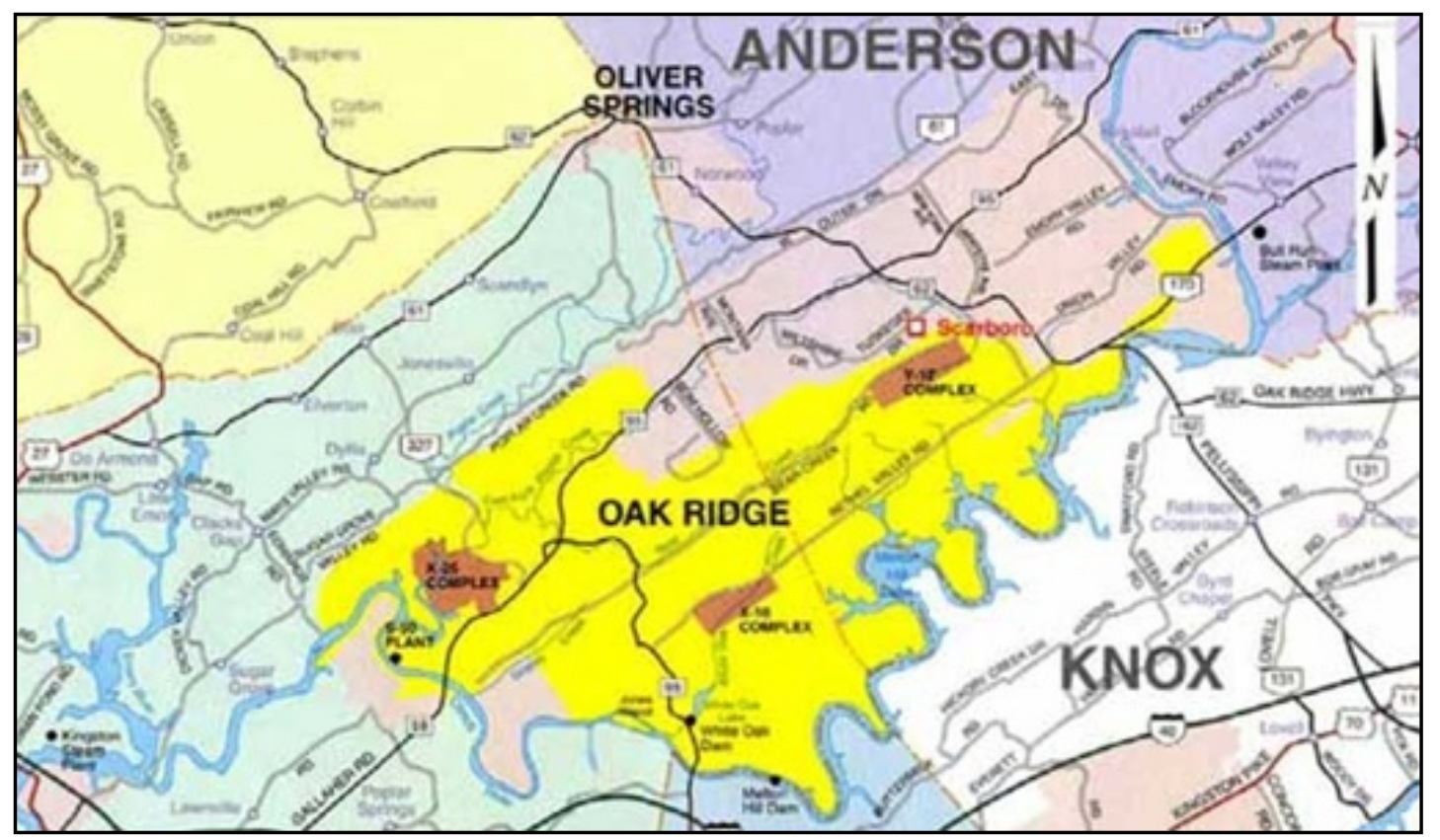

Figure 1 Oak Ridge Reservation (USEPA, 2004)

ORNL is located within the White Oak Creek (WOC) watershed, which is within the Central Bethel Valley watershed. (See Figure 1). WOC, a tributary of the Tennessee River, is the main stream running adjacent to ORNL along its south-eastern border and represents a major route for water and contaminant transport (USEPA, 2004; USEPA, 2006). The WOC watershed is comprised of approximately 2,098 acres and collects runoff and treated wastewater discharge from ORNL where it is drained into White Oak Lake and then the Clinch River (ORNL, 2008; USDOE, 1999). The location of the area of interest is located within the red circle shown in Figure 2. 


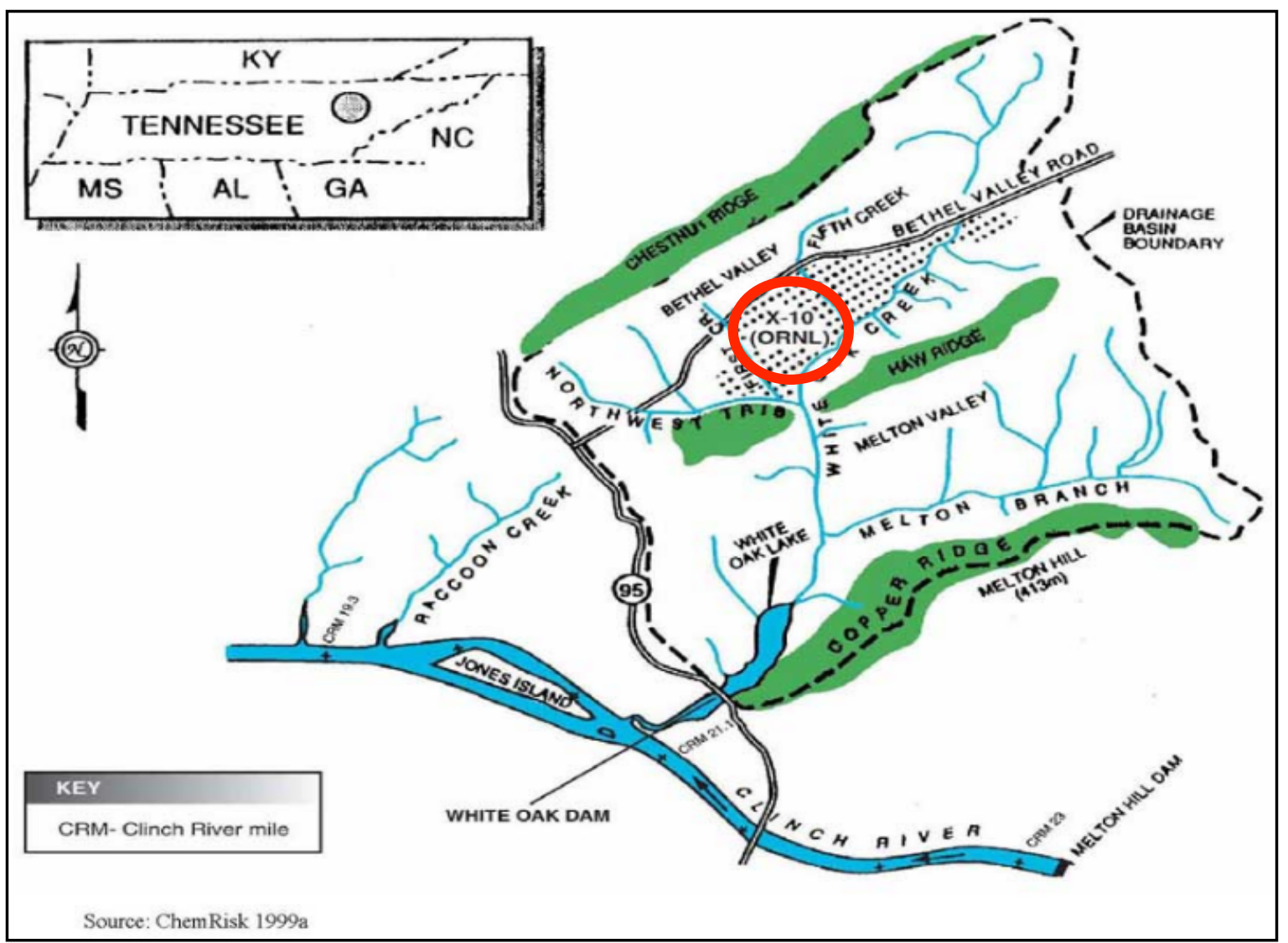

Figure 2 Location of ORNL in ORR Showing Drainage Basin (ChemRisk, 1999)

The ORNL Building 4501, the High-Level Radiochemical Laboratory, and Building 4505, the Experimental Engineering Laboratory, were built in the 1950s to house specific processes involving lithium exchange. Lithium-6 (Li-6) is a key ingredient in the design of the thermonuclear weapons and was produced by separating lithium isotopes using an aqueous solution containing mercury $(\mathrm{Hg})$ (Brooks and Southworth, 2011). The major concern now at ORNL is mercury contamination, and other pollutants resulting from these processes including radionuclides (strontium-90 and radium-228) and inorganics (Taylor, 1989).

ORNL is an industrial area and is composed of mostly impervious area with sparse pervious areas. The system of interest is bounded by mostly impervious land cover 
due to roof top runoff through storm drains and pavement to the north, south, east, and west. There are minor pervious areas throughout the drainage area.

\section{$1.1 \quad$ System Description}

The specific system of interest is a stormwater drainage system from the 4500 drainage area at the ORNL up to and including Outfall 211 (OF-211). This particular system was chosen because it serves the specific 4500 Area buildings referred to above where most of the contamination occurred. It is approximately 4.5 acres and encompasses ORNL buildings: 4500N Wings 1, 2, and part of Wing 3, 4500S Wings 1, 2, and part of Wing 3, 4501, 4505, 4507, 4508, and 4556. The buildings are shown in Figure 3 and Figure 4.

The storm system is unique in that sources from the adjacent buildings, such as cooling water and condensate from various air conditioning (AC) units contribute to the OF-211 drainage system as well as process water from the Creep Laboratory (Building 4500S). 


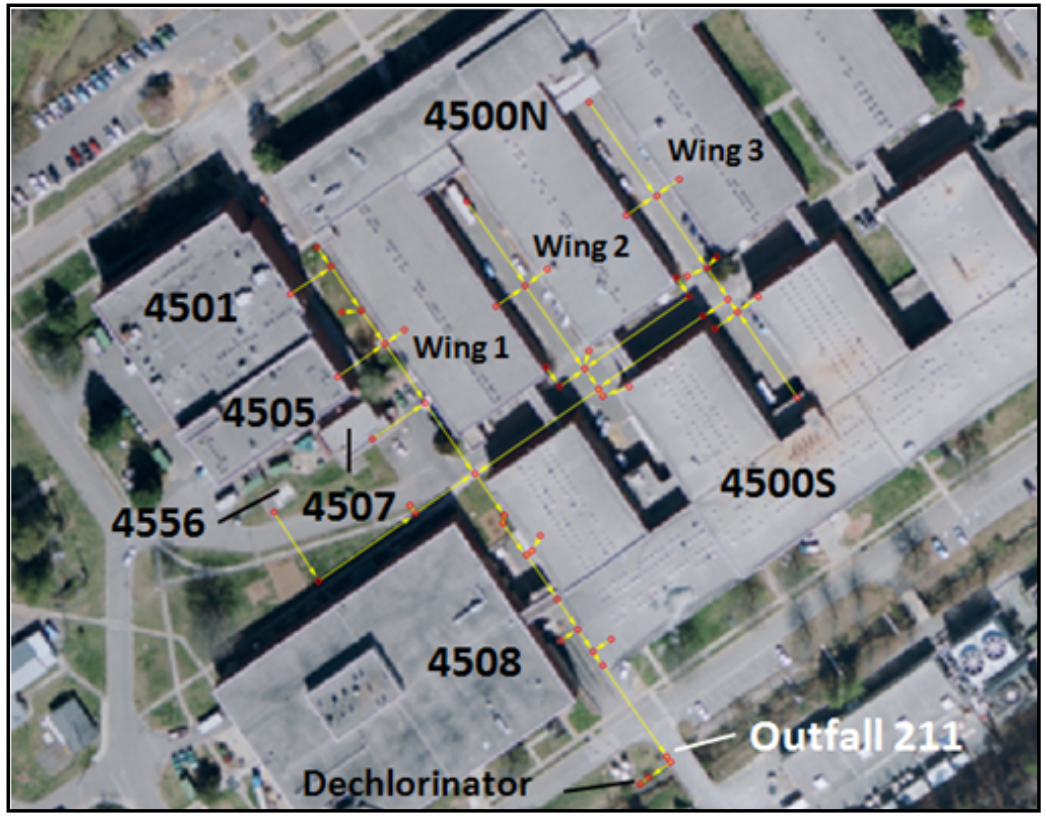

Figure 3 Building Identification in 4500 Area and Outfall 211

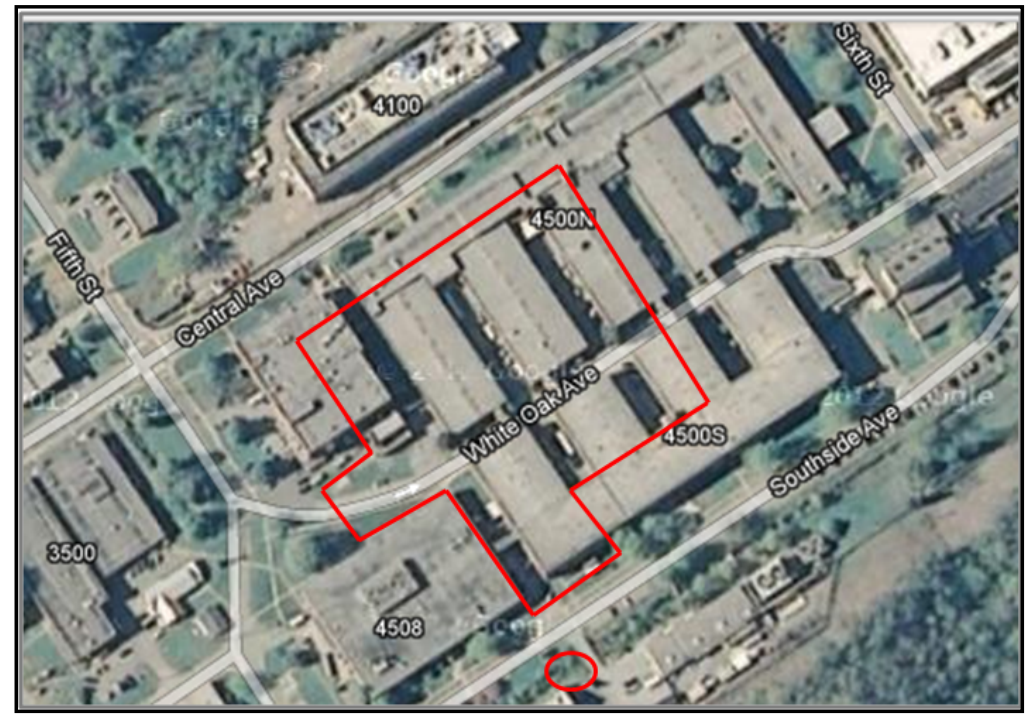

Figure 4 Area of Interest Boundary Marked in Red

The area of interest lies within the Tennessee State Plane North American Datum (NAD 1983). The area bordering the area of interest ranges in elevation from $780 \mathrm{ft}$ NAD to $855 \mathrm{ft}$ NAD as shown on the digital terrain model (DTM) in Figure 5. However, the area of interest is relatively flat ranging from $780 \mathrm{ft}$ NAD to $810 \mathrm{ft}$ NAD. 


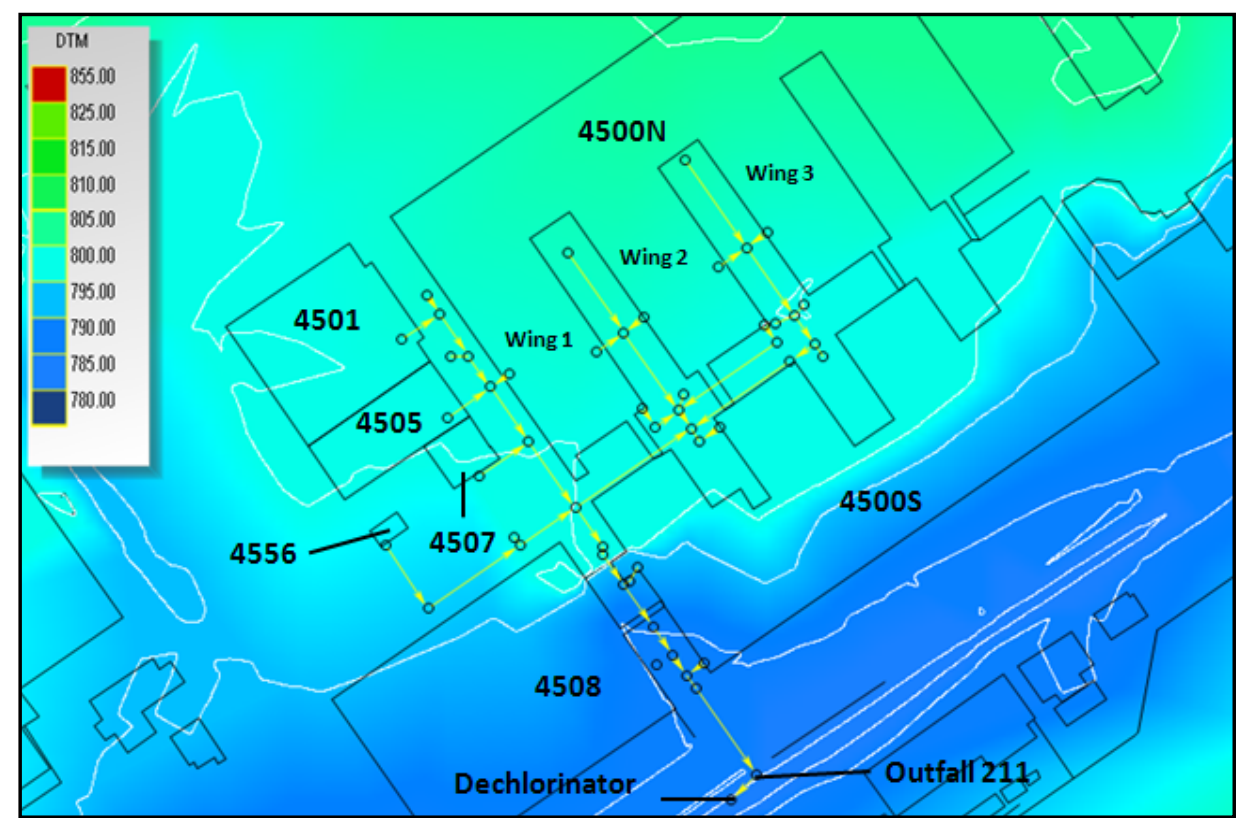

Figure 5 XPSWMM Digital Terrain Model of 4500 Area created with XPSWMM

OF-211 is the end point of the drainage system and conveys water directly into WOC. The location of OF-211 in the 4500 Area is shown in Figure 3. OF-211 is a culvert located under a bridge as shown in Figure 6. However, prior to its release during dry periods, the water is held back by a 65 " long, 13.5" high metal plate weir accompanied by an 8 " PVC pipe orifice. The 8" PVC pipe conveys the water into a dechlorinator shown in Figure 7. Just prior to the dechlorinator the 8" PVC pipe splits into two 4" PVC pipes as it is directed through the dechlorinator for disinfection prior to its final release into WOC. It seems that only one of the two 4" PVC conveys water through the dechlorinator where the other is closed via a ball valve. This immediately impacts the system by restricting flow from an 8" PVC pipe to a 4" PVC pipe. Thus, for this project the dechlorinator will not be modeled and the point of discharge for the system will be immediately after OF-211. 


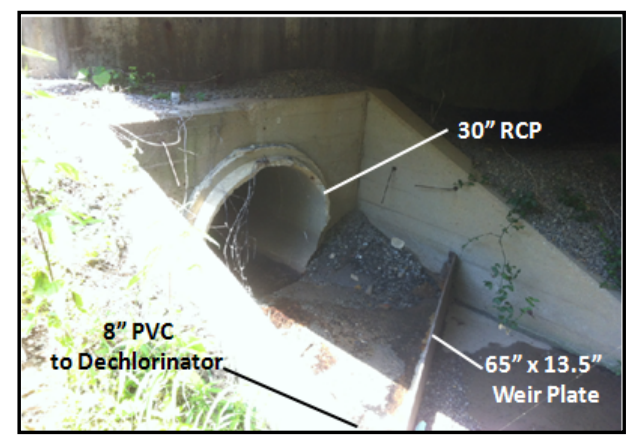

Figure 6 Outfall 211

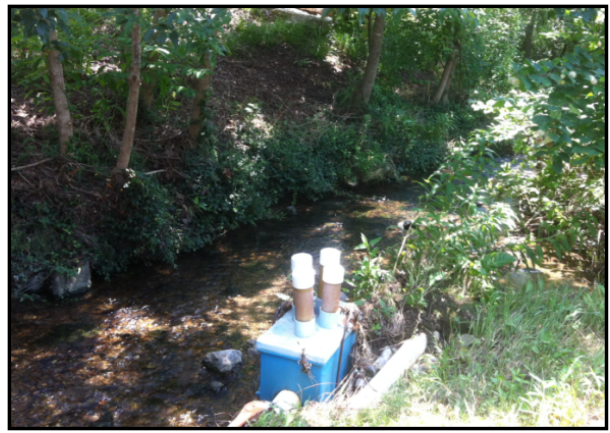

Figure 7 Dechlorinator in WOC

\subsection{System Model Description}

The system contributing drainage areas up to OF-211 was documented through observations and measurements onsite and using various maps, construction drawings, and diagrams provided by the ORNL. A GIS file provided the location of the 4500 Area drainage system. The specific locations of the pipes and junctions were drawn over the GIS file shown in Figure 8. The components of the system were entered into the XPSWMM software which included 52 nodes and 51 pipes (links) of closed circular conduits discharging into a free surface creek. The node elevations range from $793 \mathrm{ft}$, NAD, to $803 \mathrm{ft}, \mathrm{NAD}$, respectively.

The system is highly impervious. The basins containing only roof top runoff are $100 \%$ impervious. Other sub-catchment basins where minor pervious areas existed were estimated at $95 \%$ impervious. Similarly, sub-catchment basins containing minor 
impervious areas were estimated at $95 \%$ pervious. The percent impervious also dictates the quantity of contaminant transport through the system; the greater the percent impervious, the greater the mobility of the contaminant because water runoff is higher over impervious areas. These areas were estimated based on site visits as no other data was available. It is recommended that the pervious areas should be examined further.

There are multiple sub-drainage areas, with up to five sub-catchment areas for one inlet. The sub-catchment areas are defined by impervious, slope, width, and area. The sub-catchment areas were delineated and calculated based on the aerial view of the 4500 Area uploaded in XPSWMM. The sub-catchment areas are linked to a node so that once the rainfall and runoff is simulated it is then routed through the system. Model inputs include topography, pervious and impervious drainage areas of each sub-catchment area, infiltration parameters, slope of sub-catchment areas, length and diameter of pipes, and Manning's coefficient for pipe roughness. 


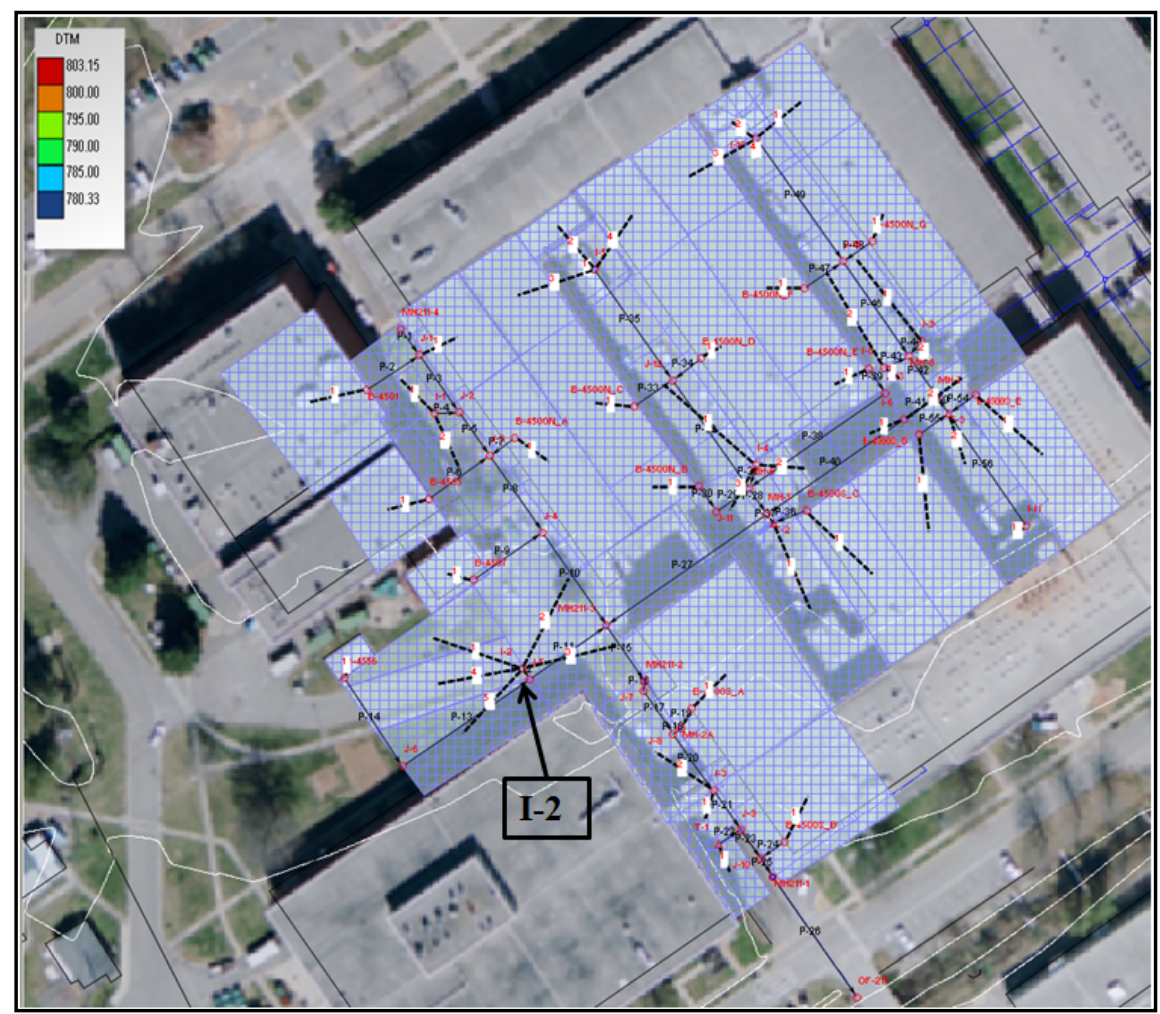

Figure 8 Sub-catchment Delineation of System

From Building 4556 a 4" vitrified pipe (VP) connects to a 10" VP which conveys water into a manhole (MH) labeled MH211-3. MH211-3 is located at the northwest corner of Building $4500 \mathrm{~S}$. The main storm line runs west of $4500 \mathrm{~N}$ and $4500 \mathrm{~S}$ and contains MH211-1, MH211-2, MH211-2a, MH211-3, MH211-4, and OF-211. It begins at MH211-4 and ends at OF-211. From MH211-4 to MH211-3, the main storm line is constructed of 15" pipe (RCP). South of MH211-3, the line is a 30" pipe (RCP). 


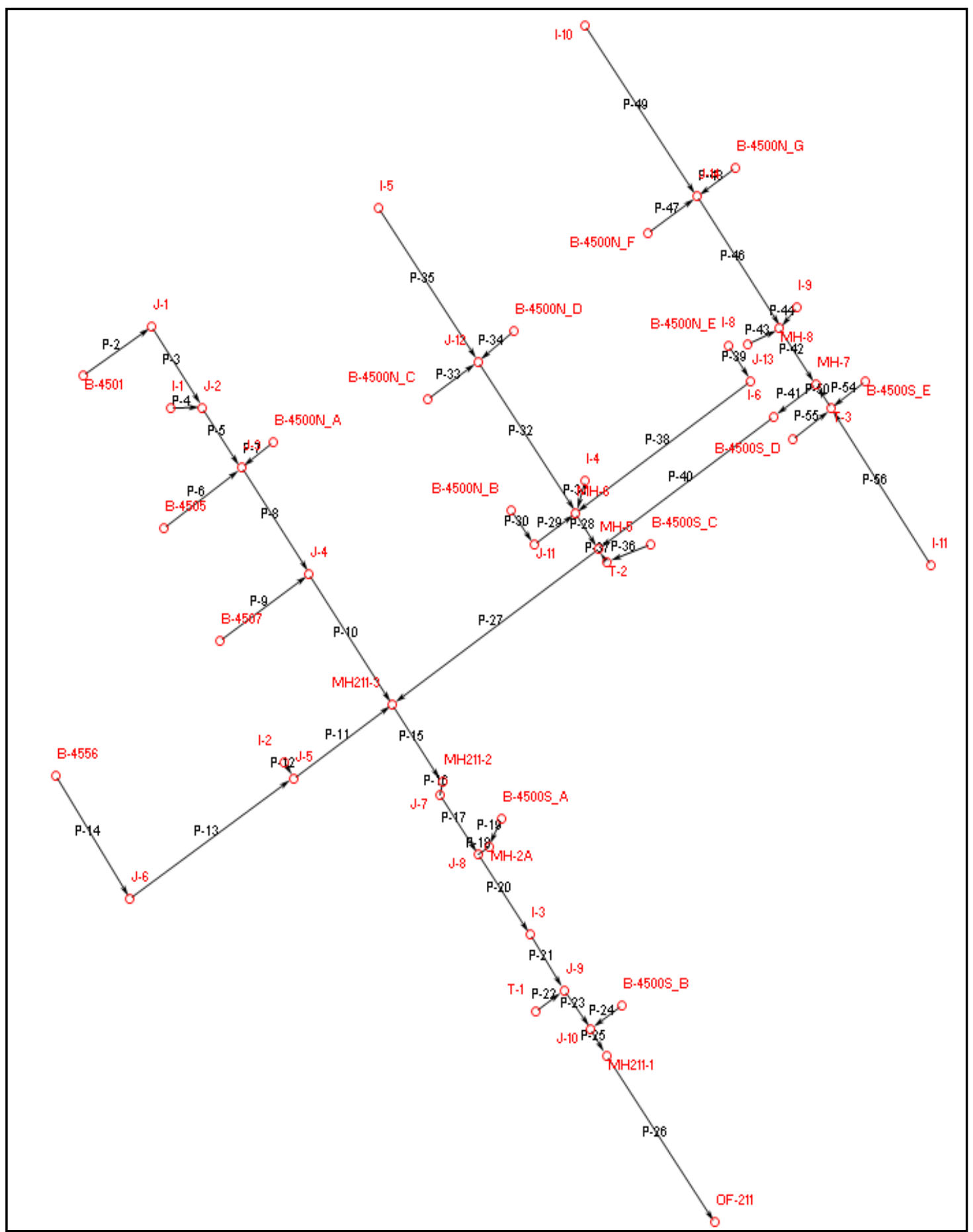

Figure 9 Stormwater Collection System diagram in XPSWMM 


\section{RESEARCH OBJECTIVES}

Contaminants within an aquatic system attach to dissolved and suspended solids (Ravichandran, 2003 and Yang, 2006) so that when rainfall occurs, suspended and dissolved solids, carrying the contaminant, can be transported through the system via stormwater runoff. In order to effectively assess the transport of contaminants within the system, it is important to know and understand the flow of water within the system of interest at the ORNL.

The research objectives of this study are to develop a hydrologic-hydraulic software model of the stormwater collection system that will:

1. Produce a calibrated surface water model for ORNL's future use in the prediction of flow rates and water stages within the 4500 Area to OF-211.

2. Provide a transport analysis by introducing a conservative contaminant into the system at various locations in order to examine the peak concentrations downstream where existing contamination may be located within the system

3. Allow the transport data to fit to:

a. probability exceedance curves (PEC) to determine the duration of peak flow rates and stages, and

b. known probability distribution functions (PDF) in order to characterize the data and understand the underlying trend of the flow rates, concentrations, and loads. 


\section{MODEL DEVELOPMENT}

The software program used to develop the stormwater model is XPSWMM, a Microsoft Windows version of the Environmental Protection Agency (EPA) stormwater modeling (SWMM) tool (USEPA, 2012). XPSWMM uses a spatially distributed link/node network to analyze the hydraulic, hydrologic, and quality of stormwater or wastewater system. The software produces models simulating the rainfall-runoff process including infiltration, evaporation, and depression storage as well as groundwater interaction.

\subsection{Basic Theory}

The system is modeled as one dimensional steady uniform flow as well as unsteady non-uniform flow. The gravity storm sewer is open to atmospheric pressure and is simulated as partially filled open channel flow. However, it is possible that during a large storm event that some pipes will operate at capacity and encounter full flow.

The total energy conveyed between the links within the system is accounted for by solving the Bernoulli's equation. Bernoulli's equation may be applied to pressurized systems and gravity systems and assumes that the fluid is incompressible, steady flow occurs along a streamline. It considers two points along a streamline, one upstream and one downstream, where the energy upstream is equal to the energy downstream plus the energy losses during the conveyance. Bernoulli's equation written in terms of specific energy is as follows:

$$
E_{1}=E_{2}+E_{f}
$$


where $E_{1}$ represents the specific energy upstream, $E_{2}$ represents specific energy downstream, and $\mathrm{E}_{\mathrm{f}}$ represents the total specific energy lost downstream.

Specific energy is the total energy of the water body relating to the channel bottom as its datum. The upstream and downstream total specific energy or head, $\mathrm{E}_{1}$ and $E_{2}$, in the Bernoulli's equation accounts for pressure, kinetic, and potential energy of the fluid and is expressed as follows:

$$
E=\frac{p}{\gamma}+\frac{v^{2}}{2 g}+z
$$

The equation above also represents the energy grade line (EGL) of the water surface where the hydraulic grade line (HGL) only accounts for the first and last term, the pressure and elevation heads. Therefore, the EGL will always be equal to or larger than the HGL by a difference of the second term, the kinetic energy.

The total energy losses due to friction, $E_{f}$, may be from a combination of head loss from pipe friction and from minor losses such as entrance and exit losses within the system. Bernoulli's equation at steady-state written in terms of pressure, kinetic, and potential energy as well as friction losses is as follows:

$$
\frac{p_{1}}{\gamma}+\frac{v_{1}^{2}}{2 g}+z_{1}=\frac{p_{2}}{\gamma}+\frac{v_{2}^{2}}{2 g}+z_{2}+h_{f}+h_{m}
$$

where $\mathrm{p}$ is the atmospheric pressure, $\gamma$ is the density of the fluid, $\mathrm{v}$ is the velocity, $\mathrm{g}$ is the gravity constant, $\mathrm{z}$ is the elevation from the datum, $\mathrm{h}_{\mathrm{f}}$ is head loss due the friction of the pipe, and $h_{m}$ is the minor friction loss.

In any control volume, the inflow must equal the outflow as defined by the law of conservation of mass at steady-state: 


$$
Q=A_{1} * v_{1}=A_{2} * v_{2}
$$

Manning's formula shown in Equation 5 may be used to calculate the flow rate if the slope and the channel (link) dimensions are known.

$$
Q=\frac{1.486}{n} A * R^{2 / 3} * S^{1 / 2}
$$

where $\mathrm{Q}$ is the flow rate, $\mathrm{n}$ is the Manning's roughness coefficient, $\mathrm{A}$ is the crosssectional area in flow, $\mathrm{R}$ is the hydraulic radius equaled to the cross-sectional area in flow divided by the wetted perimeter of the pipe, $\mathrm{S}$ is the slope of the pipe, and $\mathrm{L}$ is the length of pipe.

The friction losses between the pipes may be calculated by multiplying the length of the channel times the slope as shown in Equation 6.

$$
h_{f}=L * S
$$

Minor losses due to entrance and exit losses are computed as follows:

$$
h_{m}=k+\frac{v^{2}}{2 g}
$$

where $\mathrm{k}$ is the typical loss coefficient and was assumed to be 0.5 for entrance loss and 1 for exit loss.

When uniform depth exists normal depth occurs and Manning's formula may be rearranged to solve for normal depth, $\mathrm{d}_{\mathrm{n}}$ :

$$
D=d_{n}=1.335\left(\frac{n Q}{\sqrt{S}}\right)^{\frac{3}{8}}
$$

When there is a variation of elevation or change in width of the channel there will be a change in the depth. The specific energy of the reach may be used in order to determine the new depth of flow in the pipe. From Equation 2 the specific energy may also be expressed as: 


$$
E=d+\frac{Q^{2}}{2 g A^{2}}
$$

where $\mathrm{d}$ is the depth or critical depth.

There will be three possible depths in which the water elevation resides. One depth will be negative which is not valid. The other two are plausible depths which will provide the same energy and are known as alternate depths.

The flow rate during this period may be categorized as subcritical, supercritical, or critical. Subcritical means that the flow is tranquil having a low velocity and a high depth. Supercritical means that rapid flow occurs with high velocity and low depth. Critical depth is the depth that minimizes the energy of flow; however, it does not minimize the depth. On the contrary, for a unique slope it would maximize the quantity of flow through its cross section. Critical flow and critical depth may be computed for circular pipe as follows:

$$
\frac{Q^{2}}{g}=\frac{A^{3}}{T}
$$

The boundary conditions chosen for this study is 'free outfall outlet control' which implies that the receiving water body's, WOC, elevation is lower than OF-211 discharge elevation; thus, no backwater would occur in the system at OF-211. Furthermore, the depth criterion used is either a minimum critical depth or a normal depth depending on the computation.

When multiple pipes are connected to one stormwater inlet, transient conditions occur, causing unsteady flow. XPSWMM uses a hydraulic flow model known as EXTRAN for dynamic flow analysis. EXTRAN computes the St. Venant equations which represent one dimensional non-uniform, turbulent flow for open channel and 
closed conduit flow which would occur when multiple pipes are connected to one manhole. Backwater conditions may occur at these locations producing the non-uniform, turbulent flow within the pipes. The St. Venant equations are as follows and are based on the continuity equation expressed by Equation 11 and the latter on the momentum principle expressed by Equation 12. (Chanson, 2004):

$$
\begin{aligned}
& \frac{\partial A}{\partial t}+\frac{\partial Q}{\partial x}=0 \\
& \frac{\partial Q}{\partial t}+\frac{\partial}{\partial x}\left(V^{2} A\right)+g A \frac{\partial d}{\partial x}=g A\left(S_{0}-S_{f}\right)
\end{aligned}
$$

The St. Venant equations according to Chanson (Chanson, 2004) assume the following conditions apply: the flow is one dimensional; the pressure distributions are hydrostatic; the flow resistance and turbulent losses are the same as for a steady uniform equilibrium flow for the same depth and velocity, regardless of trends of depth; the channel slope is small; the water density is constant; sediment motion neglected for fixed boundary conditions.

XPSWMM uses the Modified Euler technique to solve the equations via numerical method when solving the St. Venant equations. The computations are completed via standard step method which means each pipe is a segment of known length where the depth is calculated by either knowing or assuming a depth at one end of the segment. The computations are completed by a one dimensional-analytical engine in three phases: Phase 1 - downstream analysis, Phase 2 - upstream analysis, and Phase 3 combined profile of downstream and upstream. The program continues the calculation via iterative approximation which is a trial and error process. If the sequence of equations is convergent the model will continue; however, if there are significant errors within the 
calculations then a warning message will appear notifying the user of the error. At that time, the model will cease all simulations and the model input should be reviewed.

\subsection{Hydraulics Mode Input}

In XPSWMM the network is made up of a series of links and nodes. A link is considered a conduit such as a storm drain, storm pipe, or culvert that conveys water from one node to another. Nodes are considered to intake stormwater runoff or other discharges, such as the AC units' condensate and cooling water or the chlorinated discharge water from the Creep Laboratory in Building 4500S. The required input data for the conveyance through the conduits are the Manning's roughness coefficient, slope, downstream invert, upstream invert, pipe length, and spill crest elevations.

Node data, conduit shapes, control structures and weirs may be modeled in the hydraulic mode. The node dialog requests the spill crest elevation where it can be the manhole elevation for a manhole, inlet elevation for an inlet, or top of pipe for a junction box. For the purpose of this project, a junction box is considered as a point where the storm pipe changes direction without a manhole or inlet, or where the storm drain enters the main storm line. Figure 10 shows the node data dialog box indicating the spill crest and invert elevations. Also, within this dialog the user inflow is incorporated for the subsequent transport analysis where timeseries flow rate and concentration data were added. 


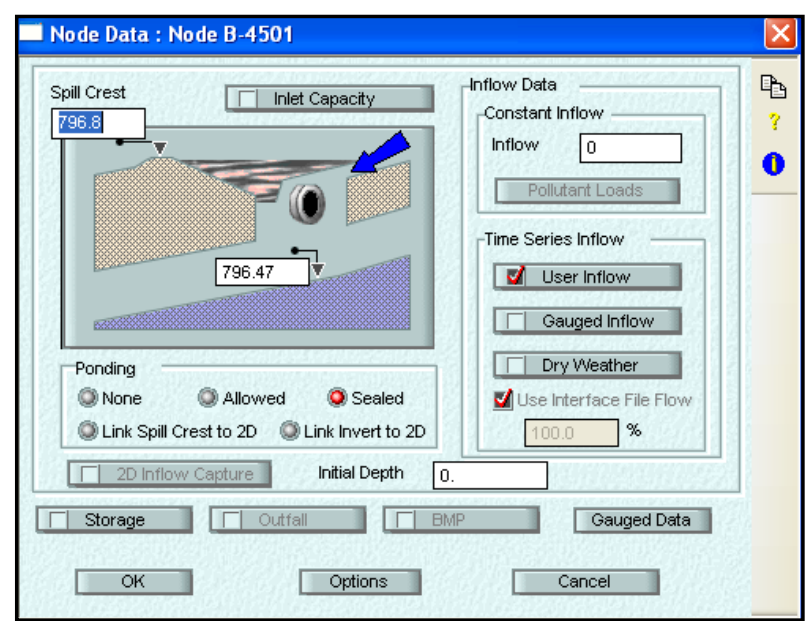

Figure 10 XPSWMM Node Data Dialog

The XPSWMM Node Data Entry table indicating the information entered for each mode within the system is shown as Table 1 . 
Table 1 XPSWMM Node Data Entry

\begin{tabular}{|c|c|c|c|c|c|c|c|}
\hline Name & $\begin{array}{c}\text { Sub- } \\
\text { catch- } \\
\text { ment }\end{array}$ & $\begin{array}{c}\text { Spill } \\
\text { Crest (ft) }\end{array}$ & $\begin{array}{c}\text { Invert } \\
\text { Elevation } \\
(\mathrm{ft})\end{array}$ & $\begin{array}{c}\text { Width } \\
(\mathrm{ft})\end{array}$ & $\begin{array}{c}\text { Slope } \\
(\mathrm{ft} / \mathrm{ft})\end{array}$ & $\begin{array}{c}\text { Area } \\
(\mathrm{ac})\end{array}$ & $\begin{array}{c}\text { Impervious } \\
\text { Percentage } \\
(\%)\end{array}$ \\
\hline B-4500N_A & 1 & 799.75 & 799.2 & 15.3 & 0.01 & 0.161 & 100 \\
\hline B-4500N_B & 1 & 799.6 & 799.1 & 13 & 0.01 & 0.043 & 100 \\
\hline B-4500N_C & 1 & 800.15 & 798.6 & 24.1 & 0.02 & 0.129 & 100 \\
\hline B-4500N_D & 1 & 800.15 & 798.6 & 47 & 0.03 & 0.183 & 100 \\
\hline B-4500N_E & 1 & 799.2 & 798.7 & 12.5 & 0.01 & 0.054 & 100 \\
\hline B-4500N_F & 1 & 802 & 799.6 & 32 & 0.01 & 0.14 & 100 \\
\hline B-4500N_G & 1 & 802 & 799.6 & 22.4 & 0.01 & 0.14 & 100 \\
\hline B-4500S_A & 1 & 789.6 & 785.5 & 37.1 & 0.05 & 0.269 & 100 \\
\hline B-4500S_B & 1 & 786.5 & 786 & 26.7 & 0.05 & 0.183 & 100 \\
\hline B-4500S_C & 1 & 797 & 796.5 & 48.6 & 0.01 & 0.129 & 100 \\
\hline B-4500S_D & 1 & 797.4 & 796.9 & 64 & 0.01 & 0.14 & 100 \\
\hline B-4500S_E & 1 & 797.4 & 796.9 & 52.5 & 0.01 & 0.14 & 100 \\
\hline B-4501 & 1 & 796.8 & 796.47 & 32.2 & 0.01 & 0.183 & 100 \\
\hline B-4505 & 1 & 797.7 & 796.8 & 19 & 0.02 & 0.086 & 100 \\
\hline B-4507 & 1 & 793.55 & 793 & 16.7 & 0.05 & 0.032 & 100 \\
\hline B-4556 & 1 & 796.1 & 795.75 & 10.6 & 0.01 & 0.011 & 100 \\
\hline I-1 & 1 & 800.57 & 795 & 43.3 & 0.05 & 0.065 & 5 \\
\hline I-1 & 2 & & & 52.2 & 0.05 & 0.108 & 5 \\
\hline I-10 & 1 & 803.15 & 795.7 & 20.3 & 0.01 & 0.075 & 100 \\
\hline I-10 & 2 & & & 12.8 & 0.01 & 0.032 & 100 \\
\hline I-10 & 3 & & & 20.3 & 0.01 & 0.075 & 100 \\
\hline I-10 & 4 & & & 14 & 0.02 & 0.032 & 100 \\
\hline I-11 & 1 & 798.2 & 797.5 & 50 & 0.015 & 0.054 & 100 \\
\hline I-2 & 1 & 799 & 795.8 & 18 & 0.02 & 0.065 & 80 \\
\hline I-2 & 2 & & & 40 & 0.02 & 0.237 & 80 \\
\hline I-2 & 3 & & & 5 & 0.02 & 0.065 & 95 \\
\hline I-2 & 4 & & & 10.2 & 0.02 & 0.086 & 100 \\
\hline I-2 & 5 & & & 13.2 & 0.01 & 0.108 & 5 \\
\hline I-3 & 1 & 790.4 & 782.3 & 14.9 & 0.015 & 0.022 & 90 \\
\hline I-3 & 2 & & & 9.9 & 0.015 & 0.075 & 95 \\
\hline I-4 & 1 & 799 & 795.5 & 14 & 0.01 & 0.161 & 100 \\
\hline I-4 & 2 & & & 17.9 & 0.02 & 0.054 & 95 \\
\hline I-4 & 3 & & & 15.5 & 0.02 & 0.075 & 95 \\
\hline I-5 & 1 & 802.21 & 795.4 & 18.4 & 0.01 & 0.054 & 100 \\
\hline
\end{tabular}

(table continues) 
Table 1 XPSWMM Node Data Entry (continued)

\begin{tabular}{|c|c|c|c|c|c|c|c|}
\hline Name & $\begin{array}{l}\text { Sub- } \\
\text { catch- } \\
\text { ment }\end{array}$ & $\begin{array}{l}\text { Spill Crest } \\
\text { (ft) }\end{array}$ & $\begin{array}{c}\text { Invert } \\
\text { Elevation (ft) }\end{array}$ & $\begin{array}{l}\text { Width } \\
\text { (ft) }\end{array}$ & $\begin{array}{l}\text { Slope } \\
(\mathrm{ft} / \mathrm{ft})\end{array}$ & $\begin{array}{l}\text { Area } \\
(\mathrm{ac})\end{array}$ & $\begin{array}{c}\text { Impervious } \\
\text { Percentage (\%) }\end{array}$ \\
\hline I-5 & 2 & & & 15.6 & 0.01 & 0.022 & 100 \\
\hline I-5 & 3 & & & 22.3 & 0.01 & 0.075 & 100 \\
\hline I-5 & 4 & & & 22.5 & 0.01 & 0.075 & 100 \\
\hline I-6 & 1 & 800 & 791 & 12.15 & 0.02 & 0.043 & 95 \\
\hline I-6 & 2 & & & 7.7 & 0.02 & 0.065 & 95 \\
\hline $\mathrm{I}-8$ & 1 & 798.2 & 793.8 & 12 & 0.02 & 0.003 & 100 \\
\hline I-8 & 2 & & & 12 & 0.02 & 0.03 & 100 \\
\hline I-9 & 1 & 798 & 793.8 & 5.3 & 0.015 & 0.065 & 100 \\
\hline I-9 & 2 & & & 5.3 & 0.02 & 0.011 & 100 \\
\hline I-9 & 3 & & & 21 & 0.02 & 0.011 & 100 \\
\hline I-9 & 4 & & & 21 & 0.02 & 0.011 & 100 \\
\hline $\mathrm{J}-1$ & 1 & 802.5 & 791.4 & 22.6 & 0.01 & 0.086 & 100 \\
\hline $\mathrm{J}-10$ & & 788 & 781.8 & 0 & 0 & 0 & 0 \\
\hline $\mathrm{J}-11$ & & 799 & 797.7 & 0 & 0 & 0 & 0 \\
\hline $\mathrm{J}-12$ & & 796.6 & 795.3 & 0 & 0 & 0 & 0 \\
\hline $\mathrm{J}-13$ & & 798.8 & 798.3 & 0 & 0 & 0 & 0 \\
\hline $\mathrm{J}-14$ & & 802 & 793.75 & 0 & 0 & 0 & 0 \\
\hline $\mathrm{J}-2$ & & 800 & 790.4 & 0 & 0 & 0 & 0 \\
\hline $\mathrm{J}-3$ & & 797 & 789.9 & 0 & 0 & 0 & 0 \\
\hline $\mathrm{J}-4$ & & 799.5 & 789 & 0 & 0 & 0 & 0 \\
\hline $\mathrm{J}-5$ & & 795.2 & 793.7 & 0 & 0 & 0 & 0 \\
\hline J-6 & & 795.8 & 795.45 & 0 & 0 & 0 & 0 \\
\hline $\mathrm{J}-7$ & & 801 & 783.5 & 0 & 0 & 0 & 0 \\
\hline $\mathrm{J}-8$ & & 792.94 & 782.7 & 0 & 0 & 0 & 0 \\
\hline J-9 & & 789 & 782 & 0 & 0 & 0 & 0 \\
\hline $\mathrm{MH}-2 \mathrm{~A}$ & & 793.16 & 785.5 & 0 & 0 & 0 & 0 \\
\hline MH-5 & & 799 & 790.4 & 0 & 0 & 0 & 0 \\
\hline MH-6 & & 800 & 795.2 & 0 & 0 & 0 & 0 \\
\hline MH-7 & & 800 & 791.3 & 0 & 0 & 0 & 0 \\
\hline MH-8 & & 797.2 & 792.3 & 0 & 0 & 0 & 0 \\
\hline MH211-1 & & 789 & 781.7 & 0 & 0 & 0 & 0 \\
\hline MH211-2 & & 800.4 & 783.6 & 0 & 0 & 0 & 0 \\
\hline MH211-3 & & 799.5 & 786.85 & 0 & 0 & 0 & 0 \\
\hline OF-211 & & 786.44 & 780.74 & 0 & 0 & 0 & 0 \\
\hline $\mathrm{T}-1$ & 1 & 786 & 784.2 & 9.5 & 0.15 & 0.043 & 100 \\
\hline $\mathrm{T}-2$ & 1 & 800 & 796 & 52.9 & 0.015 & 0.151 & 100 \\
\hline $\mathrm{T}-3$ & 1 & 800 & 796 & 18 & 0.1 & 0.14 & 100 \\
\hline
\end{tabular}


XPSWMM provides a dialog for the conduit characteristics where a variety of pipe shapes are available along with an aid to visualize the conduit profiles. All pipes within this study are circular. Additional pipe characteristics such as the diameter, slope, length, and Manning's roughness coefficient are input in the conduit profile dialog as shown below in Figure 11.

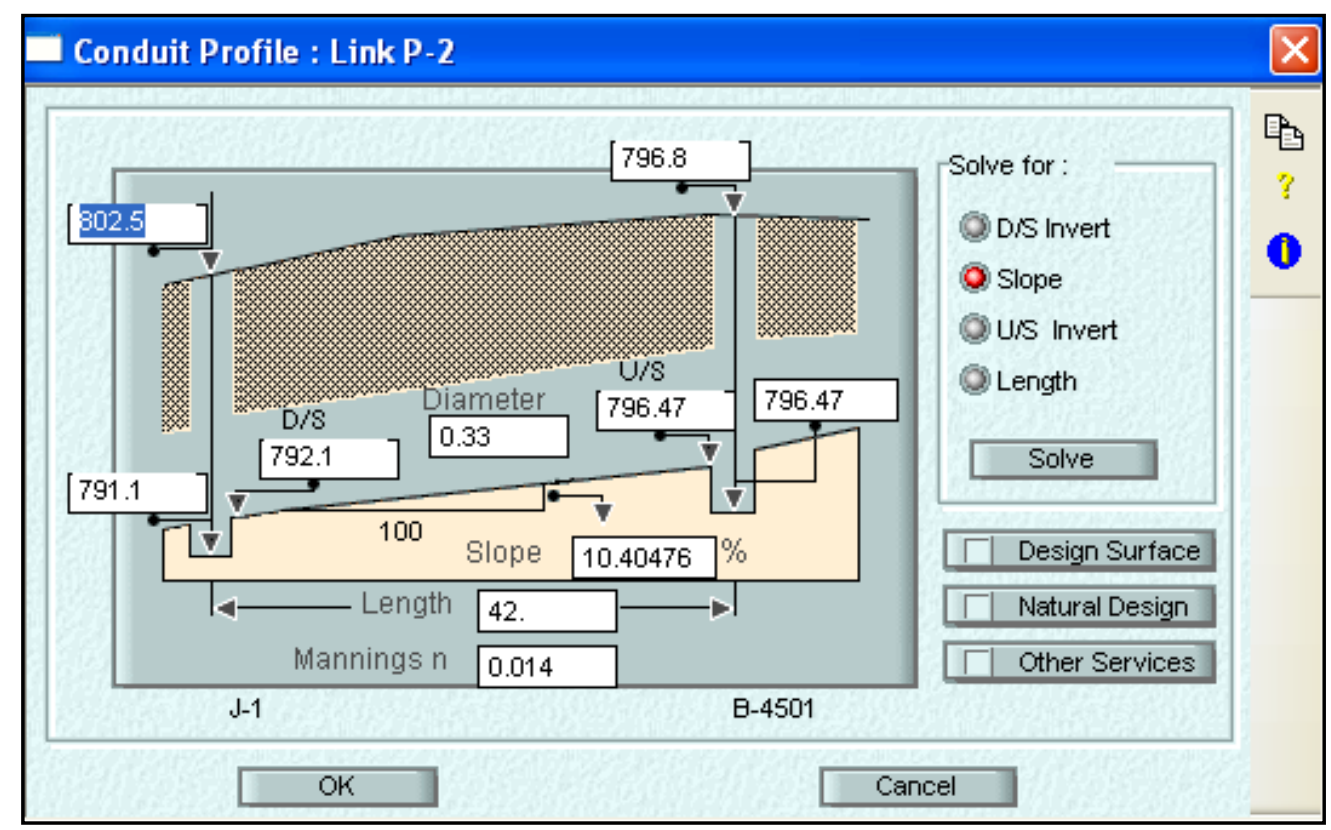

Figure 11 XPSWMM Conduit Profile

The XPSWMM Link Data Entry table indicating the information entered for each link within the system is shown in Table 2 . 
Table 2 XPSWMM Link Data Entry

\begin{tabular}{|c|c|c|c|c|c|}
\hline Name & Shape & $\begin{array}{l}\text { Length } \\
\text { (ft) }\end{array}$ & $\begin{array}{c}\text { Manning's } \\
\text { Roughness } \\
\text { Coeff. }\end{array}$ & $\begin{array}{c}\text { Conduit } \\
\text { Slope } \\
(\mathrm{ft} / \mathrm{ft})\end{array}$ & $\begin{array}{l}\text { Diameter } \\
\text { (in) }\end{array}$ \\
\hline P-10 & Circular & 78.4 & 0.015 & 1.148 & 15 \\
\hline P-11 & Circular & 64.3 & 0.015 & 8.709 & 15 \\
\hline P-12 & Circular & 8.8 & 0.015 & 23.864 & 15 \\
\hline P-13 & Circular & 106.6 & 0.015 & 0.563 & 3.996 \\
\hline $\mathrm{P}-14$ & Circular & 72.55 & 0.015 & 0.414 & 3.996 \\
\hline P-15 & Circular & 45.3 & 0.015 & 7.174 & 30 \\
\hline P-16 & Circular & 5.6 & 0.015 & 1.786 & 30 \\
\hline P-17 & Circular & 35.3 & 0.015 & 2.266 & 30 \\
\hline P-18 & Circular & 6.6 & 0.015 & 12.121 & 6 \\
\hline P-19 & Circular & 16.1 & 0.015 & 0 & 6 \\
\hline P-2 & Circular & 43.95 & 0.015 & 9.488 & 3.96 \\
\hline $\mathrm{P}-20$ & Circular & 45 & 0.015 & 0.889 & 30 \\
\hline $\mathrm{P}-21$ & Circular & 29.1 & 0.015 & 1.031 & 30 \\
\hline $\mathrm{P}-22$ & Circular & 18.27 & 0.015 & 1.095 & 6 \\
\hline $\mathrm{P}-23$ & Circular & 20.2 & 0.015 & 0.99 & 30 \\
\hline $\mathrm{P}-24$ & Circular & 20.37 & 0.015 & 10.8 & 6 \\
\hline $\mathrm{P}-25$ & Circular & 11.7 & 0.015 & 0.855 & 30 \\
\hline P-26 & Circular & 100.3 & 0.015 & 0.957 & 30 \\
\hline $\mathrm{P}-27$ & Circular & 135.3 & 0.015 & 2.217 & 24 \\
\hline P-28 & Circular & 21.8 & 0.015 & 10.55 & 15 \\
\hline P-29 & Circular & 27.9 & 0.015 & 6.452 & 6 \\
\hline P-3 & Circular & 46.6 & 0.015 & 2.146 & 15 \\
\hline P-30 & Circular & 21.35 & 0.015 & 6.557 & 6 \\
\hline $\mathrm{P}-31$ & Circular & 17 & 0.015 & 1.765 & 15 \\
\hline $\mathrm{P}-32$ & Circular & 88.5 & 0.015 & 0.113 & 15 \\
\hline $\mathrm{P}-33$ & Circular & 32.6 & 0.015 & 10.123 & 6 \\
\hline P-34 & Circular & 24.7 & 0.015 & 13.36 & 6 \\
\hline $\mathrm{P}-35$ & Circular & 90.1 & 0.015 & 0.111 & 15 \\
\hline $\mathrm{P}-36$ & Circular & 24.6 & 0.015 & 2.033 & 6 \\
\hline P-37 & Circular & 7.8 & 0.015 & 1.282 & 6 \\
\hline P-38 & Circular & 115.9 & 0.015 & 2.071 & 6 \\
\hline
\end{tabular}

(table continues) 
Table 2 XPSWMM Link Data Entry (continued)

\begin{tabular}{|c|c|c|c|c|c|}
\hline Name & Shape & $\begin{array}{c}\text { Length } \\
\text { (ft) }\end{array}$ & $\begin{array}{c}\text { Manning's } \\
\text { Roughness } \\
\text { Coeff. }\end{array}$ & $\begin{array}{c}\text { Conduit } \\
\text { Slope } \\
\text { (ft/ft) }\end{array}$ & $\begin{array}{c}\text { Diameter } \\
\text { (in) }\end{array}$ \\
\hline P-39 & Circular & 21.1 & 0.015 & 1.896 & 6 \\
\hline P-4 & Circular & 16.4 & 0.015 & 26.829 & 12 \\
\hline P-40 & Circular & 115.9 & 0.015 & 0.518 & 24 \\
\hline P-41 & Circular & 28.14 & 0.015 & 1.066 & 24 \\
\hline P-42 & Circular & 34.37 & 0.015 & 2.037 & 15 \\
\hline P-43 & Circular & 19 & 0.015 & 7.895 & 15 \\
\hline P-44 & Circular & 14.1 & 0.015 & 10.638 & 15 \\
\hline P-46 & Circular & 80.29 & 0.015 & 1.806 & 15 \\
\hline P-47 & Circular & 32.34 & 0.015 & 15.77 & 6 \\
\hline P-48 & Circular & 25.3 & 0.015 & 20.158 & 6 \\
\hline P-49 & Circular & 104.7 & 0.015 & 1.862 & 15 \\
\hline P-5 & Circular & 35.4 & 0.015 & 1.412 & 15 \\
\hline P-50 & Circular & 14.5 & 0.015 & 23.448 & 8.04 \\
\hline P-54 & Circular & 22.8 & 0.015 & 3.07 & 6 \\
\hline P-55 & Circular & 25.3 & 0.015 & 2.767 & 6 \\
\hline P-56 & Circular & 108.2 & 0.015 & 1.386 & 8.04 \\
\hline P-6 & Circular & 51.5 & 0.015 & 12.621 & 9.996 \\
\hline P-7 & Circular & 21.6 & 0.015 & 39.815 & 6 \\
\hline P-8 & Circular & 62.3 & 0.015 & 1.4 & 15 \\
\hline P-9 & Circular & 58.2 & 0.015 & 5.584 & 6 \\
\hline
\end{tabular}

\subsection{Runoff Mode Input}

In the runoff mode, inlet drainage areas are delineated via sub-catchments. The sub-catchments are areas that are assigned an inlet. One inlet can have up to five subcatchment areas where each sub-catchment may have the following parameter input specific to each sub-catchment: areas, impervious percentage, width, and slope. The various sub-catchments are delineated by the highest contour surrounding the subcatchment area. The rainfall is simulated and runoff is produced over the sub-catchment areas, routed into the inlet, and through the network system. 


\subsection{Routing Method}

The SWMM Runoff Non-linear Reservoir Method, also known as the runoff routing method, was chosen for the simulations as it allowed for the rainfall-runoff process for single rainfall events and continuous rainfall simulations. The runoff routing method is a deterministic method, where the calculations are of known relationships, thus producing precise values. The runoff method is equipped to simulate rainfall, snowmelt, infiltration, evaporation, and groundwater interaction processes. This study accounts for infiltration and evaporation losses during the hydrologic cycle. The surface water runoff is defined as the rainfall minus losses. The runoff is conveyed via overland flow from divided drainage and sub-catchments areas. Overland flow is computed by taking into account the drainage area, percent impervious, basin width and slope, rainfall, and evaporation and infiltration loss.

\subsection{Rainfall}

Both single rainfall events and continuous rainfall events are used within the study. The calibrations and design storm simulations were single event runs. Single event simulations are for a short period time such as 24 hours. The sensitivity analysis and transport analysis utilized actual rainfall data from the year 2010 which contain continuous rainfall events retrieved from ORNL's Tower $\mathrm{C}$ monitoring station. The rainfall distribution data is entered as a hyetograph which is time series data of the intensity of the rainfall event with either 15 or 60 minute intervals depending on availability of data.

The first rainfall event simulated was for steady uniform flow calibration of the model where a single 24-hour rainfall event (hypothetical) having a uniform intensity was 
entered into the system. The next sets of rainfall data simulated were used to calibrate the model under unsteady non-uniform flow conditions. These simulations utilized single rainfall events also retrieved from ORNL's Tower C monitoring station. They also varied in the date collected and timeframe analyzed; however, all hyetographs had intervals of 60 minutes. The next set of simulations was run for the $5,10,25$, and 100 year design storm events. The design storms utilized the SCS Type II unit-hyetograph which was multiplied by a factor corresponding to the magnitude of the design storm. Lastly, the sensitivity analysis and the transport analysis simulate yearly continuous rainfall data from January 1, 2010 through December 31, 2010.

\subsection{Infiltration Methods and Parameters}

The ORNL site is composed of buildings, pavement, and minor pervious areas. It is surrounded by ORR's wooded lands. Soils in the area are a mixture of reddish-brown clays and silts resulting from in-situ weathering of shaley limestone bedrock.

Green Ampt and the Horton's infiltration methods were both used and compared for the infiltration sensitivity analysis and to test the robustness of the model. The sensitivity analysis simulates the actual Year 2010 continuous rainfall data collected at Tower C of the ORNL.

Because the Green Ampt infiltration method is commonly used for simulating continuous rainfall events, it was chosen for the sensitivity analysis. Horton's infiltration method was also examined as an alternative to the Green Ampt infiltration method. 


\subsubsection{Green Ampt Infiltration Method}

XPSWMM calculates the infiltration rates by utilizing the Green Ampt - Mein Larson equations, the first being the Mein-Larson equation where the soil has yet to become saturated and the Green Ampt equation once saturation of the soil has occurred (Mein and Larson, 1973).

The Mein Larson calculations assume that the infiltration rate approaches the rainfall intensity rate then calculates the unsaturated soil's infiltration rate as if the cumulative infiltration volume is less than the required cumulative infiltration volume for the soil to become saturated. The cumulative infiltration volume is then determined by the following formula:

$$
F S=\frac{(S u * I M D)}{\frac{i}{K S}-1}
$$

where $\mathrm{Fs}=$ cumulative infiltration volume required to cause surface saturation, $\mathrm{ft}$; $\mathrm{Su}=$ average capillary suction at the wetting front, $\mathrm{ft}$ water; IMD = initial moisture deficit, $\mathrm{ft} / \mathrm{ft} ; \mathrm{i}=$ rainfall intensity, $\mathrm{ft} / \mathrm{sec} ; \mathrm{Ks}=$ saturated hydraulic conductivity of soil, $\mathrm{ft} / \mathrm{sec}$.

If the soil has been saturated where the infiltration rate approaches the infiltration capacity then the following scenario is run through XPSWMM:

$$
F p=K s *\left(1+S u *\left(\frac{I M D}{F}\right)\right)
$$

where, Fp = infiltration capacity, $\mathrm{ft} / \mathrm{sec} ; \mathrm{Ks}$ = saturated hydraulic conductivity of soil, $\mathrm{ft} / \mathrm{sec} ; \mathrm{Su}=$ average capillary suction at the wetting front, $\mathrm{ft}$ water; $\mathrm{IMD}=$ initial moisture deficit for the event, $\mathrm{ft} / \mathrm{ft} ; \mathrm{F}=$ cumulative infiltration volume, $\mathrm{ft}$.

The Green Ampt parameters and their values are based on clay loamy soil consistent with the ORNL 4500 Area. Figure12 shows the entry for the Green Ampt 
parameters: depression storage and Manning's roughness coefficient for impervious and pervious areas, and a zero detention percentage for the impervious area.

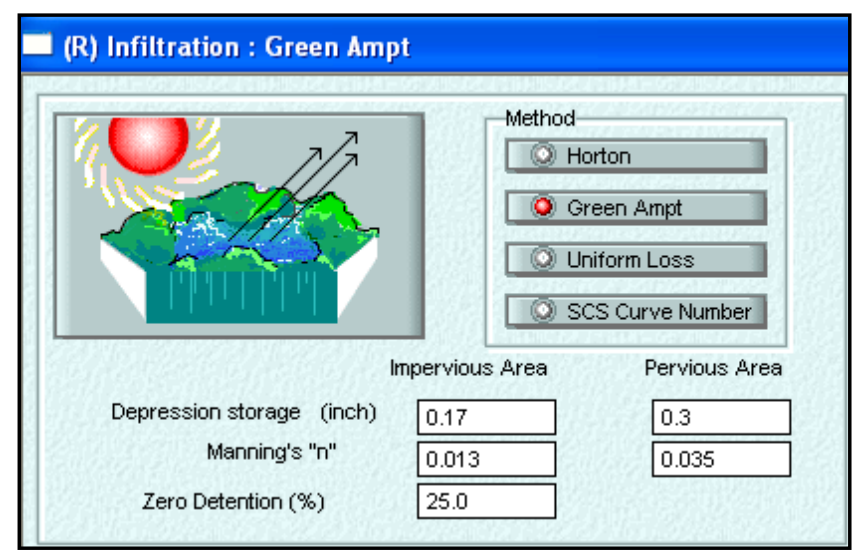

Figure 12 Infiltration Parameters

Figure 13 is a continuation screen for the Green Ampt infiltration method that prompts for the average capillary suction, initial moisture deficit, and the saturated hydraulic conductivity.

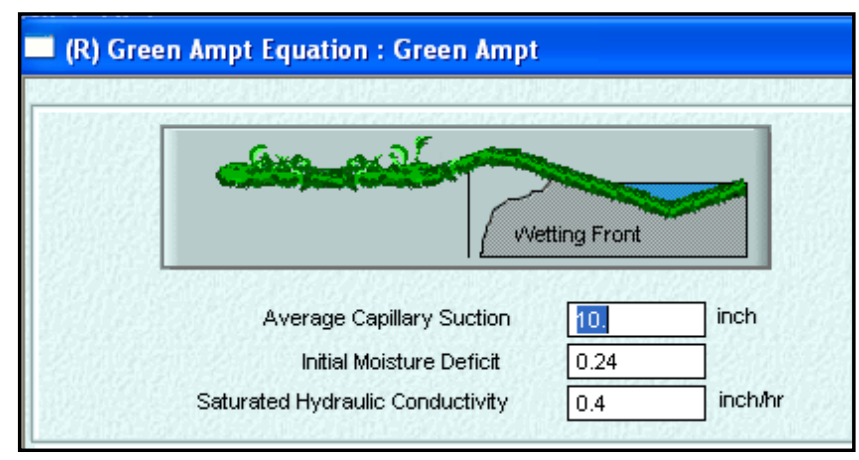

Figure 13 Green Ampt Parameters

\subsubsection{Horton Infiltration Method}

The Horton Infiltration Method was chosen as the infiltration method to be compared to the Green Ampt simulations as it may also simulate unsteady continuous rainfall events. 
The Horton equation indicates infiltration capacity as a function of time as follows (Verma, 1982):

$$
F_{p}=F_{c}+\left(F_{0}-F_{c}\right) e^{-k t}
$$

where $\mathrm{F}_{\mathrm{p}}=$ infiltration rate into soil, in. $/ \mathrm{hr}(\mathrm{mm} / \mathrm{hr}){ }_{\mathrm{Fc}}=$ minimum or asymptotic value of $\mathrm{Fp}$, in. $/ \mathrm{hr}(\mathrm{mm} / \mathrm{hr})$ Fo $_{\mathrm{F}}=$ maximum or initial value of $\mathrm{Fp}_{\mathrm{p}}$, in. $/ \mathrm{hr}(\mathrm{mm} / \mathrm{hr}) ; \mathrm{t}=$ time from beginning of storm, sec; $\mathrm{k}=$ decay coefficient, $1 / \mathrm{sec}$.

Horton's Infiltration Method is known to calculate infiltration rates for single storm events (Verma,1982). However, XPSWMM provides an option for Horton's infiltration calculations to be regenerated, using a regeneration and decay rate. For the Horton simulation a regeneration of 0.01 was used with a decay rate of 0.001 . This allowed the Horton's method to be used for a yearlong simulation for the 2010 rainfall data.

\subsection{Sensitivity Analysis}

Multiple sensitivity analyses were run and analyzed in order to understand the impacts of the various parameters on the system. They were produced with actual continuous rainfall data from year 2010 (January 1, 2010 thru December 31, 2010). Year 2010 rainfall data was retrieved from ORNL's Tower C monitoring station in 15 minute intervals as shown in Figure 14. 


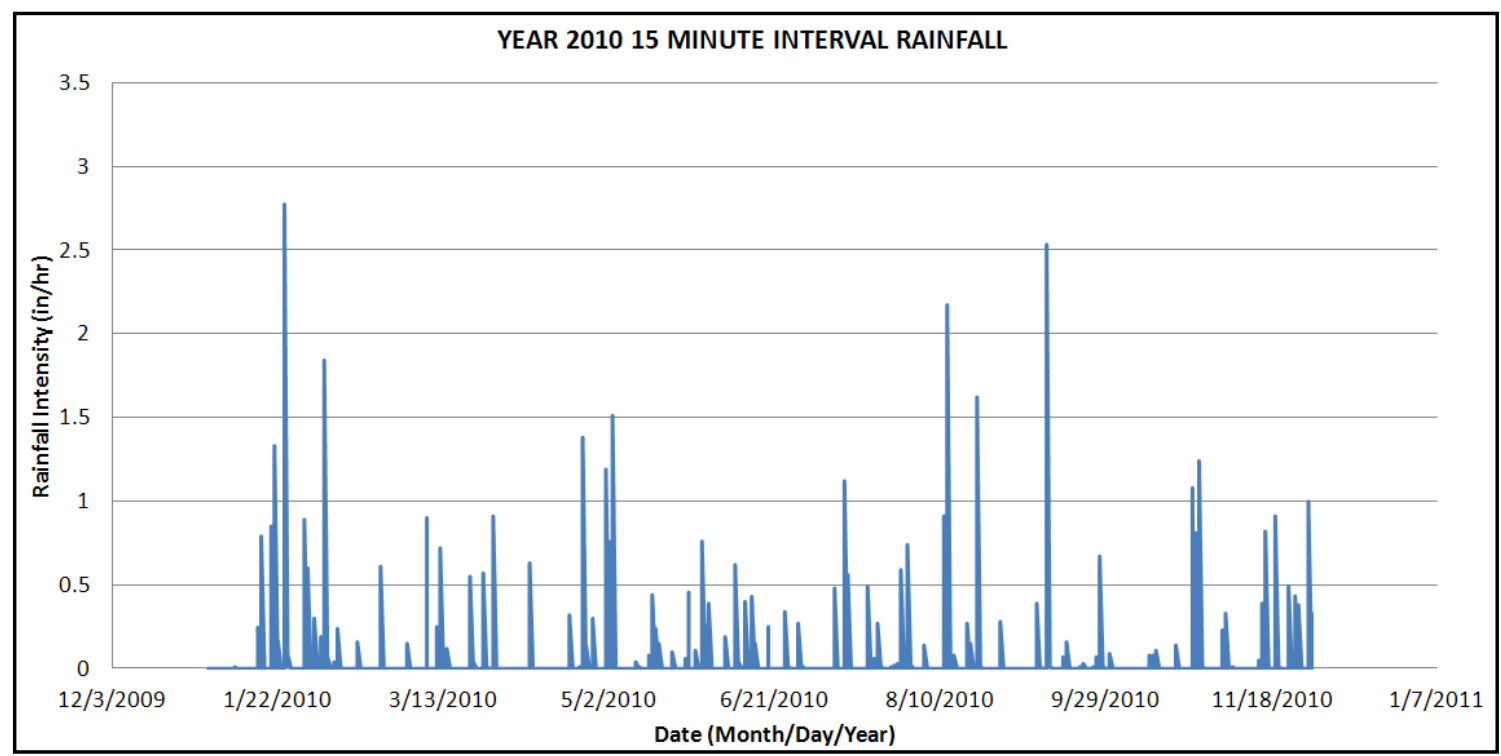

Figure 14 Year 2010 Rainfall Data

For the purpose of demonstrating the effects the various parameters have on the network, the nodes MH211-3 and OF-211 and the links P-10, P-11, P-15, P-27, and P-26 are used. P-10 conveys the inflow from the north, P-11 from the west, P-27 from the east into the node MH211-3. P-15 then collects those waters and conveys them south to P-26 which is the last pipe prior to the discharge OF-211. The simulations used continuous rainfall from year 2010, the Green Ampt method, and an evaporation rate of $0.1 \% /$ day assumed. MH211-3 and OF-211 were selected for analysis because of their location. MH211-3 is located at the major junction where it conveys stormwater from the north, east, and west. OF-211 is the node that all stormwater runoff and system discharge is conveyed through prior to the discharge into WOC. The selected nodes and links are shown in Figure 15. 


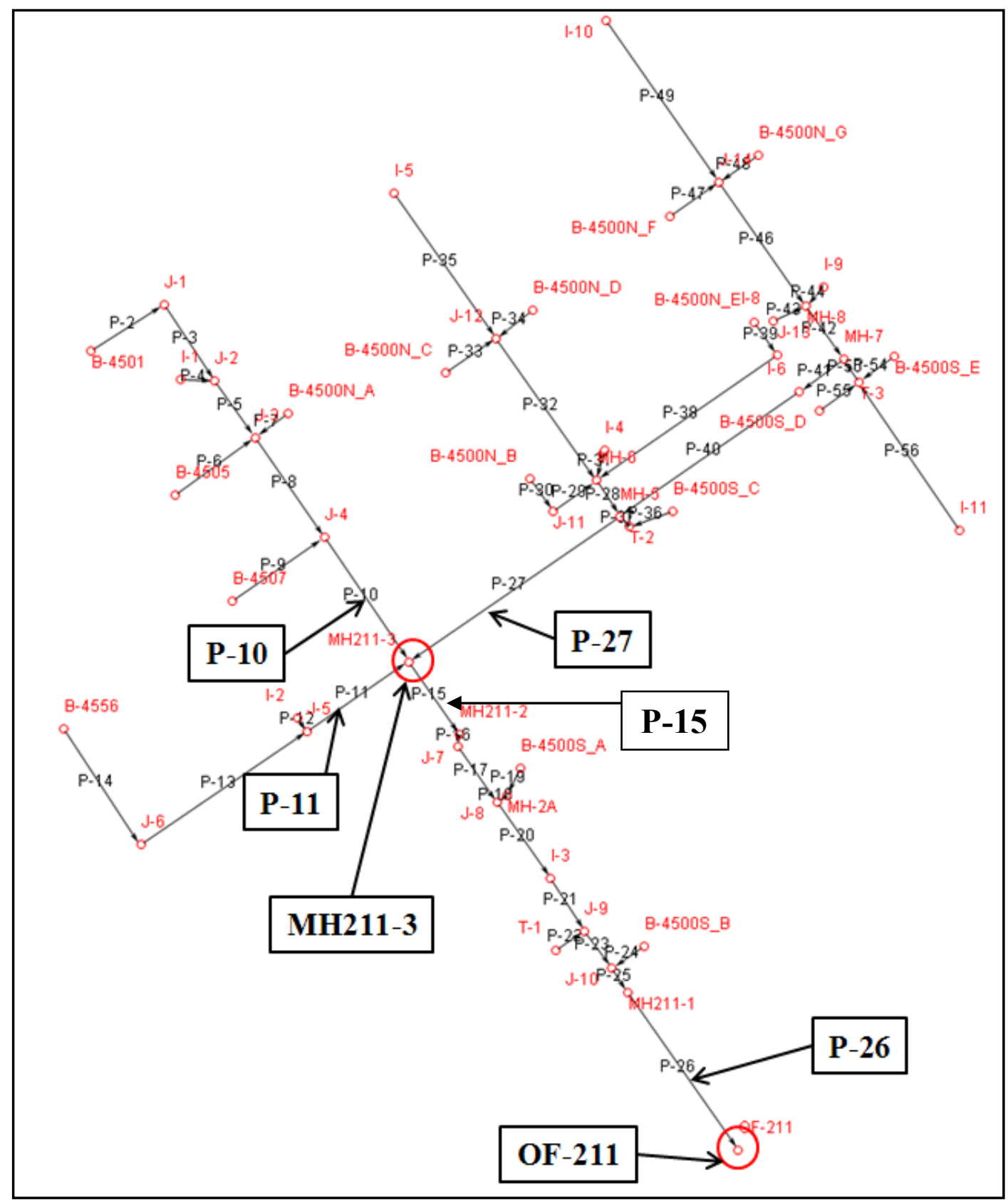

Figure 15 Storm System showing key locations for analysis 


\subsubsection{Manning's Roughness Sensitivity Analysis Results}

The Manning's roughness coefficient is based on the material of the pipe or the type of channel. The system network contains the following types of pipes: wrought iron (WI), vitrified pipe (VP), concrete pipe (CP), reinforced concrete pipe (RCP), and polyvinyl chloride (PVC).

The following Manning's roughness coefficients were simulated for the sensitivity analysis: $0.011,0.013,0.015,0.017$, and 0.035. Although Manning's coefficient of 0.035 is specific to grassy areas, this larger coefficient was included to provide a larger scope to the sensitivity of the simulation. The larger the Manning's coefficient the larger the resistance the flow encounters, which decreases the flow rate and causes a rise in water stage elevation. As expected, the coefficient 0.035 does have a larger impact than the smaller numbers.

MH211-3 was analyzed because this point is where the north, east, and west portions of drainage system meet. MH211-3 invert elevation is $786.85 \mathrm{ft}, \mathrm{NAD}$, and its inlet elevation at $799.5 \mathrm{ft}$, NAD. The hydrograph in Figure 16 accurately depicts the water staging at the bottom of the manhole at the invert elevation entered for the node, and is responsive to the rainfall peaks introduced into the system. Based on the probability exceedance curve, the maximum stage of $787.25 \mathrm{ft}$, NAD, occurs for $1 \%$ of the time at elevation, for coefficients $0.011,0.013,0.015$, and 0.017 . At $89 \%$ of the time for continuous storm events the elevation was held at $786.9 \mathrm{ft}$, NAD. Results for Manning's roughness coefficient 0.035 indicate the maximum elevation of $787.45 \mathrm{ft}$, NAD, for $1 \%$ of the time. The larger the Manning's coefficient the larger the resistance 
flow rates encounter, which ultimately decreases the flow rate and causes a rise in elevation. Note the graph in Figure 16 shows a range from 0 to 1 and not in percentages.

Based on the hydrographs and PEC, the MH211-3 did not reach inlet capacity; thus, did not cause ponding or flooding during the 2010 continuous rainfall events. In addition, the graphs asymptote coincides with the invert elevation, $786.85 \mathrm{ft}$, NAD for $85 \%$ of the duration of the 2010 yearly rainfall.

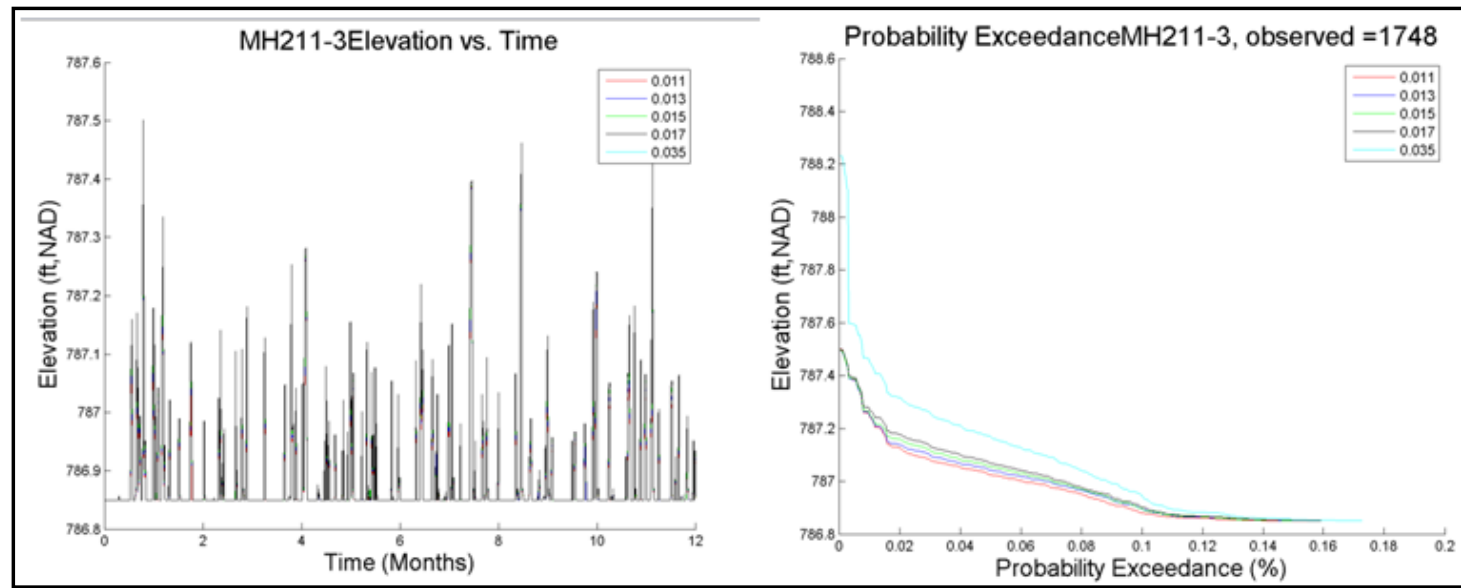

Figure 16 MH211-3 Hydrograph and PE Curves for Manning's Roughness Coefficient Sensitivity Analysis

OF-211 was also analyzed. OF-211 has an invert elevation is 780.74, ft NAD, and spill crest elevation is 786.44 which is the elevation to the bridge above the pipe. Unlike MH211-3 results, all five coefficients proportionally vary in elevation, and 0.035 has less of an impact on the system downstream of MH211-3. This could be because fewer pipes were encountered. The pipes along the main trunk line between MH211-3 and OF-211 are 30 " in diameter and only minimal runoff is entered from storm drains. Elevations range from $781.3 \mathrm{ft}, \mathrm{NAD}$, to $781.55 \mathrm{ft}, \mathrm{NAD}$, for $1 \%$ of the duration. Based on the results, OF-211 does not reach capacity during the yearly rainfall events. This is shown in Figure 17. 

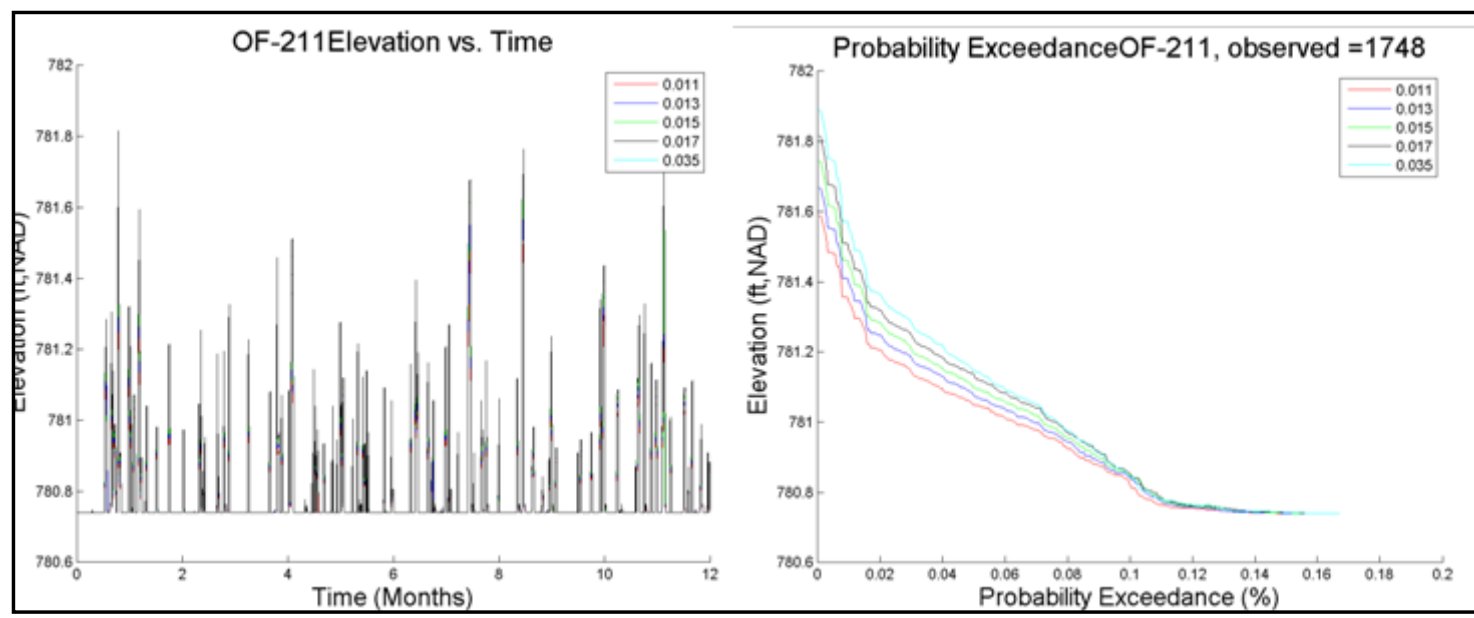

Figure 17 OF-211 Hydrograph and PE Curves for Manning's Roughness Coefficient Sensitivity Analysis

For the purposes of the study and the remaining simulations a coefficient of 0.015 was chosen as it is the typical value for closed conduits flowing through partly full concrete sewer gravity pipes. This is shown in Table 3.

Table 3 Manning's Values for Concrete Pipe

\begin{tabular}{|l|c|c|c|}
\hline \multicolumn{3}{|c|}{ Manning's n for Concrete Closed Conduits Flowing Partly Full (Chow, 1988) } \\
\hline Type of Conduit and Description & Minimum & Normal & Maximum \\
\hline Concrete: & & & \\
\hline Culvert, straight and free of debris & 0.010 & 0.011 & 0.013 \\
\hline $\begin{array}{l}\text { Culvert with bends, connections, and some } \\
\text { debris }\end{array}$ & 0.011 & 0.013 & 0.014 \\
\hline Finished & 0.011 & 0.012 & 0.014 \\
\hline Sewer with manholes, inlet, etc., straight & 0.013 & 0.015 & 0.017 \\
\hline Unfinished, steel form & 0.012 & 0.013 & 0.014 \\
\hline Unfinished, smooth wood form & 0.012 & 0.014 & 0.016 \\
\hline Unfinished, rough wood form & 0.015 & 0.017 & 0.020 \\
\hline
\end{tabular}

\subsubsection{Infiltration Sensitivity Analysis Results}

The Green Ampt and Horton's parameters were determined based on the soils found in the area. The system has minimal pervious area. However, the rainfall duration is one year and was assumed that the infiltration methods may impact the water stages. Nodes MH211-3 and OF-211 PE curves are shown in Figures 18 and 19. 


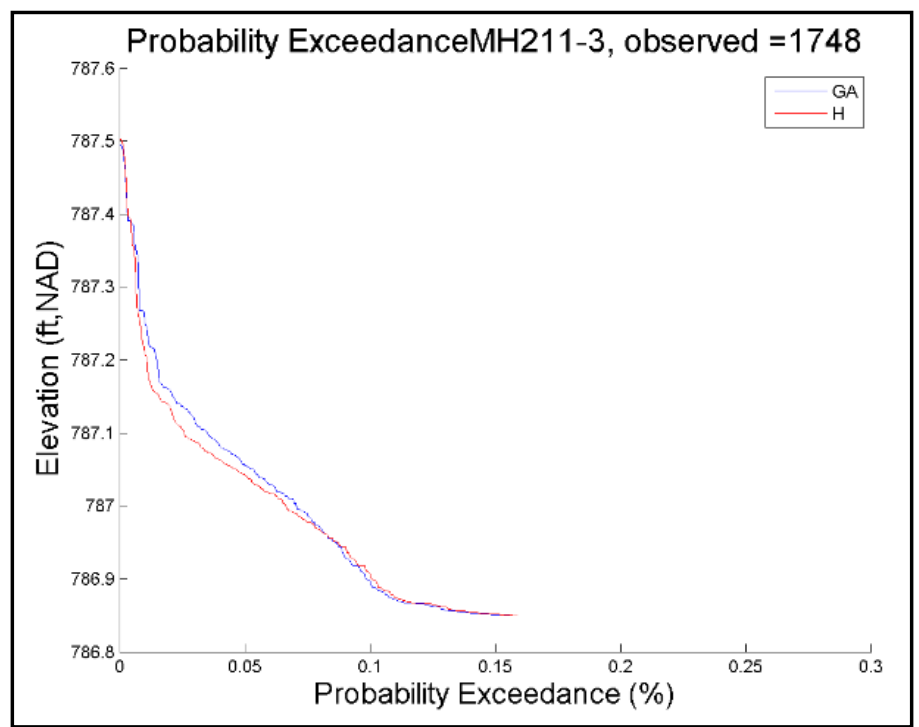

Figure 18 MH211-3 PE Curves for Infiltration Sensitivity Analysis

The Green Ampt elevations are shown in blue and the Horton's in red. The water stage elevation $787.2 \mathrm{ft}$, NAD, is held for a longer period under the Green Ampt simulations indicating less infiltration occurred when applying the Green Ampt parameters and slightly more infiltration occurred when applying the Horton parameters.

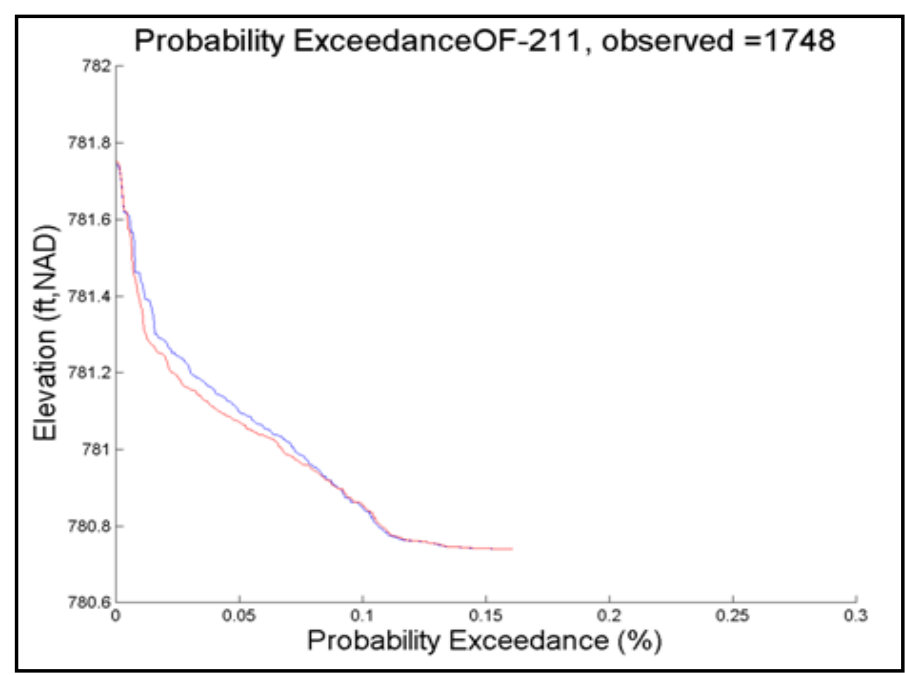

Figure 19 OF-211 PE Curves for Infiltration Sensitivity Analysis

Similarly, with MH211-3 PE curves, OF-211 PE curves follow the same trend. Green Ampt indicates less infiltration and Horton slightly more. The slight difference in infiltration implies that the model is stable. This could be that the Horton's regeneration 
rate of $0.01 \mathrm{and} /$ or decay rate of 0.001 were not large enough to produce a significant regeneration throughout the continuous rainfall.

Previous studies reported (Risse, 1994) that the Green Ampt method simulates one dimensional unsteady continuous rainfall events effectively and due to the fact there are only minor differences in the two methods, Green Ampt infiltration parameters have been chosen for the remaining simulations as the more generally accepted method.

If larger variations in results are desired then greater variations in infiltration parameters should be pursued. It is recommended that further analysis of the infiltration parameters be examined, such as simulating the Horton's infiltration method but varying $\mathrm{k}$, the decay coefficient.

\subsection{Design Storm Simulations}

The U.S. Natural Resources Conservation Service (NRCS), formerly known as the U.S. Soil Conservation Services (SCS) method, is used to compute rainfall distributions. NRCS has divided the United States into four main regions where Type II distribution represents rainfall for the Tennessee Valley (Fiuzat, 1991; City of Knoxville, 2012). For the design storms, the SCS Type II unit-hyetograph shown in the Figure 20 is multiplied by a precipitation corresponding to its storm event in order to duplicate flow rates and water elevations corresponding to the magnitude of the storm event throughout the site for analysis. 


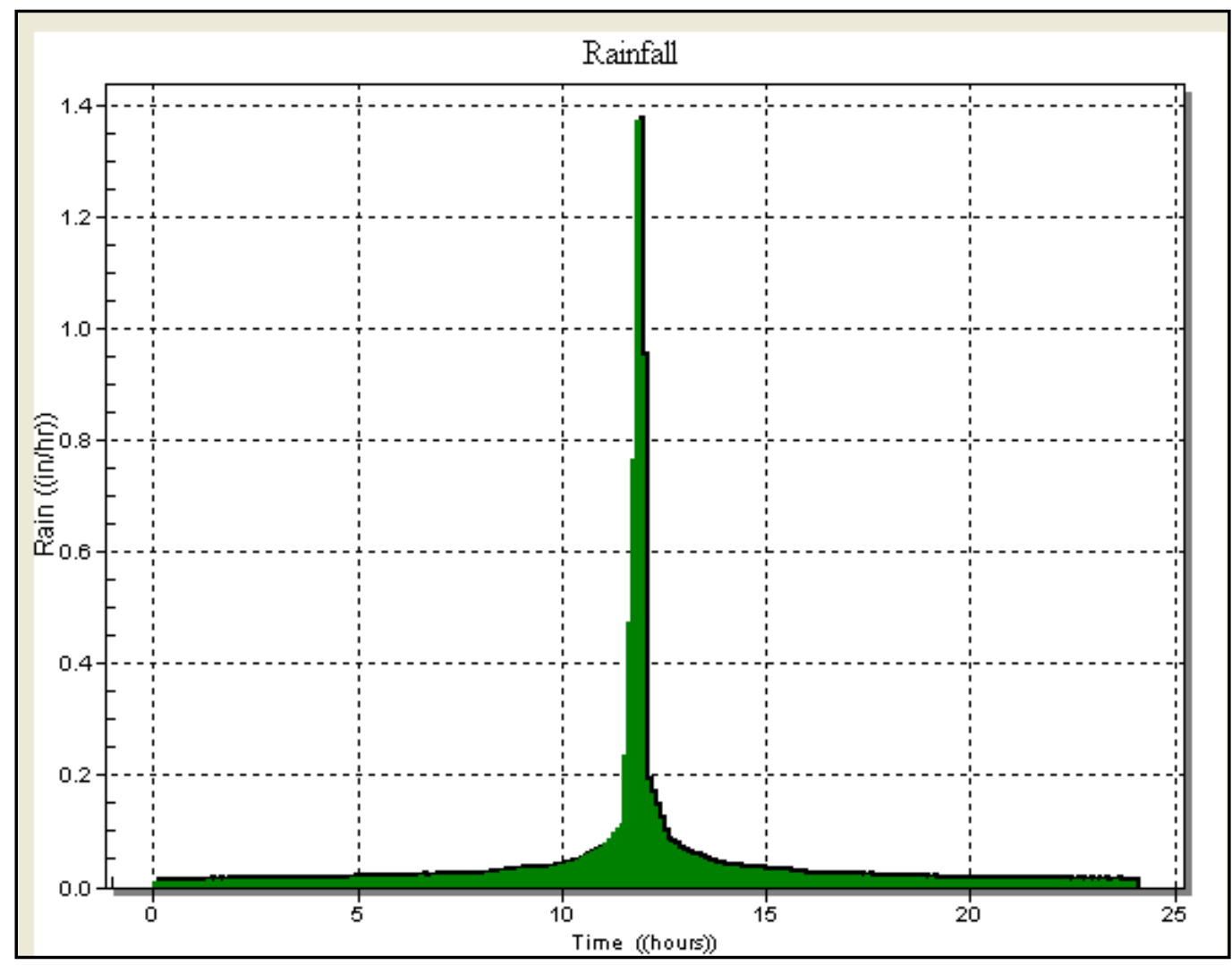

Figure 20 SCS Type II Unit Hyetograph

During land development, design storms are examined for pre-development and post-development conditions to ensure that the post conditions do not exceed the preconditions. The analysis of pre-post conditions ensure flooding on adjacent properties do not occur. The 5 year storm event is assessed to determine parking lot elevations, the 10 year storm event for roadways, the 25 year storm event for property berm elevations, and and the 100 year storm event for the building's finish floor. Because flooding of the 4500 Area buildings could be of concern, these four design storms types have been simulated over the network. The design simulations are based on a Manning's roughness coefficient of 0.015, Green Ampt infiltration method, and the estimated percent impervious from site visits. The Table 4 below indicates the single design storm events and their corresponding precipitation that the unit-hyetograph will be multiplied by in order to simulate the design 
storm event (NOAA, 2006). The precipitation quantities were determined by the National Oceanic Atmospheric Administration (NOAA) and are based on specific regions. These values are specific to the Tennessee area.

Table 4 NOAA Precipitation

\begin{tabular}{|c|c|}
\hline Storm Event & Precipitation \\
\hline 5 year - 24 hour & $4.1{ }^{\prime}$ \\
\hline 10 year - 24 hour & $4.7{ }^{\prime}$ \\
\hline 25 year - 24 hour & 5.5 \\
\hline 100 year - 24 hour & $6.8 ”$ \\
\hline
\end{tabular}

Table 5 is a summary of the maximum stages and flow rates for the chosen nodes and links. The design storms precipitation amounts vary in magnitude from 0.6 " to 1.3 ". A difference in node elevations and link stages throughout the events are observed. The 5 year design storm event simulates less flow as the least amount of precipitation is generated over the area, and the 100 year the generated the most. MH211-3's invert elevation is $786.85 \mathrm{ft}$, NAD, and its manhole elevation is $799.5 \mathrm{ft}$, NAD. Based on the results below, the water stage rises $2.15 \mathrm{ft}$ during the 5 year storm event. The 100 year water stage rises to $3.35 \mathrm{ft}, 1.20$ feet higher than the 5 year storm event. The flow rates in $\mathrm{P}-11$ are the least of the links shown due to the fact that P-11 represents the least amount of area, the west portion; thus, conveys the least amount of runoff into the system. The flow rate shown in link P-26 is the total flow through the system including P-10, P-11, and P-27 links; thus, having the greatest flow rates. 
Table 5 Design Storm Stage and Flow Rate Results

\begin{tabular}{|c|c|c|c|c|c|c|}
\hline \multirow{2}{*}{ Design Storm } & \multicolumn{2}{|c|}{ Peak Stage (ft, NAD) } & \multicolumn{4}{c|}{ Peak Flow Rate (cfs) } \\
\cline { 2 - 7 } & MH211-3 & OF-211 & P-10 & P-11 & P-26 & P-27 \\
\hline 5 yr - 24 hour & 789 & 782.2 & 3.1 & 2.4 & 21.8 & 13.2 \\
\hline 10 yr - 24 hour & 789.3 & 782.3 & 3.8 & 3 & 25.5 & 15.2 \\
\hline 25 yr - 24 hour & 789.7 & 782.5 & 4.7 & 3.6 & 30.2 & 17.9 \\
\hline 100 yr - 24 hour & 790.2 & 782.8 & 5.8 & 4.8 & 37.7 & 22 \\
\hline
\end{tabular}

The larger the precipitation the greater the flow rate and the greater the water will stage. This is verified by the hydrographs for links P-10, P-11, P-26, and P-27 shown in Figure 21.

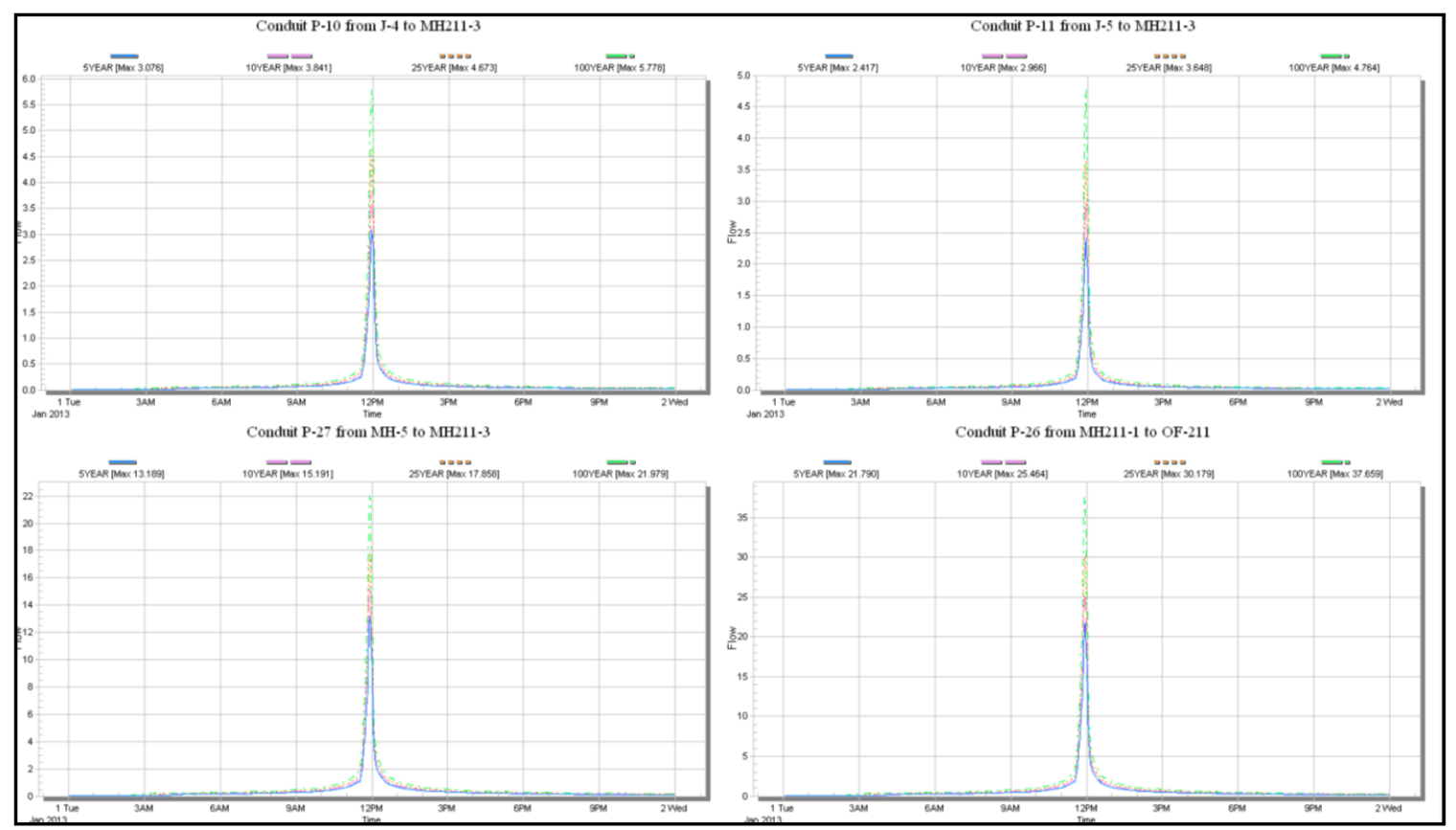

Figure 21 XPSWMM Design Storm Hydrographs 


\section{RESULTS AND DISCUSSION}

\subsection{Model Calibration}

A hydrology analysis was performed on the model beginning with a calibration of the model using both synthetic storm events for steady uniform flow conditions and actual rainfall data for unsteady non-uniform conditions. The results of the simulations using actual rainfall data from ORNL are compared to existing OF-211 flow data provided by ORNL.

The hydrology analysis of the model includes the following:

1. Calibration
a. Calibration of Steady Uniform Flow Conditions
b. Calibration of Non-steady Non-Uniform Flow Conditions

2. Sensitivity Analysis
a. Manning's Roughness Coefficients
b. Green Ampt and Horton's Infiltration Methods

3. Design Storm Analysis
a. 5 Year - 24 Hour Design Storm Event
b. 10 Year - 24 Hour Design Storm Event
c. 25 Year - 24 Hour Design Storm Event
d. 100 Year -24 Hour Design Storm Event

\subsubsection{Calibration of Steady Uniform Flow Conditions}

The model was calibrated for steady uniform flow conditions where the rainfall intensity remained constant for the duration of the storm event. For the steady uniform flow simulation a hypothetical 24 hour rainfall having an intensity of 0.5 inch/hour, as 
shown in Figure 22 Rainfall Hyetograph for Steady Uniform Flow, was simulated through two inlets on the main line.

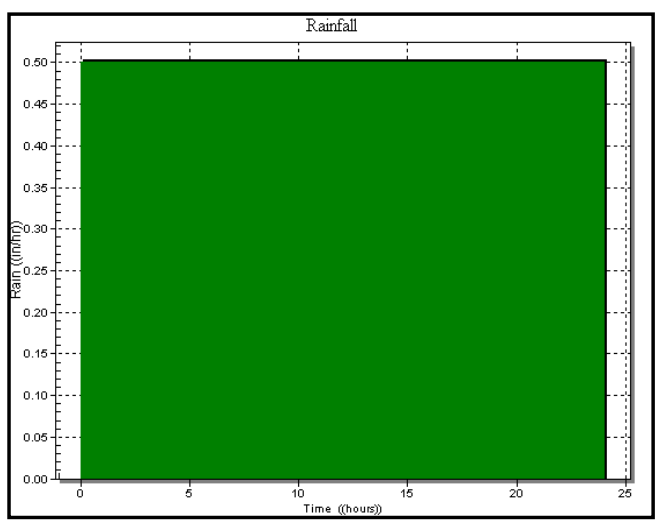

Figure 22 Rainfall Hyetograph for Steady Uniform Flow

Only inlet 1 and the nodes on the main trunk line were active. All other nodes and links were disabled so that flow entered only into inlets 1 and 3 (I-1 and I-3) in order to calibrate the model for steady uniform flow. These are shown in Figure 23. 


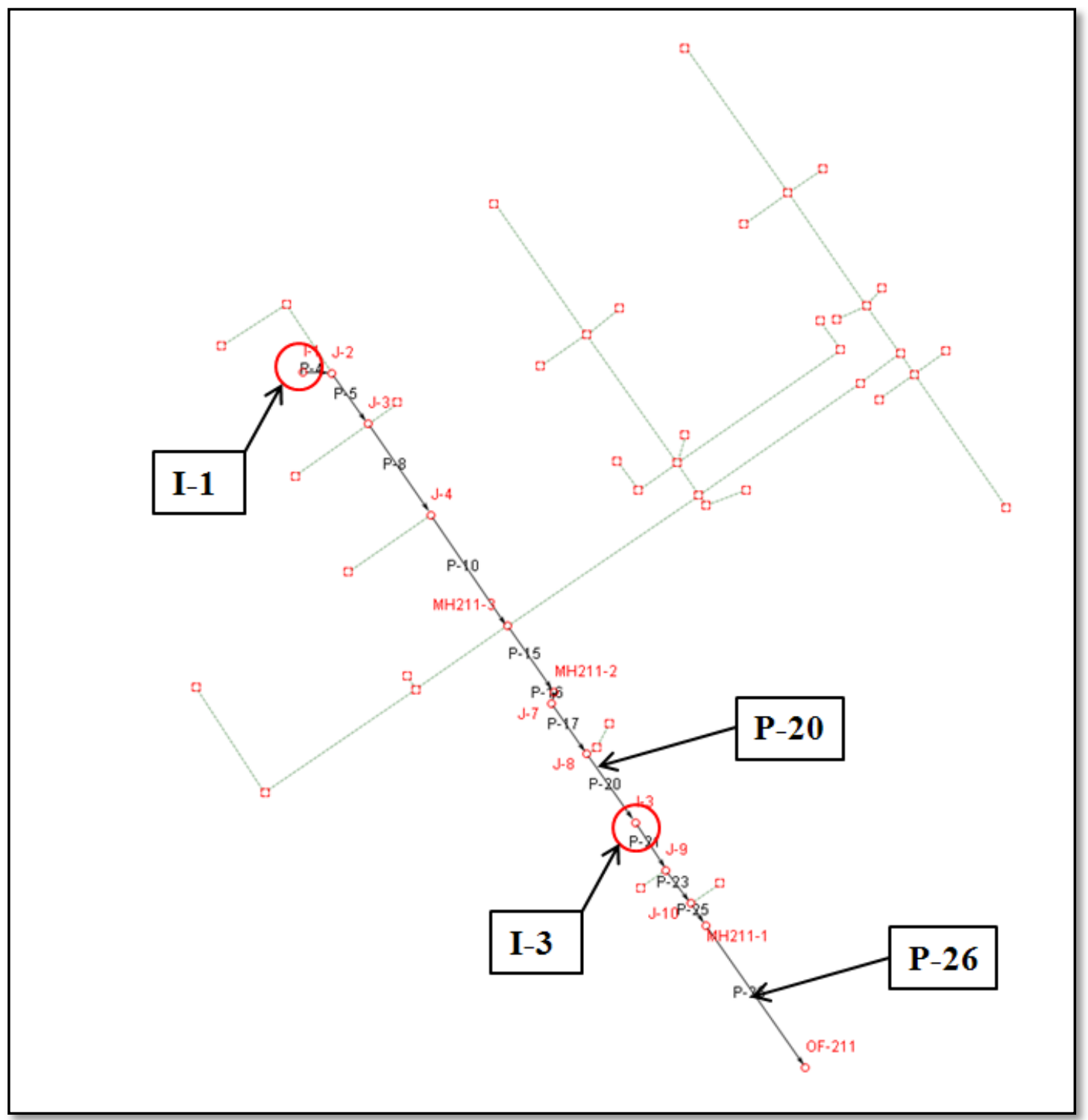

Figure 23 Stormwater Collection System for Steady Uniform Flow

From the conservation of mass equation, mass flow rate in equals mass flow rate out, the system was analyzed.

$$
\begin{aligned}
& m=\rho * Q \\
& \rho_{I-1} * Q_{I-1}+\rho_{I-3} * Q_{I-3}=\rho_{\text {out }} * Q_{\text {out }}
\end{aligned}
$$

where $\rho$ is the density of the surface water in pounds per square foot $(\mathrm{lb} / \mathrm{sf})$ and $\mathrm{Q}$ is the flow rate of the surface water in cubic feet per second (cfs). Knowing that the density of 
the surface water is constant, the density can be cancelled out leaving the flow rate of I-1 plus the flow rate of I-3 to equal the flow rate out.

$$
Q_{I-1}+Q_{I-3}=Q_{\text {out }}
$$

where

$$
Q=c * i * A
$$

Equation 19 is known as the rational formula, where $\mathrm{c}$ is the dimensionless runoff coefficient, $i$ is the rainfall intensity in inches per hour (in/hr), A is the area of the subdrainage area in acres (ac). The flow is in cfs and represents the peak flow rate.

The steady uniform flow calibration was performed by simulating a constant rainfall intensity of $0.5 \mathrm{inch} /$ hour for a 24 hour duration over the site.

The rational formula equations representing the flow rate entering I-1 is calculated as follows:

$$
\begin{aligned}
Q_{I-1} & =0.05 * 0.5\left(\frac{i n}{h r}\right) *(0.173 a c) \\
Q_{I-1} & =0.004 c f s
\end{aligned}
$$

The sub-drainage areas are mostly green space with an estimated impervious area of $5 \%$. A rainfall intensity of $0.5 \mathrm{in} / \mathrm{hr}$ and a sub-drainage area total of 0.173 ac were used. A rational runoff coefficient may be estimated as 0.05 to 0.35 for lawns. The rational method runoff coefficient is shown in Table 6. 
Table 6 Rational Method Runoff Coefficients

\begin{tabular}{|l|c|}
\hline \multicolumn{2}{|c|}{ Rational Method Runoff Coefficients (Chow, 1988) } \\
\hline \multicolumn{1}{|c|}{ Ground Cover } & Runoff Coefficient, c \\
\hline Lawns & $0.05-0.35$ \\
\hline Forest & $0.05-0.25$ \\
\hline Cultivated land & $0.08-0.41$ \\
\hline Meadow & $0.1-0.5$ \\
\hline Parks, cemeteries & $0.1-0.25$ \\
\hline Unimproved areas & $0.1-0.3$ \\
\hline Pasture & $0.12-0.62$ \\
\hline Residential areas & $0.3-0.75$ \\
\hline Business areas & $0.5-0.95$ \\
\hline Industrial areas & $0.5-0.9$ \\
\hline Asphalt streets & $0.7-0.95$ \\
\hline Brick streets & $0.7-0.85$ \\
\hline Roofs & $0.75-0.95$ \\
\hline Concrete streets & $0.7-0.95$ \\
\hline
\end{tabular}

The flow rate produced by XPSWMM was compared to the flow rate produced by the rational formula. Dense grass is present in this area; thus, the runoff coefficient of 0.05 was chosen. The peak flow rate in P-20 should be equal to that of resulting flow rate of $Q_{I-1}$. The XPSWMM hydrograph results in Figure 24 Conduit P-20 Results for Steady Uniform Flow indicate that the peak flow rate is $0.004 \mathrm{cfs}$, which complies with the results produced by the rational method for $Q_{I-1}$ which equals $0.004 \mathrm{cfs}$. 


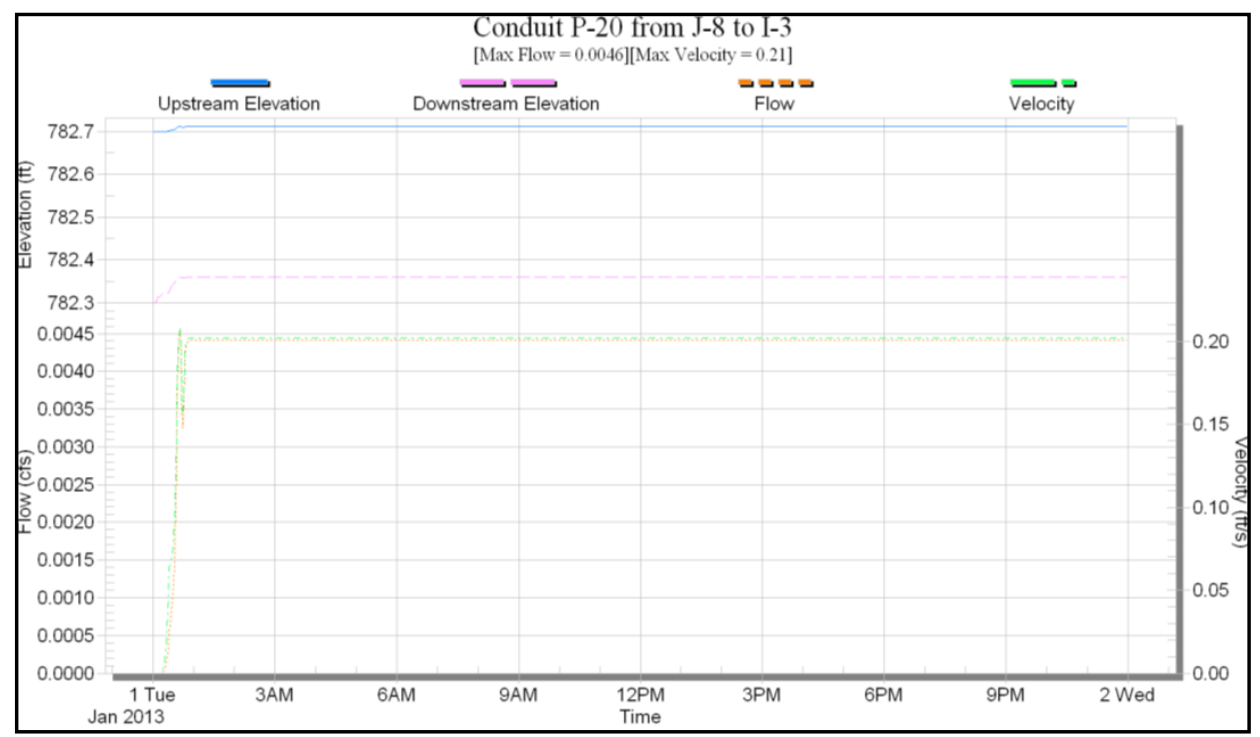

Figure 24 Conduit P-20 Results for Steady Uniform Flow

The calculation using the rational formula for the flow rate entering I-3 is calculated as follows:

$$
\begin{aligned}
& Q_{I-3}=0.95 * 0.5\left(\frac{i n}{h r}\right) *(0.097 a c) \\
& Q_{I-3}=0.046 c f s \\
& Q_{\text {out }}=Q_{I-1}+Q_{I-3}=0.004 c f s+0.046 c f s=0.05 c f s
\end{aligned}
$$

I-3 sub-catchments total $0.097 \mathrm{ac}$, a steady uniform rainfall of $0.5 \mathrm{in} / \mathrm{hr}$, and an assumed rational runoff coefficient of 0.95 for asphalt streets was used as this is an asphalt driveway resulting in a flow rate of $0.046 \mathrm{cfs}$.

Link P-26 is located immediately before Outfall 211; therefore, the peak flow rate in P-20 should equal that of $Q_{o u t}$ The XPSWMM hydrograph results in Figure 25 Conduit P-26 Results for Steady Uniform Flow indicate that the peak flow rate is 0.05 cfs, which complies with the results provided by the rational formula for $Q_{\text {out }}$. 


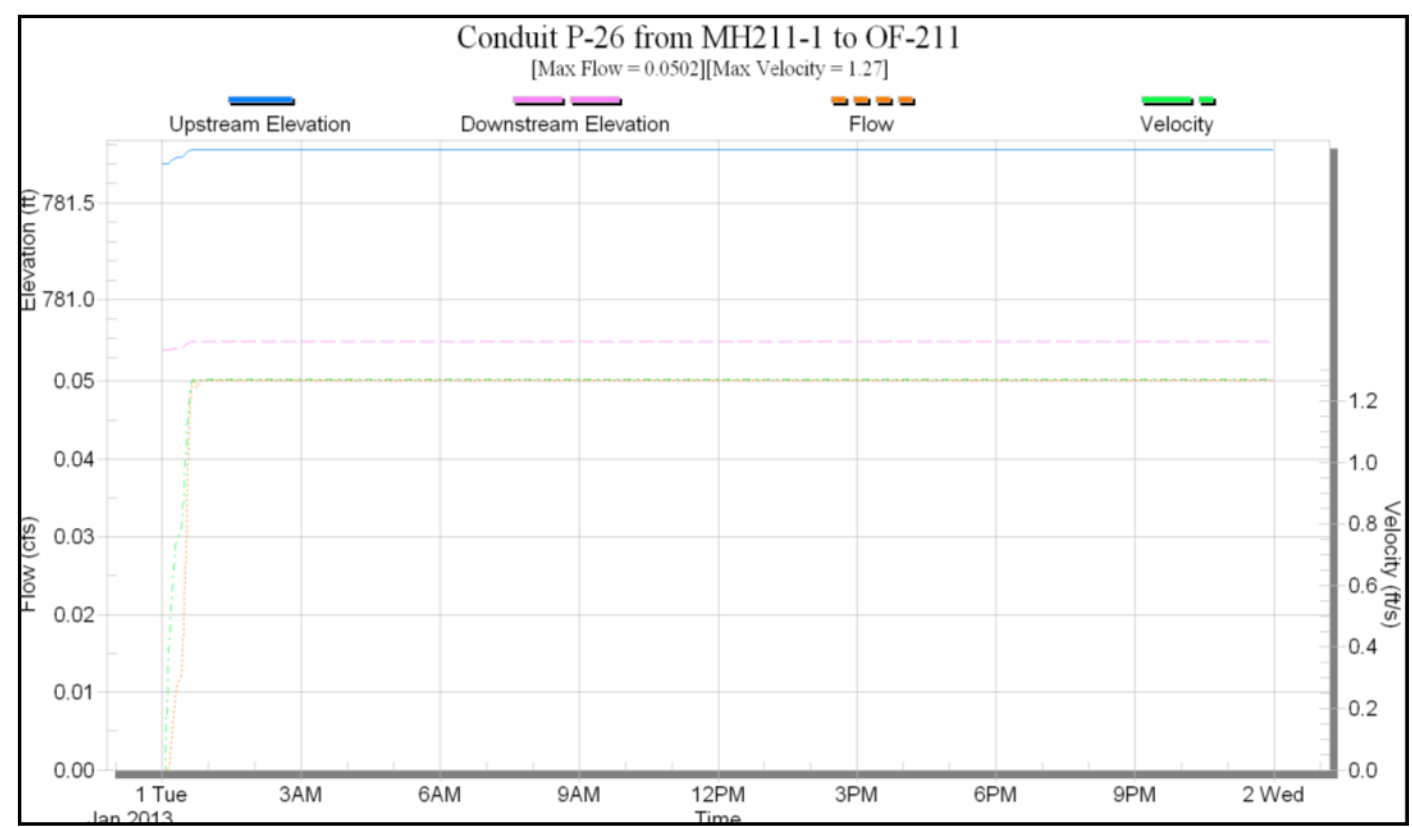

Figure 25 Conduit P-26 Results for Steady Uniform Flow

\subsubsection{Unsteady Non-Uniform Flow Calibrations}

In order for the ORNL surface water model of the 4500 Area to be considered a valuable source to assess flow rates within the network, it must be calibrated with existing OF-211 data. The non-uniform flow calibration was conducted by simulating actual rainfall that occurred during the timeframe that ORNL provided OF-211 flow rate data to XPSWMM predicted flow rates. ORNL monitored the OF-211 flow rate discharge from October 21, 2012 11:00 AM to December 19, 2012 9:00 AM. ORNL noted dates and times that precipitation occurred. After review of the ORNL data, the following dates and timeframes (hereby referred to as trials) were used for the calibration based upon peak flow rates indicated by the ORNL hydrographs provided:

1. November 12, 2012 1:00 PM - 10:10 PM

2. November 26, 2012 10:15 PM - November 27, 2012 5:50 AM

3. December 10, 2012 3:25 AM - 6:30 PM

4. December 15, 2012 9:45 PM - December 16, 2012 8:55 PM 
For the calibration trials base conditions including a Manning's roughness coefficient of 0.015, the Green Ampt infiltration method, and evaporation rate of 0.1\%/day were used. The calibrations are based on 24-hour simulations and were conducted by analyzing the ORNL observed flow rate data at OF-211. Rainfall data was retrieved around the time that the data produced peak flow rates. Once the baseflow rate was subtracted from the ORNL observed data, the XPSWMM P-26 results were overlaid. A timeframe was chosen where the beginning and end times corresponded to flow rates that were zero. Peak flow rates and their corresponding times are noted as well as a summation of flow rates for both the ORNL data and the XPSWMM results during the time of calibration for comparison.

The unsteady non-uniform calibration was performed by simulating actual rainfall events and comparing the model results of OF-11 to OF-211 monitored data. After analyzing the OF-211 flow rate data provided by ORNL, an approximate $0.17 \mathrm{cfs}$ baseflow rate was observed by graphing the data. It is known from the construction of the system, that the OF-211 storm system contains baseflow and is defined as once-through cooling water and steam condensate from the adjacent buildings' AC units; however, their exact quantities and locations are unknown. Therefore, a $0.17 \mathrm{cfs}$ has been extracted from the ORNL flow rate data in order to compare the XPSWMM results for calibration purposes due to the fact that exact baseflow quantities and locations of entry into the system are unknown. The XPSWMM model introduces actual 60-minute interval rainfall data that was retrieved from ORNL Tower C monitoring station for calibration purposes. XPSWMM provides resulting flow rates within each pipe and resulting elevations at each node after the model is solved; thus, flow rates from pipe 26 (P-26), which is the 
pipe immediately prior to OF-211, were analyzed. The data provided by ORNL is in 5minute intervals; thus, the XPSWMM P-26 resulting flow rates were extracted in 5minute intervals, and both data are presented as hydrographs for comparison. The calibration is based on flow rates presented in cubic feet per second (cfs). ORNL provided data in gallons per minute $(\mathrm{gpm})$. A conversion factor of $0.002228 \mathrm{cfs}$ per gpm was used.

\subsubsection{Model calibration for November 12, 2012}

Sixty-minute interval rainfall data was retrieved from ORNL Tower $\mathrm{C}$ and indicates that precipitation occurred on November 12, 2012 between the hours of 12:00 AM and 7:00 PM. The rainfall data was simulated through the network. The timeframe for calibration purposes was chosen as November 12, 2012 from 1:00 PM to 10:10 PM. XPSWMM produced the hyetograph shown below based upon the rainfall data entered into the model.

Table 7 Rainfall Data for Calibration Trial 1

\begin{tabular}{|c|c|c|c|}
\hline \multicolumn{5}{|c|}{ Tower C } & \multicolumn{3}{|c|}{ Rainfall Data 60 min Intervals } \\
\hline Time & $\begin{array}{c}\text { Rain } \\
\text { (in) }\end{array}$ & Time & $\begin{array}{c}\text { Rain } \\
\text { (in) }\end{array}$ \\
\hline $11 / 12 / 201211: 00$ & 0 & $11 / 12 / 201216: 00$ & 0.12 \\
\hline $11 / 12 / 201212: 00$ & 0.01 & $11 / 12 / 201217: 00$ & 0.08 \\
\hline $11 / 12 / 201213: 00$ & 0.04 & $11 / 12 / 201218: 00$ & 0.06 \\
\hline $11 / 12 / 201214: 00$ & 0.07 & $11 / 12 / 201219: 00$ & 0.03 \\
\hline $11 / 12 / 201215: 00$ & 0.24 & $11 / 12 / 201220: 00$ & 0 \\
\hline
\end{tabular}




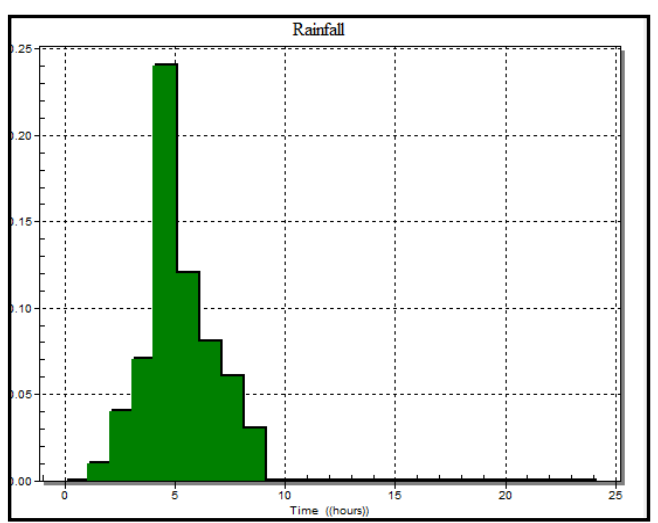

Figure 26 Rainfall Hyetograph for Calibration Trial 1

The rainfall event that occurred on November 12, 2012 between the hours of 12:00 AM and 7:00 PM was utilized for the calibration trial 1. Figure 27 is a hydrograph of the ORNL OF-211 data provided during the time the precipitation occurred and includes the $0.17 \mathrm{cfs}$ baseflow which was later extracted for calibration purposes.

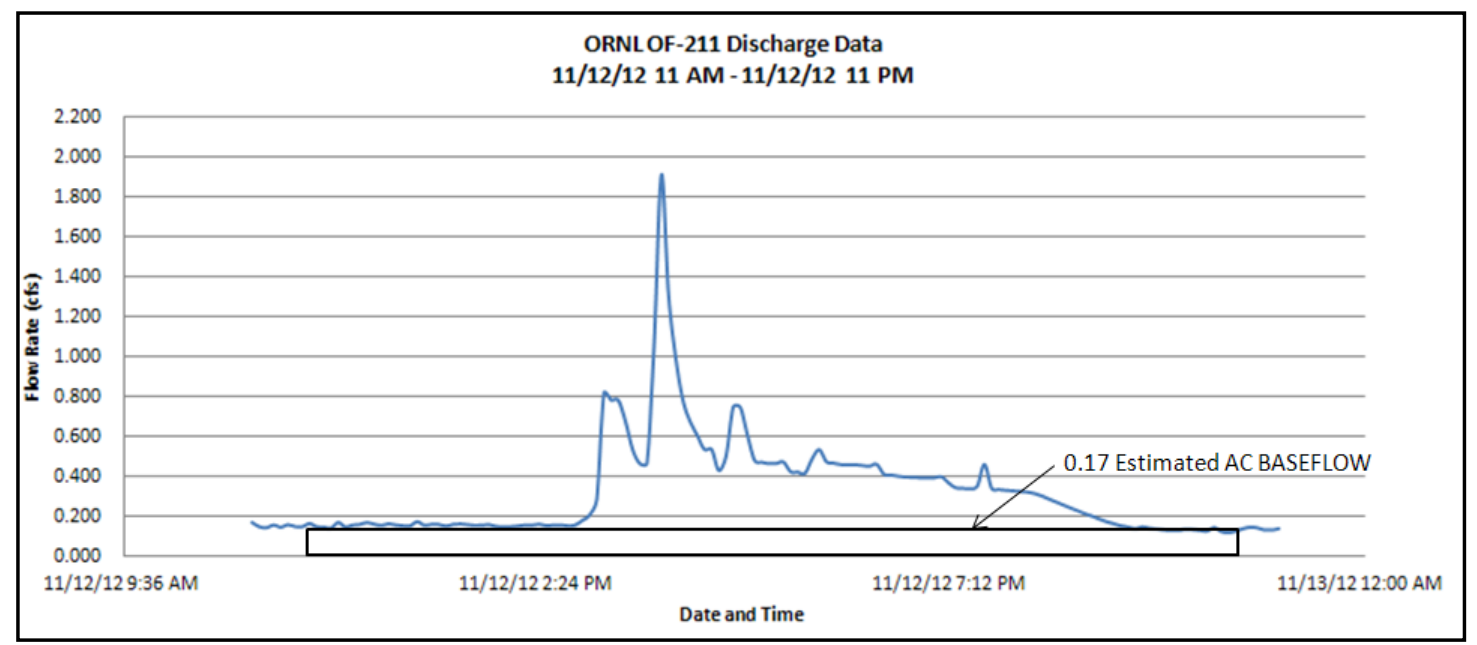

Figure 27 ORNL Data with Baseflow

Figure 28 shows that the ORNL observed flow rate data has a peak flow rate of 1.73 cfs (excluding $0.17 \mathrm{cfs}$ baseflow) on November 12, 2012 at 3:50 PM. The XPSWMM hydrograph does not indicate as large of a peak as the ORNL data, however the summation of flow rates under the curve are very similar. The lag time for the model to simulate the rainfall is approximately 25 minutes. 


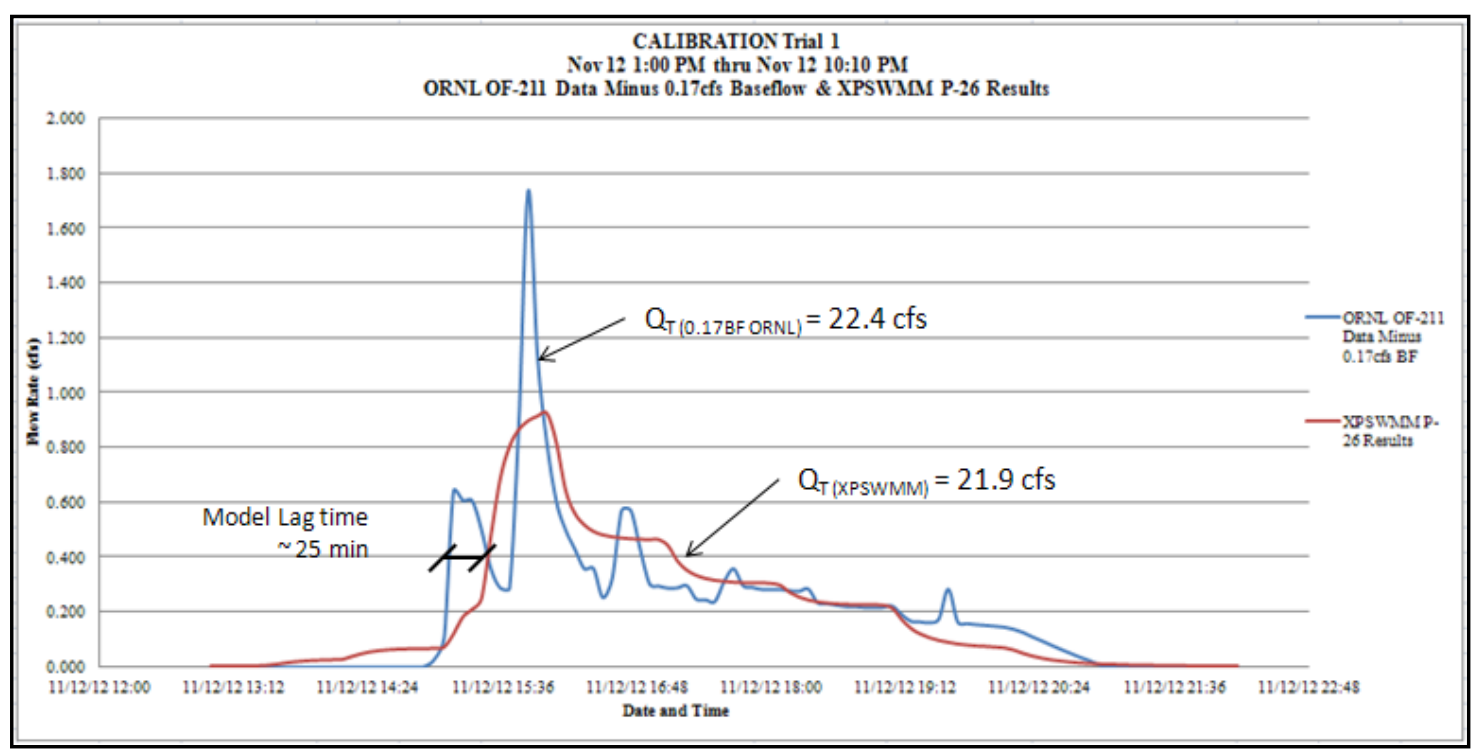

Figure 28 ORNL Data and XPSWMM Results Hydrograph

This may be considered a successful calibration as the summation of flow rates during the calibration duration vary by a minimal $0.5 \mathrm{cfs}$, which is shown in Figure 29. This is the cumulative flow rate versus time which indicates more clearly the two sets of data summation of flow rates.

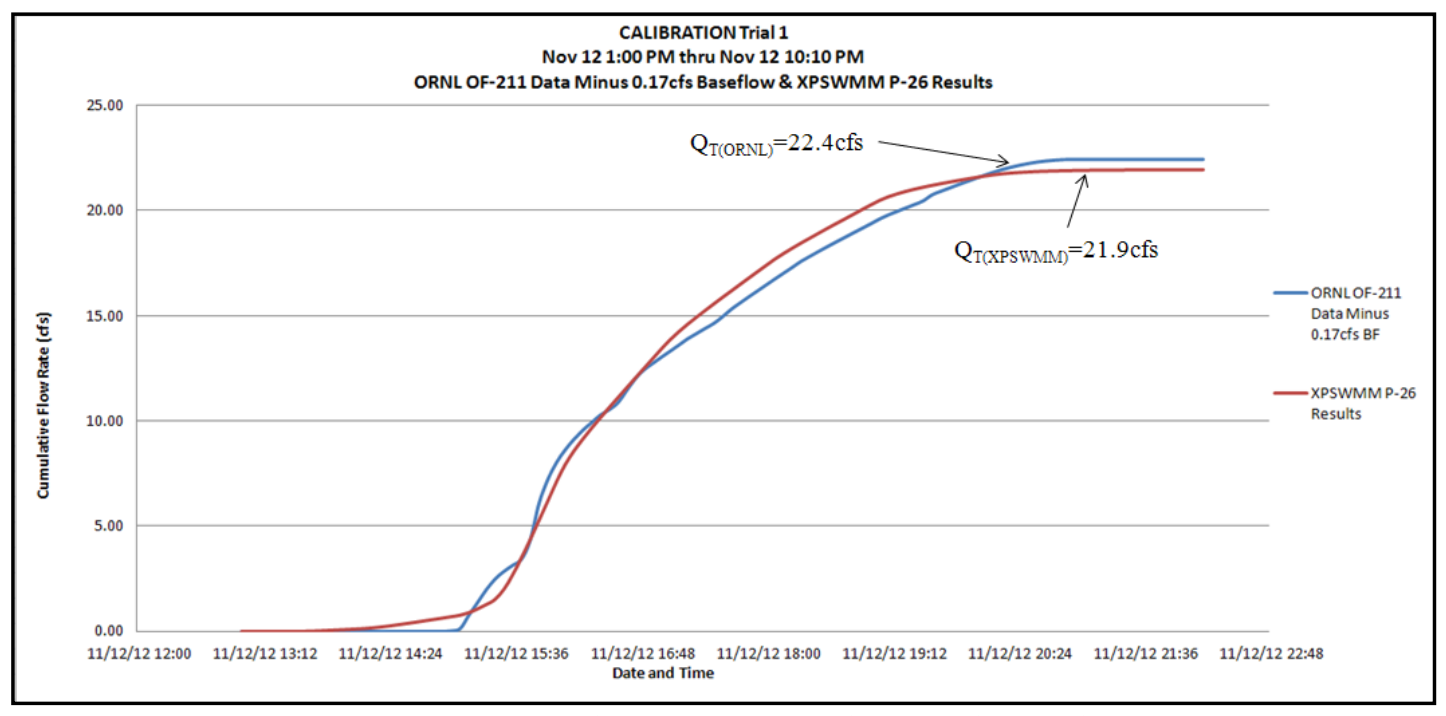

Figure 29 ORNL Data and XPSWMM Results Cumulative Flow Rates 


\subsubsection{Model calibration for November 26, 2012}

The precipitation data beginning on November 26, 2012 at 9PM thru November 27, 2012 at 6AM is shown below in Table 8 and was simulated through the network. The timeframe for calibration purposes was chosen as November 26, 2012 10:15 PM - November 27, 2012 6:05 AM. XPSWMM produced the hyetograph in Figure 30 based upon the rainfall data entered into the model.

Table 8 Rainfall Data for Calibration Trial 2

\begin{tabular}{|c|c|c|c|}
\hline \multicolumn{5}{|c|}{ Tower C Rainfall Data 60 min Intervals } \\
\hline Date \& Time & $\begin{array}{c}\text { Rain } \\
\text { (in) }\end{array}$ & Date \& Time & Rain (in) \\
\hline $11 / 26 / 201221: 00$ & 0 & $11 / 27 / 20123: 00$ & 0.04 \\
\hline $11 / 26 / 201222: 00$ & 0.07 & $11 / 27 / 20124: 00$ & 0 \\
\hline $11 / 26 / 201223: 00$ & 0.07 & $11 / 27 / 20125: 00$ & 0 \\
\hline $11 / 27 / 20120: 00$ & 0.12 & $11 / 27 / 20126: 00$ & 0.01 \\
\hline $11 / 27 / 20121: 00$ & 0.04 & $11 / 27 / 20127: 00$ & 0 \\
\hline $11 / 27 / 20122: 00$ & 0.02 & & \\
\cline { 1 - 3 } & & &
\end{tabular}

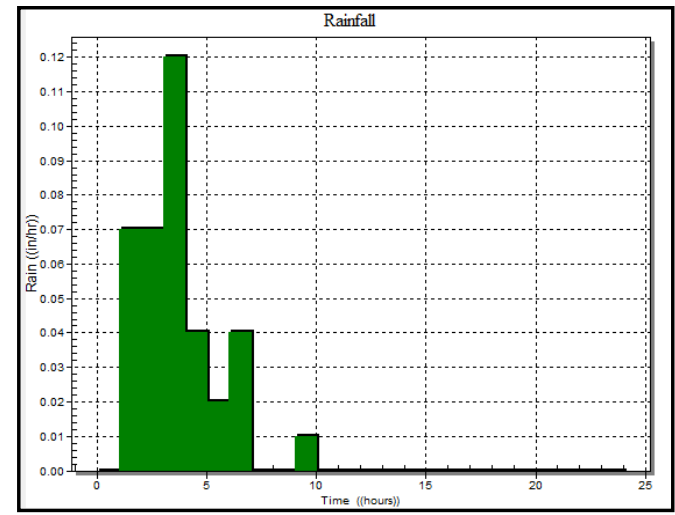

Figure 30 Rainfall Hyetograph for Calibration Trial 2

The rainfall event that occurred on November 26, 2012 at 9PM thru November 27,2012 at $6 \mathrm{AM}$ was utilized for the calibration trial 2. Figure 31 is a hydrograph of the ORNL OF-211 data provided during the time the precipitation occurred and includes the 0.17 cfs baseflow which was later extracted for calibration purposes. 


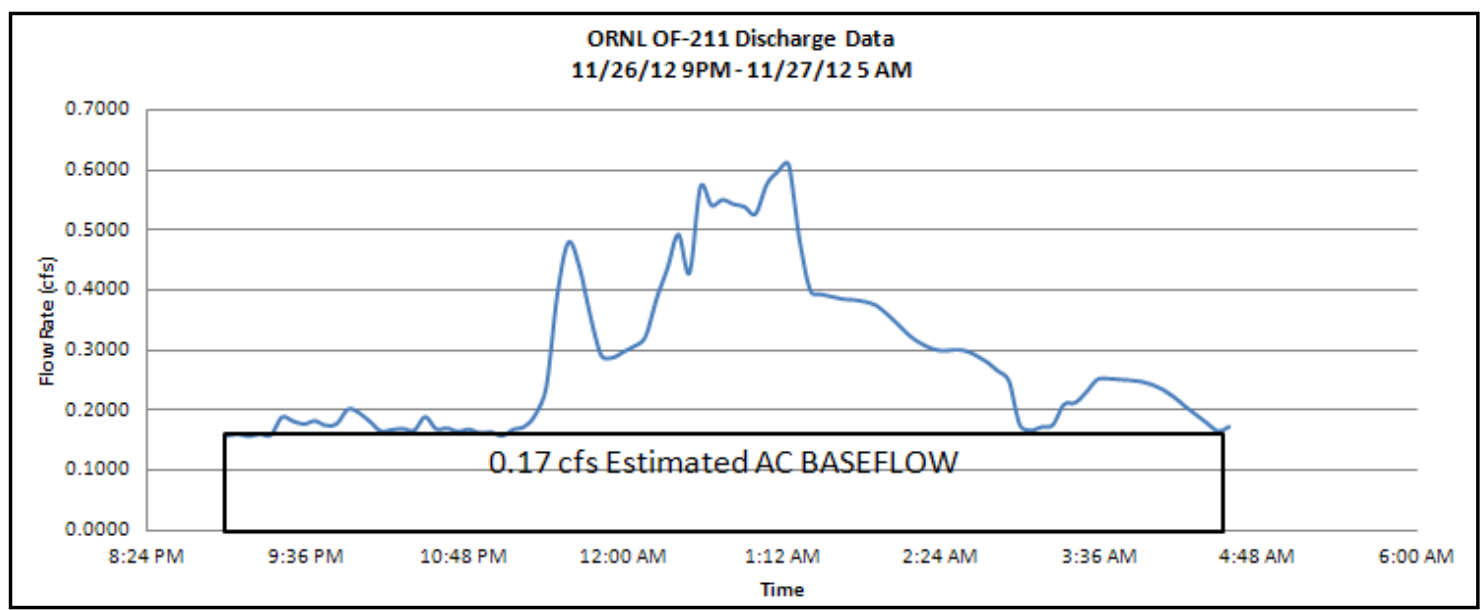

Figure 31 ORNL Data with Baseflow

The ORNL observed data indicates a peak flow rate of $0.44 \mathrm{cfs}$ (excludes $0.17 \mathrm{cfs}$ baseflow) on November 27, 2012 at 1:15 AM. The XPSWMM hydrograph indicates a peak flow rate of $0.44 \mathrm{cfs}$ at 1:00 AM. A summation of the ORNL OF-211 flow rates and the XPSWMM results are also depicted in the Figure 32 below. The peak flow rates are consistent if one accepts that a 0.17 cfs baseflow occurs during that timeframe. ORNL's peak falls behind the model results by 15 minutes. However, the XPSWMM model lags behind ORNL data by approximately 55 minutes. The lag time is the difference in time between the two sets of data where the first rainfall interval has been routed through the system. 


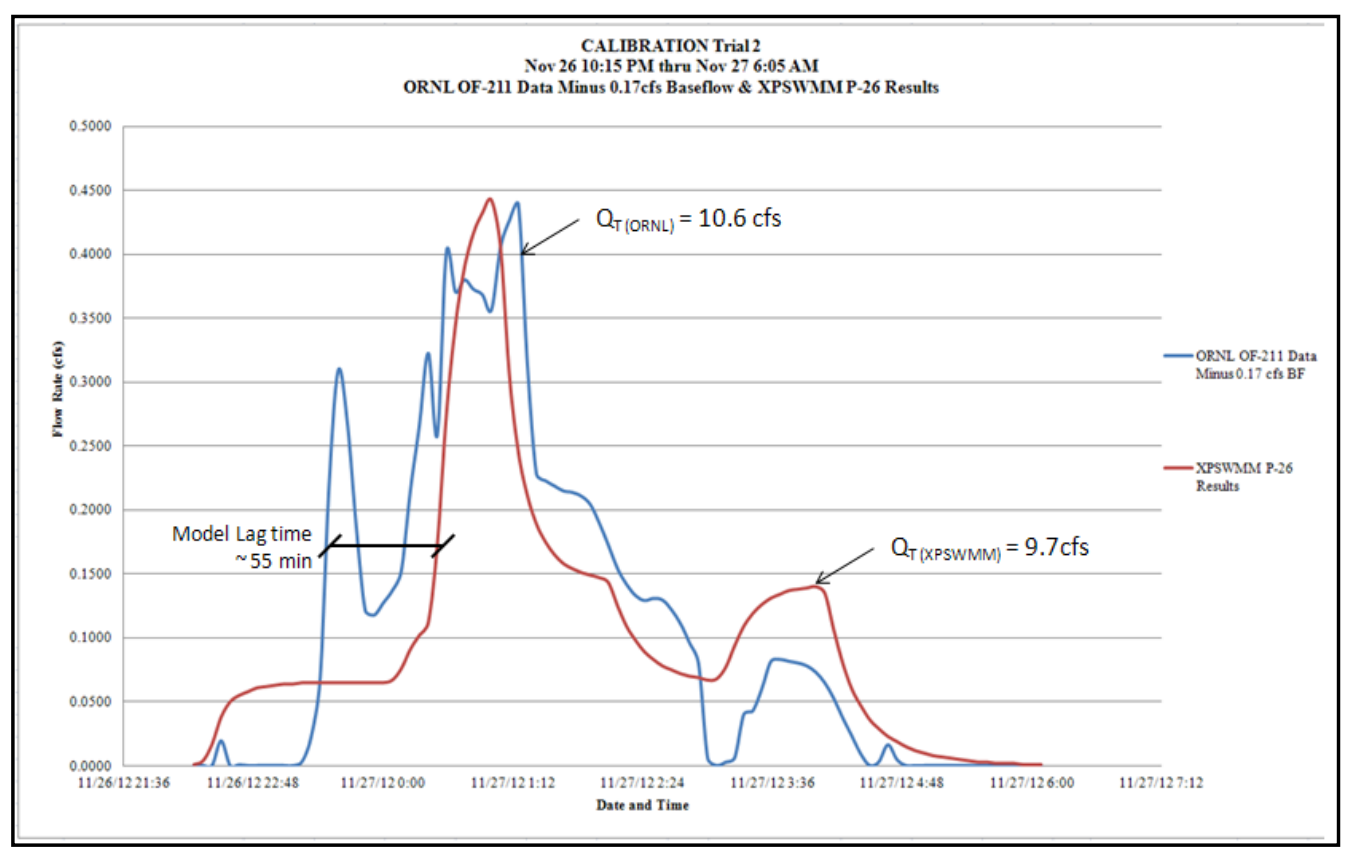

Figure 32 ORNL Data and XPSWMM Results Hydrograph

The summation of the flow rates during the calibration timeframe is similar.

Below Figure 33 indicates the cumulative flow rate versus time which indicates more clearly the two sets of data summation of flow rates during the calibration duration.

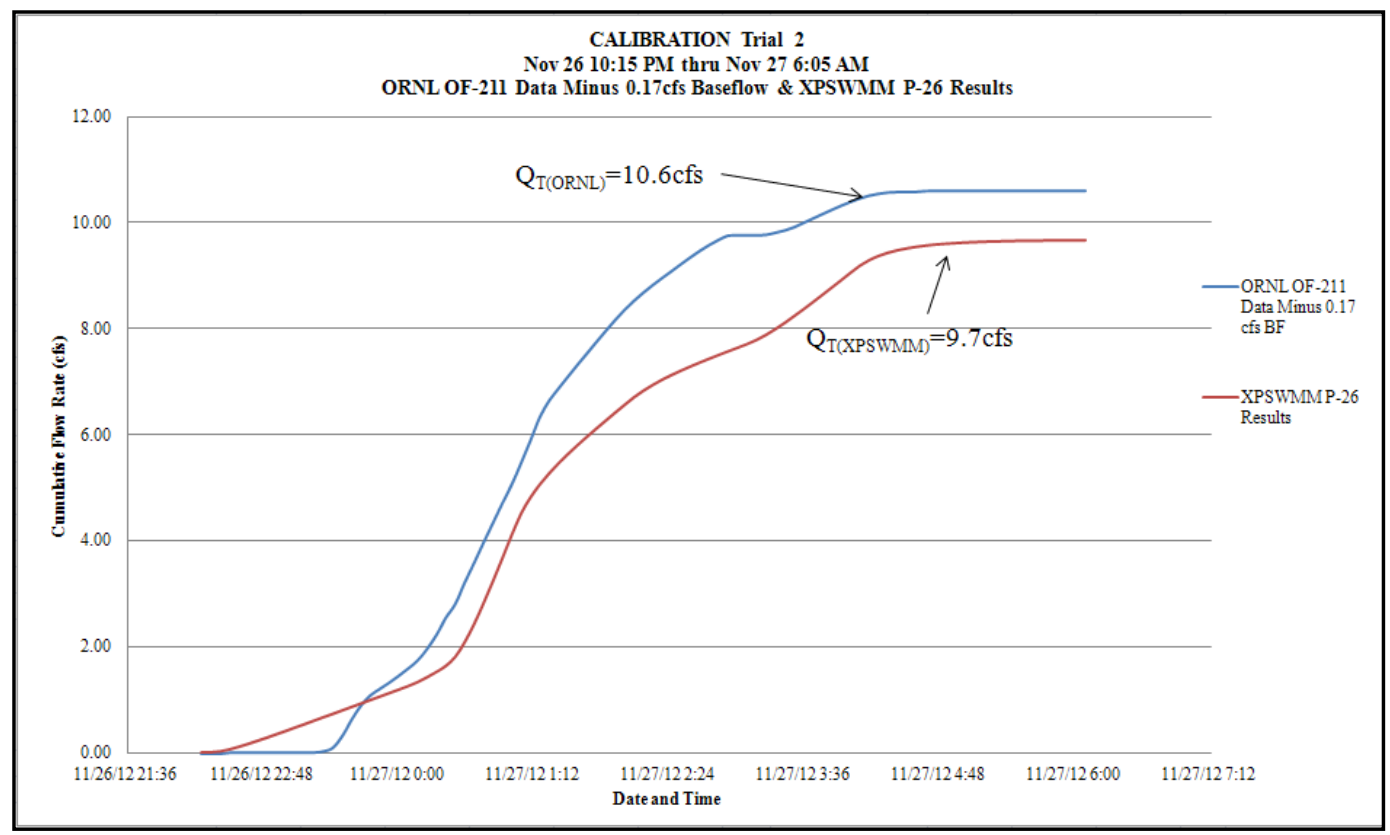

Figure 33 ORNL Data and XPSWMM Results Cumulative Flow Rates 


\subsubsection{Model calibration for December 10, 2012}

Sixty-minute interval rainfall data was retrieved from ORNL Tower C and indicates that precipitation occurred on December 10, 2012 between the hours of 3:00 AM and 4:00 PM. The rainfall was simulated through the network. ORNL OF-211 data provided for calibration is shown in the hydrograph Figure 34. The timeframe for calibration purposes was chosen as December 10, 2012 3:25 AM - 6:30 PM. XPSWMM produced the hyetograph in Figure 34 based upon the rainfall data entered into the model.

Table 9 Rainfall Data for Calibration Trial 3

\begin{tabular}{|c|c|c|c|c|c|}
\hline \multicolumn{6}{|c|}{ Tower C Rainfall Data 60 min intervals } \\
\hline Time & $\begin{array}{l}\text { Rain } \\
\text { (in) }\end{array}$ & Time & Rain (in) & Time & Rain (in) \\
\hline $12 / 10 / 20122: 00$ & 0 & $12 / 10 / 20128: 00$ & 0.1 & $12 / 10 / 201214: 00$ & 0 \\
\hline 12/10/20123:00 & 0.03 & 12/10/2012 9:00 & 0.1 & $12 / 10 / 201215: 00$ & 0 \\
\hline $12 / 10 / 20124: 00$ & 0.12 & $12 / 10 / 201210: 00$ & 0.05 & $12 / 10 / 201216: 00$ & 0.01 \\
\hline $12 / 10 / 20125: 00$ & 0.02 & $12 / 10 / 201211: 00$ & 0.02 & $12 / 10 / 201217: 00$ & 0 \\
\hline $12 / 10 / 20126: 00$ & 0.31 & $12 / 10 / 201212: 00$ & 0.04 & & \\
\hline $12 / 10 / 20127: 00$ & 0.08 & $12 / 10 / 201213: 00$ & 0.04 & & \\
\hline
\end{tabular}

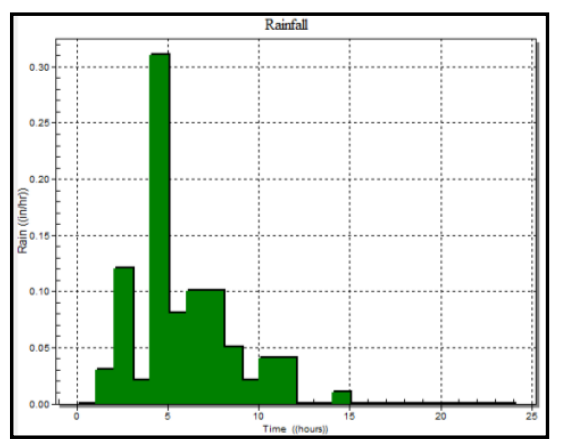

Figure 34 Rainfall Hyetograph for Calibration Trial 3

The rainfall event that occurred on December 10, 2012 between the hours of 3:00 AM and 4:00 PM was utilized for the calibration trial 3. Figure 35 is a hydrograph of the ORNL OF-211 data provided during the time the precipitation occurred and includes the 0.17 cfs baseflow which was later extracted for calibration purposes. 


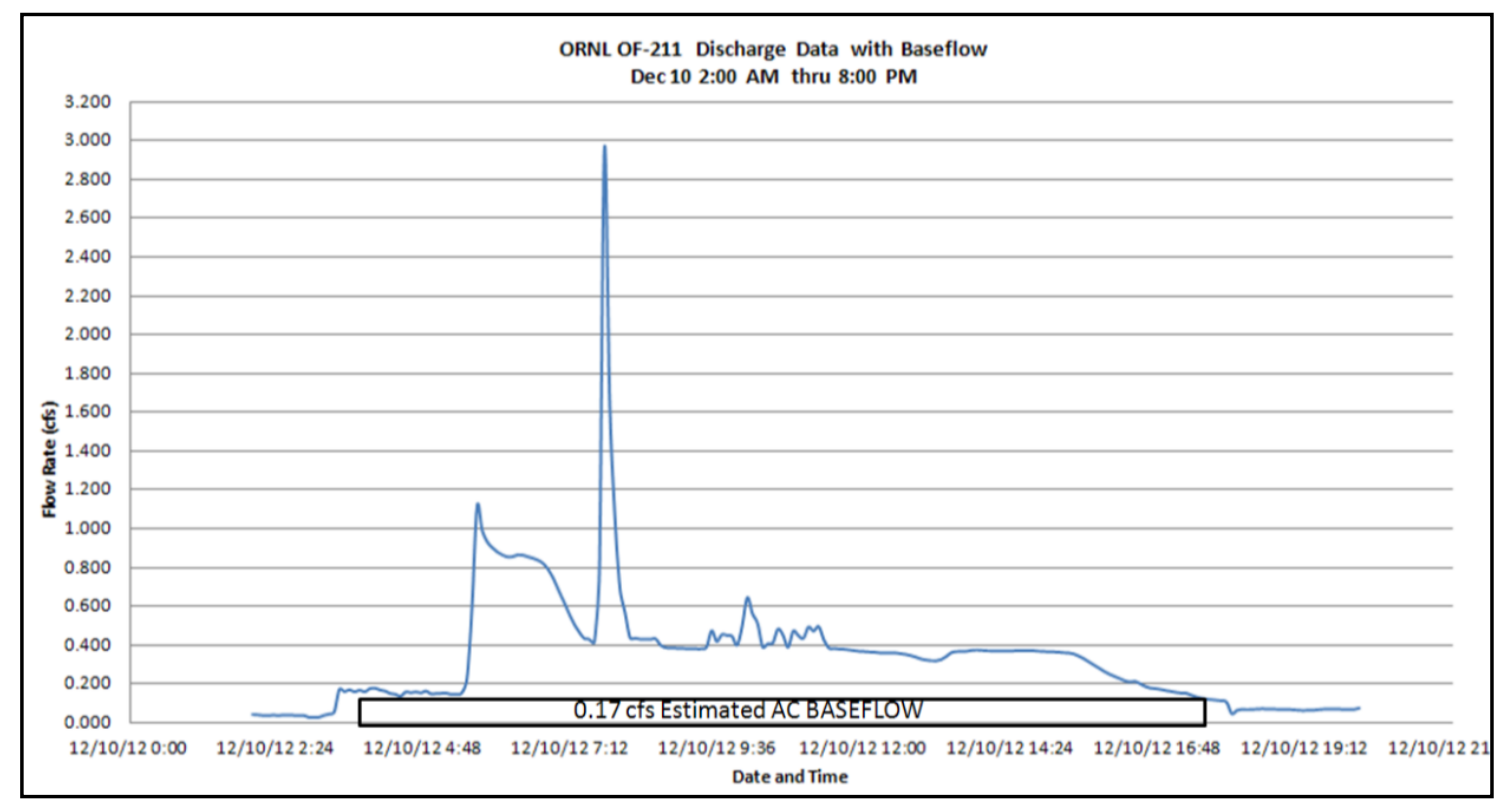

Figure 35 ORNL Data with Baseflow

ORNL noted that the 3 cfs peak flow rate may be a faulty reading from the flow rate monitor. Figure 36 is an overlay of the ORNL data (minus 0.17 cfs baseflow) and XPSWMM results. ORNL observed data indicates a peak flow rate of $2.79 \mathrm{cfs}$ (excludes 0.17 baseflow) on December 10, 2012 at 7:45 AM. Below that is a figure indicating the cumulative flow rate versus time which indicates more clearly the two sets of data summation of flow rates during the calibration duration. The hydrograph produced by XPSWMM portrays a peak flow rate of $1.22 \mathrm{cfs}$ at 7:00 AM. The lag between the two sets of data is approximately 40 minutes. The total flow rate summation results are relatively close. 


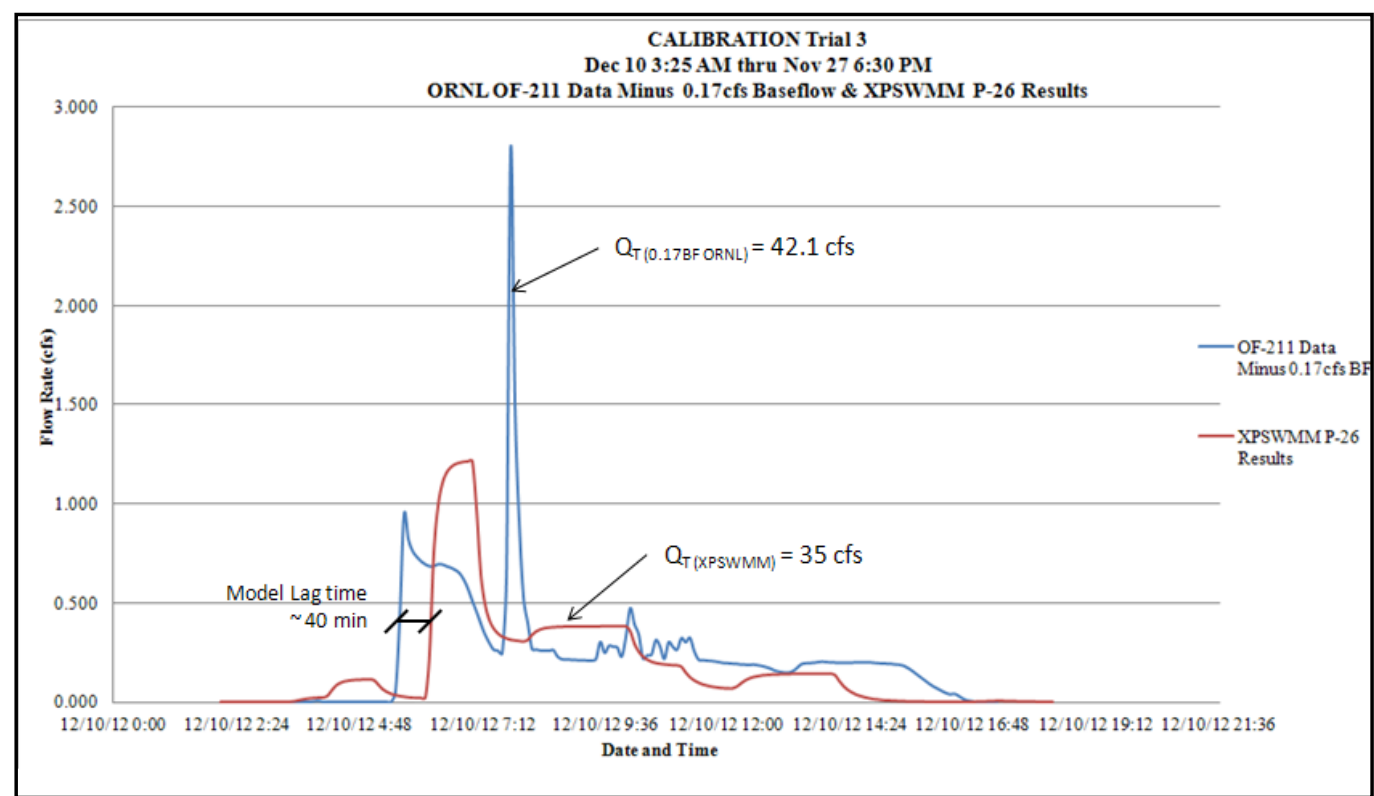

Figure 36 ORNL Data and XPSWMM Results Hydrograph

The summation of the flow rates during the calibration timeframe differ by $7.1 \mathrm{cfs}$ which is larger than the first two calibrations. The may be seen in the graph Figure 37.

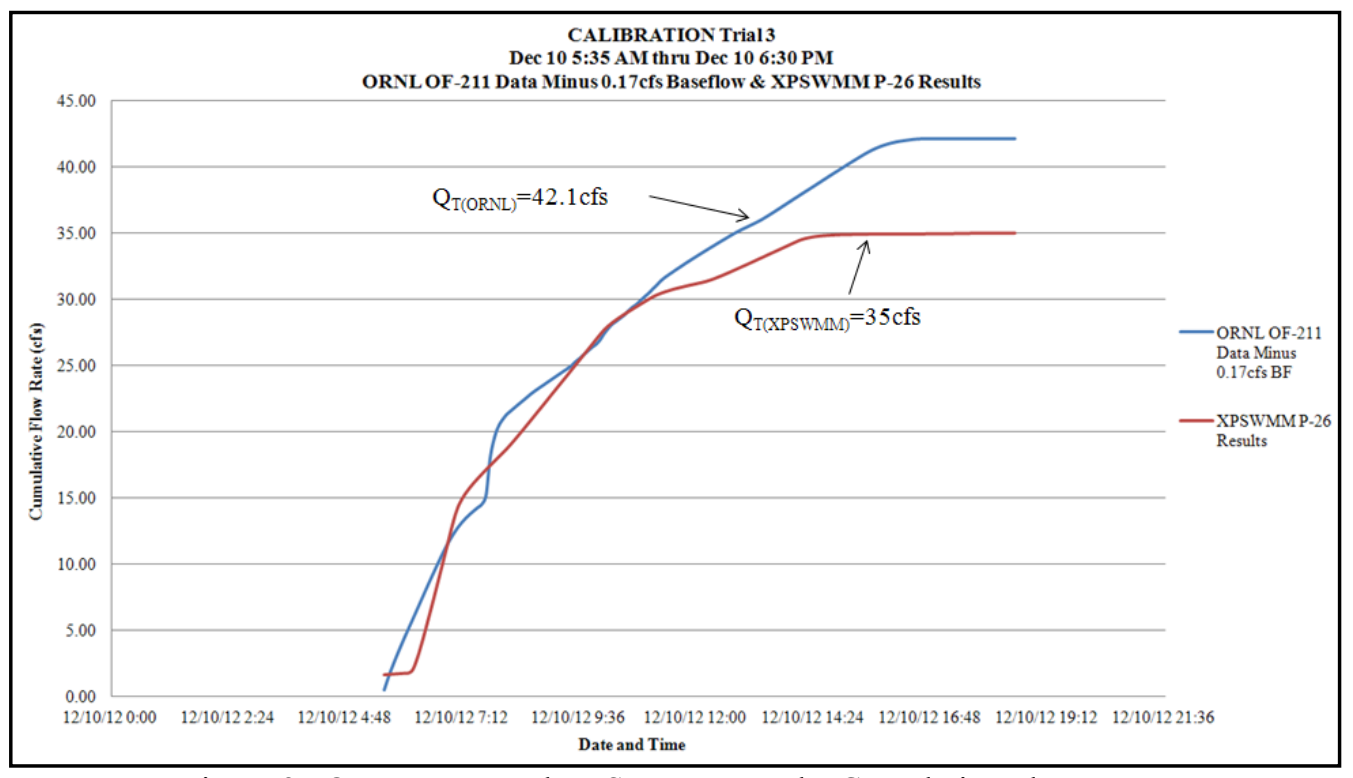

Figure 37 ORNL Data and XPSWMM Results Cumulative Flow Rates 


\subsubsection{Model for December 15, 2012}

Sixty-minute interval rainfall data was retrieved from ORNL Tower C and indicates that precipitation occurred on December 15, 2012 between the hours of 9:00 PM and 8:00 PM. The rainfall was simulated through the network. The timeframe for calibration purposes was chosen as December 15, 2012 9:45 AM - 8:55 PM. XPSWMM produced the hyetograph shown in Figure 38 based upon the rainfall data entered into the model.

Table 10 Rainfall Data for Calibration Trial 4

\begin{tabular}{|c|c|c|c|c|c|}
\hline \multicolumn{6}{|c|}{ Tower C Rainfall Data 60 min intervals } \\
\hline Time & Rain (in) & Time & Rain (in) & Time & Rain (in) \\
\hline $12 / 15 / 201220: 00$ & 0 & $12 / 16 / 20126: 00$ & 0.12 & $12 / 16 / 201214: 00$ & 0 \\
\hline $12 / 15 / 201221: 00$ & 0.01 & $12 / 16 / 20127: 00$ & 0.06 & $12 / 16 / 2012$ 15:00 & 0 \\
\hline $12 / 15 / 201222: 00$ & 0.1 & 12/16/2012 8:00 & 0.09 & $12 / 16 / 201216: 00$ & 0 \\
\hline $12 / 15 / 201223: 00$ & 0.06 & 12/16/2012 9:00 & 0.04 & $12 / 16 / 201217: 00$ & 0.01 \\
\hline $12 / 17 / 20120: 00$ & 0.01 & $12 / 16 / 20128: 00$ & 0.09 & 12/16/2012 18:00 & 0.01 \\
\hline 12/16/2012 1:00 & 0.01 & 12/16/2012 9:00 & 0.04 & 12/16/2012 19:00 & 0.02 \\
\hline $12 / 16 / 20122: 00$ & 0 & $12 / 16 / 201210: 00$ & 0.05 & $12 / 16 / 201220: 00$ & 0.01 \\
\hline $12 / 16 / 20123: 00$ & 0.01 & $12 / 16 / 2012$ 11:00 & 0.03 & $12 / 16 / 201221: 00$ & 0 \\
\hline $12 / 16 / 20124: 00$ & 0.26 & $12 / 16 / 201212: 00$ & 0 & & \\
\hline 12/16/2012 5:00 & 0.34 & $12 / 16 / 201213: 00$ & 0.01 & & \\
\hline
\end{tabular}

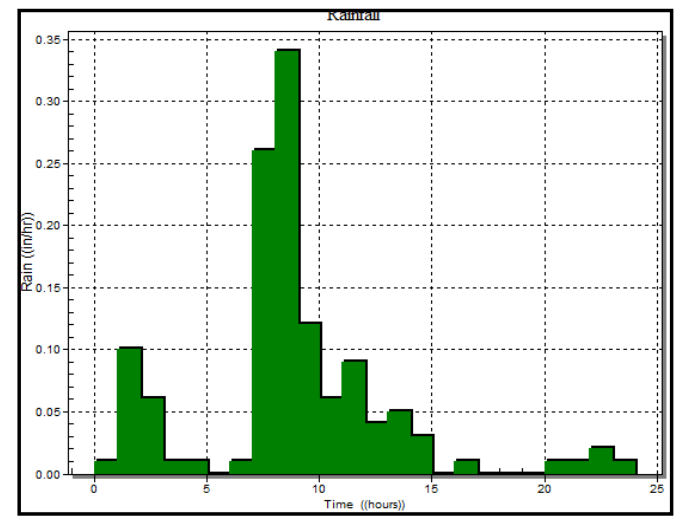

Figure 38 Rainfall Hyetograph for Calibration Trial 4 
The rainfall event that occurred on December 15, 2012 between the hours of 9:00 PM and 8:00 PM was utilized for the calibration trial 4. Figure 39 is a hydrograph of the ORNL OF-211 data provided during the time the precipitation occurred and includes the 0.17 cfs baseflow which was later extracted for calibration purposes.

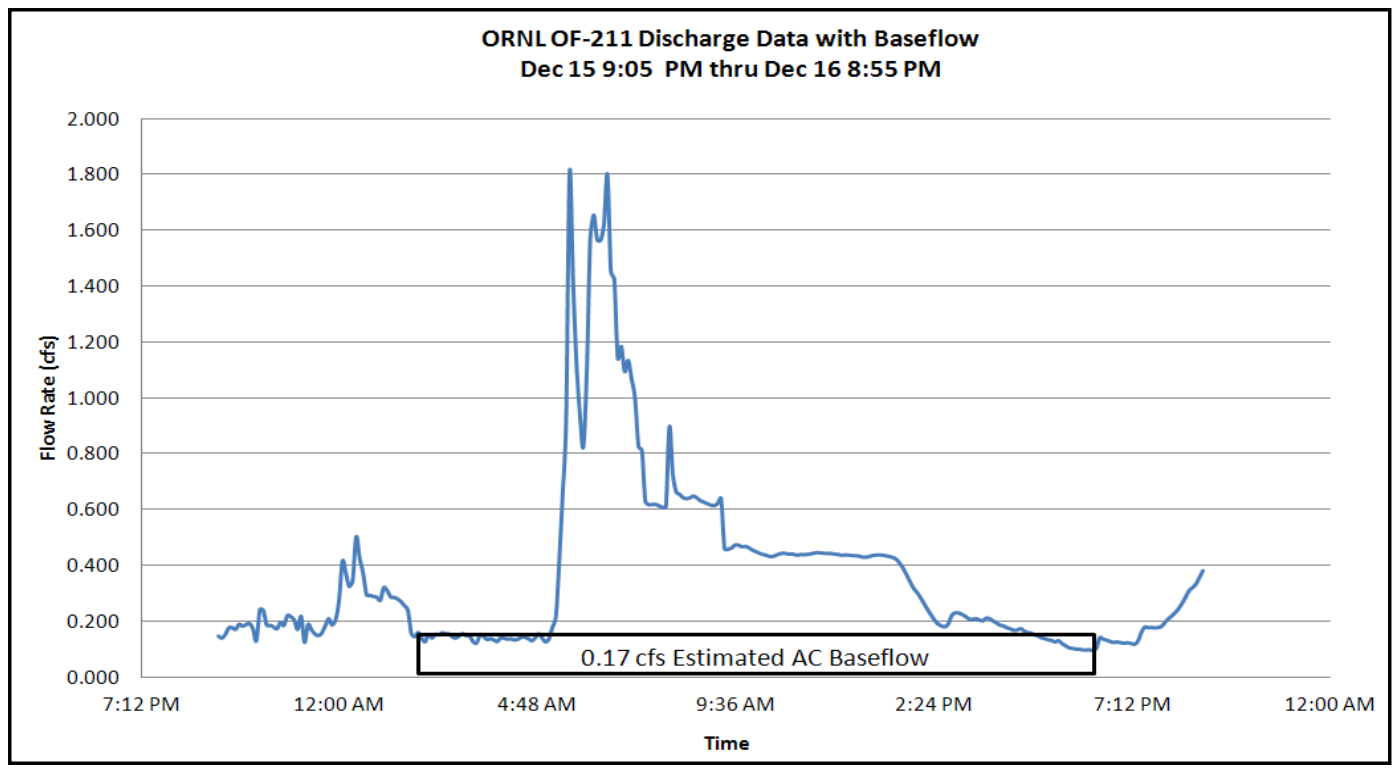

Figure 39 ORNL Data with Baseflow

Figure 40 shows that the ORNL observed flow rate data has a peak flow rate of 1.64 cfs (excluding baseflow) on December 16, 2012 at 5:35 AM. Similarly, the XPSWMM hydrograph, Figure 40, specifies a peak flow rate of $1.34 \mathrm{cfs}$ at 5:50 AM. The lag between the two sets of data is approximately 35 minutes. 


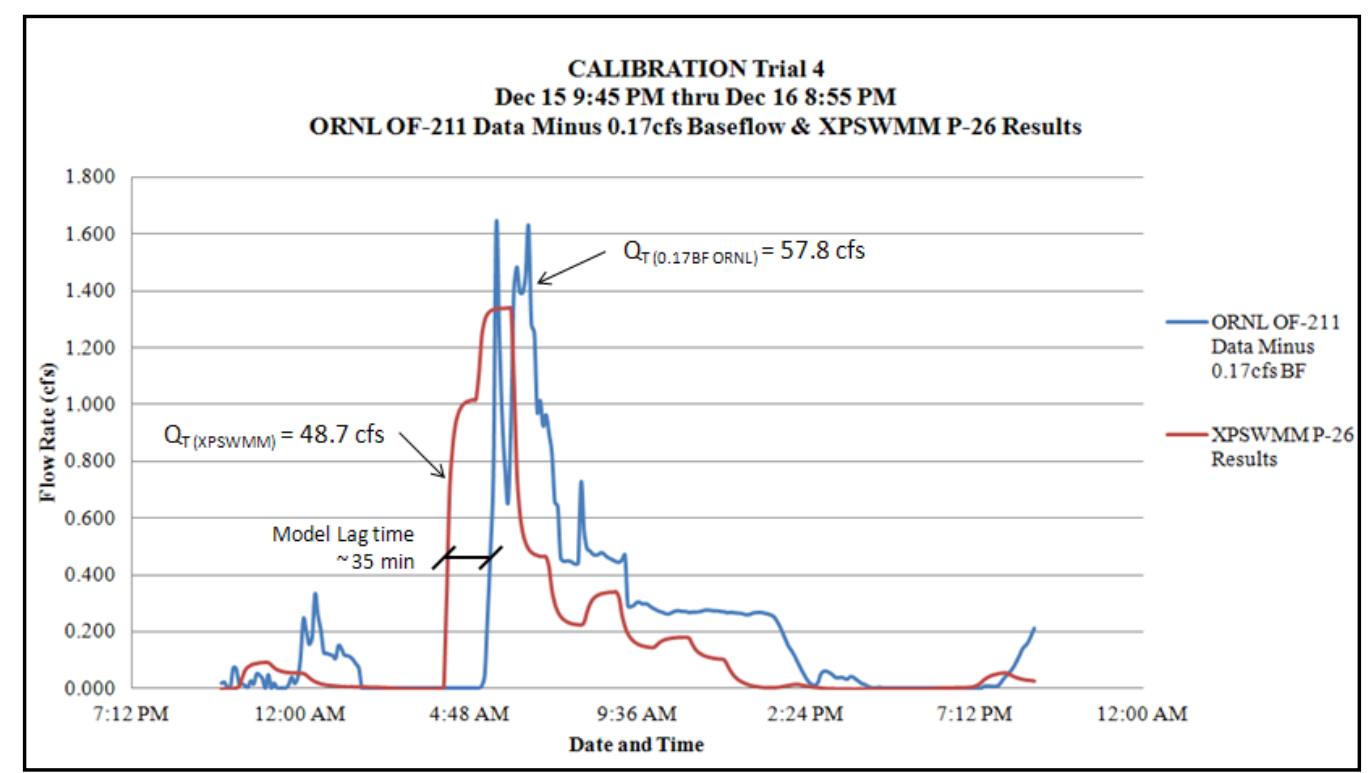

Figure 40 ORNL Data and XPSWMM Results Hydrograph

The total flow rates vary the greatest in the fourth trial by $9.1 \mathrm{cfs}$. This is clearly shown in Figure 41 below.

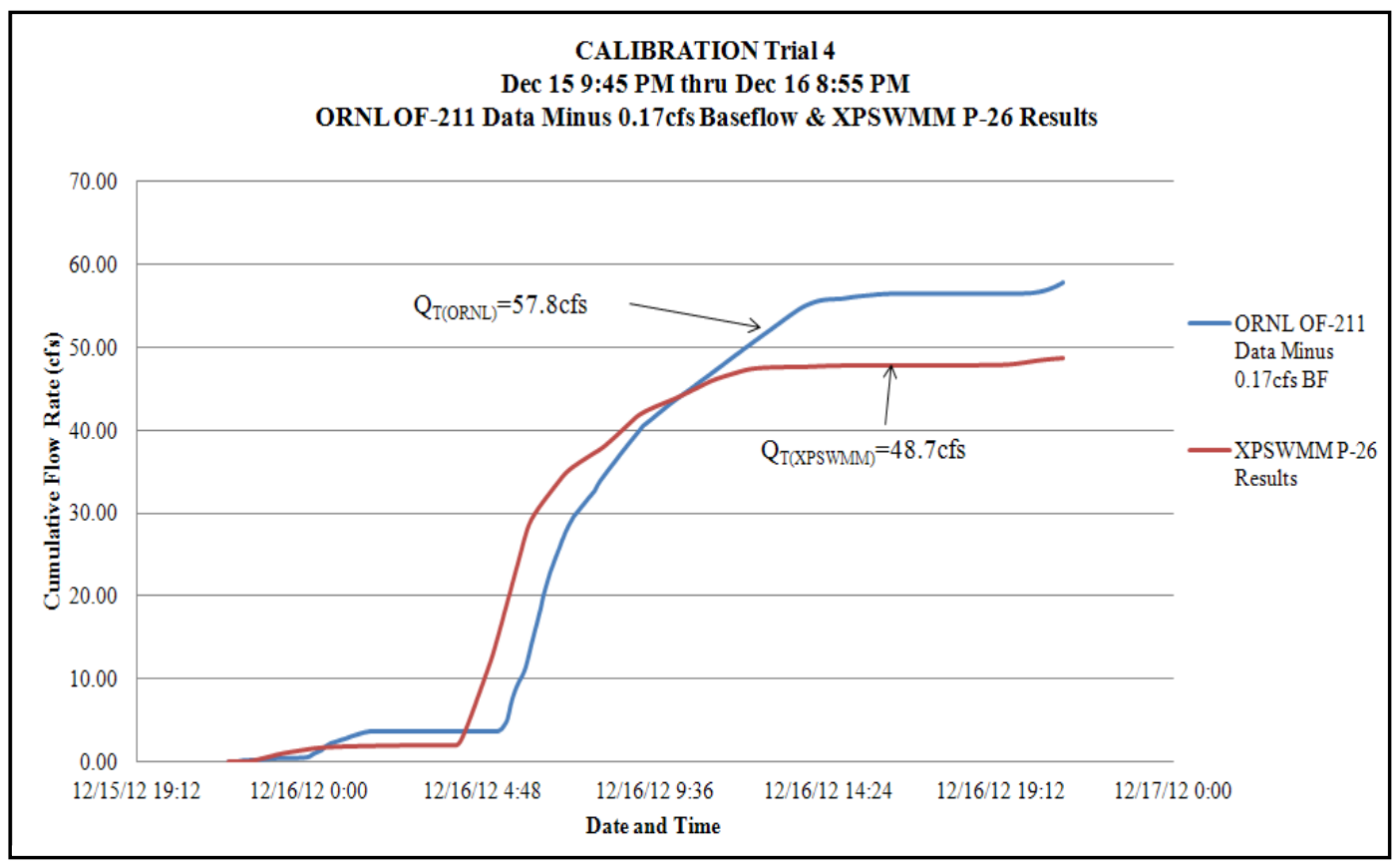

Figure 41 ORNL Data and XPSWMM Results Cumulative Flow Rates 


\subsection{Analysis of Transport}

The transport analysis has been conducted by introducing a hypothetical conservative contaminant into the system. Examples of conservative contaminants are bromine, nitrate, technetium-99, and dye, as opposed to a non-conservative contaminant where adsorption/desorption would occur.

It is known that contamination is still present within the ORNL 4500 Area. It is also known that when contaminants encounter suspended or dissolved solids the two bind together which further enhances the possibility of dispersion (Ravichandran, 2003 and Yang, 2006). Thus, the results produced by the transport analysis provide insight to possible contamination locations, if the existing conditions were similar to the hypothetical scenarios.

The conservative contaminant (described as 'pollutant' by XPSWMM) allows for the routing of pollutants via the Hydraulics or the Runoff mode within XPSWMM. Introducing the pollutant via the Hydraulics mode may be interpreted as having a residual contaminant within an existing pipe and/or inlet within the system. This study focuses on introducing a pollutant into the Hydraulics mode specifically as user timeseries inflow at various nodes. Four transport scenarios were simulated for analysis.

Similarly to the sensitivity analysis, the simulations were run using the following base conditions: actual 15 minute interval rainfall data that occurred during the year 2010; Manning's roughness coefficient of 0.015; Green Ampt infiltration parameters for loamy clay soil; an evaporation rate of $0.1 " /$ day; and estimated percent impervious from site visits. The following describes the various simulations run in order to assess the effects that a hypothetical pollutant has on the model when entered into the system as a 
residual contaminant within the pipes. Four timeseries were used for the simulations that included one steady flow and concentration timeseries and three varied flow and concentration timeseries.

The first is the timeseries containing a constant flow of 0.17 cfs and a constant pollutant concentration of $0.1 \mathrm{mg} / \mathrm{L}$, which from here onwards will be referred to as the 'steady timeseries' followed by three varied flow rate and concentration timeseries for a duration of 24 hours. The pollutant concentrations are hypothetical; however, the flow rates resemble the baseflow rate found during the calibration of the model which is approximately $0.17 \mathrm{cfs}$ in the system due to the once through cooling water for the $\mathrm{AC}$ units. The hypothetical scenarios used for the simulations are listed below:

1. Scenario 1: Steady timeseries A was introduced into the system at both locations B-4501 and B-4500N_G

2. Scenario 2: Steady timeseries A was introduced into the system at B-4556 and varied timeseries B into I-5

3. Scenario 3: Varied timeseries B was introduced into the system at I-11 and varied timeseries $\mathrm{C}$ at $\mathrm{I}-10$

4. Scenario 4: Varied timeseries $\mathrm{C}$ was introduced into the system at B-4500S_C and varied timeseries $\mathrm{D}$ at $\mathrm{T}-1$

Table 11 depicts the steady timeseries (A) and the three varied timeseries (B), (C), and (D) that were introduced into the system for the four various simulations. 
Table 11 Transport Simulations Hypothetical Timeseries

\begin{tabular}{|c|c|c|c|c|c|c|c|c|c|c|c|}
\hline \multicolumn{4}{|c|}{$(\mathbf{A})$} & \multicolumn{4}{c|}{$(\mathbf{B})$} & \multicolumn{3}{c|}{$(\mathbf{C})$} & \multicolumn{3}{|c|}{ (D) } \\
\hline $\begin{array}{c}\text { Time } \\
(\mathbf{h r})\end{array}$ & $\begin{array}{c}\mathbf{Q} \\
(\mathbf{c f s})\end{array}$ & $\begin{array}{c}\mathbf{C} \\
(\mathbf{m g} / \mathbf{L})\end{array}$ & $\begin{array}{c}\text { Time } \\
(\mathbf{h r})\end{array}$ & $\begin{array}{c}\mathbf{Q} \\
(\mathbf{c f s})\end{array}$ & $\begin{array}{c}\mathbf{C} \\
(\mathbf{m g} / \mathbf{L})\end{array}$ & $\begin{array}{c}\text { Time } \\
(\mathbf{h r})\end{array}$ & $\begin{array}{c}\mathbf{Q} \\
(\mathbf{c f s})\end{array}$ & $\begin{array}{c}\mathbf{C} \\
(\mathbf{m g} / \mathbf{L})\end{array}$ & $\begin{array}{c}\text { Time } \\
(\mathbf{h r})\end{array}$ & $\begin{array}{c}\mathbf{Q} \\
(\mathbf{c f s})\end{array}$ & $\begin{array}{c}\mathbf{C} \\
(\mathbf{m g} / \mathbf{L})\end{array}$ \\
\hline 0 & 0.17 & 0.1 & 0 & 0.14 & 0.1 & 0 & 0.11 & 0.2 & 0 & 0.17 & 0.5 \\
\hline 1000 & 0.17 & 0.1 & 2220 & 0.15 & 0.5 & 500 & 0.13 & 0.3 & 500 & 0.14 & 0.2 \\
\hline 2000 & 0.17 & 0.1 & 3210 & 0.16 & 0.7 & 2100 & 0.12 & 0.1 & 2100 & 0.13 & 0.4 \\
\hline 3000 & 0.17 & 0.1 & 4320 & 0.17 & 0.4 & 3400 & 0.15 & 0.25 & 3400 & 0.15 & 0.15 \\
\hline 4000 & 0.17 & 0.1 & 5555 & 0.13 & 0.2 & 4990 & 0.18 & 0.5 & 4990 & 0.16 & 0.6 \\
\hline 6000 & 0.17 & 0.1 & 6000 & 0.15 & 0.15 & 6230 & 0.16 & 0.4 & 6230 & 0.18 & 0.15 \\
\hline 7000 & 0.17 & 0.1 & 7000 & 0.14 & 0.3 & 7110 & 0.15 & 0.35 & 7110 & 0.11 & 0.3 \\
\hline 8448 & 0.17 & 0.1 & 8448 & 0.13 & 0.1 & 8000 & 0.14 & 0.1 & 8000 & 0.13 & 0.25 \\
\hline
\end{tabular}

Table 12 summarizes the location and which timeseries (steady or varied)

were introduced into the system. Two timeseries were entered for each simulation.

Table 12 Transport Simulation Scenarios

\begin{tabular}{|c|c|c|c|c|}
\hline $\begin{array}{c}\text { Hydraulics } \\
\text { Mode } \\
\text { Scenarios }\end{array}$ & Node 1 & Input 1 & Node 2 & Input 2 \\
\hline 1 & B-4501 & A & B-4500N_G & A \\
\hline 2 & B-4556 & A & I-5 & B \\
\hline 3 & I-11 & B & I-10 & C \\
\hline 4 & B-4500S_C & C & T-1 & D \\
\hline
\end{tabular}

The simulations run in the Hydraulics mode take into account an assumed event mean concentration of $0.1 \mathrm{mg} / \mathrm{L}$, with a standard deviation of $0.01 \mathrm{mg} / \mathrm{L}$ and an assumed initial pollutant concentration of $0.1 \mathrm{mg} / \mathrm{L}$. No buildup is assumed for these simulations, only washoff of the pollutant which is calculated via the event mean concentration rating curve approach with a coefficient of 1 . The event mean concentration approach assumes that the quantity of the pollutant plus or minus its standard deviation is proportional to the quantity of runoff. 
Note that in the XPSWMMS hydrographs the program labels the y-axis as "lbs" instead of the correct "lb".

\subsubsection{Transport Analysis Scenario 1}

The flow and pollutant steady timeseries (A) was introduced at the two nodes B4501 and B-4500N_G as shown in Figure 42. A pollutant load is expected to occur within P-10 as a result from the flow and concentration timeseries data entered into node B4501. Similarly, a pollutant load should occur within to the east P-27 due to the flow and concentration timeseries introduced into node B-4500S_G.

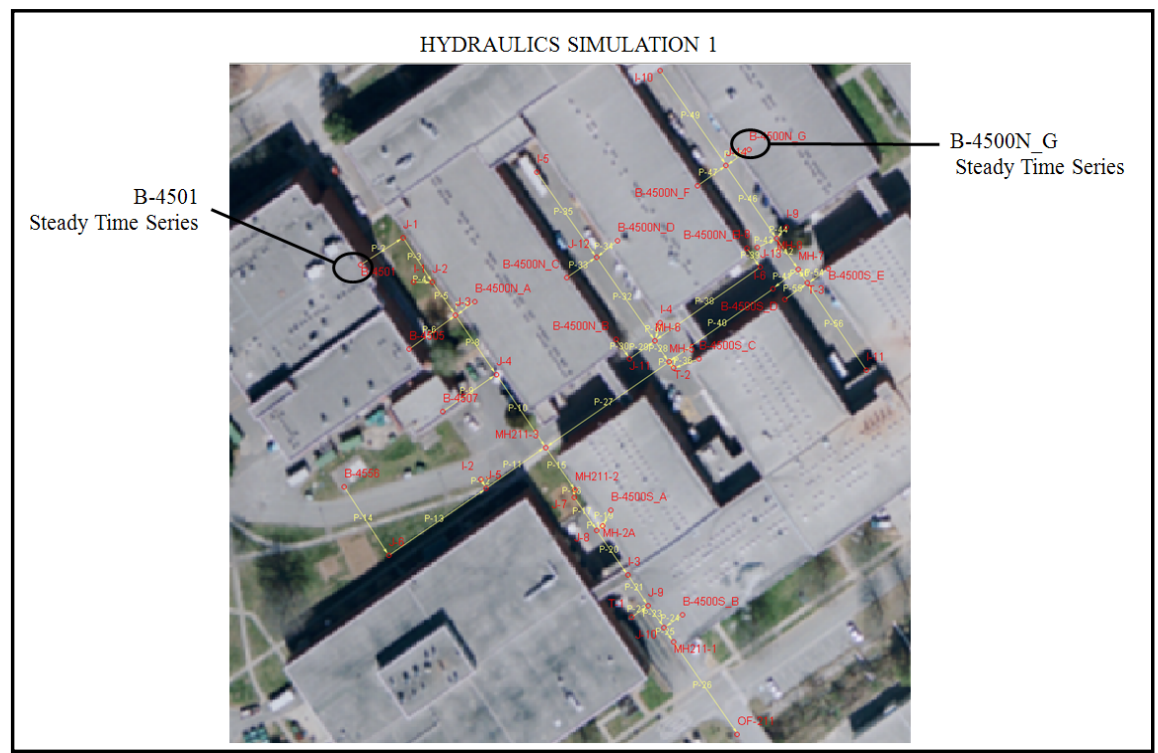

Figure 42 Transport Scenario 1 Entrance of Pollutant Location

The term load is equal to the concentration of a pollutant times the flow rate as shown below:

$$
\mathrm{L}=Q * C
$$

where $\mathrm{Q}$ is the flow rate (cfs) and the $\mathrm{C}$ is the concentration of the contaminant $(\mathrm{mg} / \mathrm{L})$. XPSWMM calculates the load, L, in pounds (lb); however, a conversion factor would be 
necessary. XPSWMM calculates a total load which the sum of the cumulative load produced during the duration of the event. The model does not produce a loading rate.

XPSWMM calculates the concentrations using mass balance of flow rates and concentrations. The mass balance equation under steady state conditions is as follows

$$
Q_{T} * C_{T}=Q_{1} * C_{1}+Q_{2} * C_{2}
$$

Steady timeseries flow and concentration data were entered into the nodes B-4501 and B-4500N_G. The results for the first transport analysis are in the Table 13 below. No pollutant or additional flow was introduced to the east; therefore, no pollutant concentration or load should appear to the east within P-11. Only the runoff from continuous yearly rainfall events is routed through the system to the east. The concentrations and loads within P-15 depict a combination of the two loads from P-10 and P-27.

The peak concentration is $0.10 \mathrm{mg} / \mathrm{L}$ which is consistent with the steady concentration timeseries entered into the system. It is difficult to see the steady baseflow rate of $0.17 \mathrm{cfs}$ entered into the system in the table below due to the runoff generated over the site produced by the rainfall is also indicated. The $0.17 \mathrm{cfs}$ hypothetical baseflow rate is represented in the resulting hydrographs to follow. The peak flow rate listed in Table 13 is the maximum peak flow rate for the duration of the continuous rainfall events. 
Table 13 XPSWMM Scenario 1 Results

\begin{tabular}{|c|c|c|c|}
\hline \multicolumn{4}{|c|}{ Scenario 1 Link Results } \\
\hline Link & $\begin{array}{c}\text { Peak } \\
\text { Flow } \\
(\mathbf{c f s})\end{array}$ & $\begin{array}{c}\text { Peak } \\
\text { Concentration } \\
(\mathbf{m g} / \text { L) }\end{array}$ & Total Load (lb) \\
\hline P-10 & 2.10 & 0.10 & 33.38 \\
\hline P-11 & 1.51 & 0.00 & 0.00 \\
\hline P-15 & 10.5 & 0.10 & 66.75 \\
\hline P-26 & 12.15 & 0.10 & 66.75 \\
\hline P-27 & 6.89 & 0.10 & 33.38 \\
\hline
\end{tabular}

As expected, loads were present in links P-10, P-15, P-26, and P-27; however, no load was present in P-11, as no load was introduced west. Therefore, P-10, P-15, P-26 and P-27 hydrographs and pollutographs have the same pattern but vary by a magnitude equal to the difference in the rainfall runoff from that accumulated upstream.

The constant $0.1 \mathrm{mg} / \mathrm{L}$ concentration entered into B-4501 and B-4500N_G appears as the maximum concentration of $0.1 \mathrm{mg} / \mathrm{L}$. The concentration decreases between intervals as it responds to the rainfall runoff introduced into the system, but when the next interval arrives the concentration rises back to $0.1 \mathrm{mg} / \mathrm{L}$. After P-10 and P-27 are conveyed through MH211-3, the maximum concentration decreases to $0.1 \mathrm{mg} / \mathrm{L}$ which complies with mass balance. Similarly, with the flow, 0.17 cfs baseflow is noted throughout the continuous rainfall event. The $0.17 \mathrm{cfs}$ flow increases when the rainfall runoff is simulated through the links.

The hydrographs and pollutographs (concentration versus time and load versus time) for links P-10, P-11, P-15, P-26 and P-27 are represented below to visually indicate the data provided by XPSWMM. Link P-10 collects water from the north, P-11 from the east, and P-27 from the west, then the water is conveyed via MH211-3 into P-15, then P26 and into OF-211. In addition, the XPSWMM model specifies the velocity on the 
hydrographs. These velocities are cumulative velocities hence their magnitude. In addition, the loads shown on the pollutographs are also cumulative load values represented by a diagonal line.

P-10's hydrograph, Figure 43, represents the flow rate and concentration from the northern portion of the system. The hydrograph below indicates a baseflow rate of 0.17 cfs at the beginning which is responsive to the timeseries entered, and increases as the runoff is routed through the system. The peak flow rate, $2.10 \mathrm{cfs}$, occurs in February which corresponds to the first peak in the 2010 rainfall hydrograph. The steady concentration $0.10 \mathrm{mg} / \mathrm{L}$ timeseries entered is held constant. The concentration decreased as runoff is introduced, but then rises again to respond to the timeseries entered. This concludes the model is responsive to the timeseries data entered. The total load up to P$10 \mathrm{is} 33.38 \mathrm{lb}$.

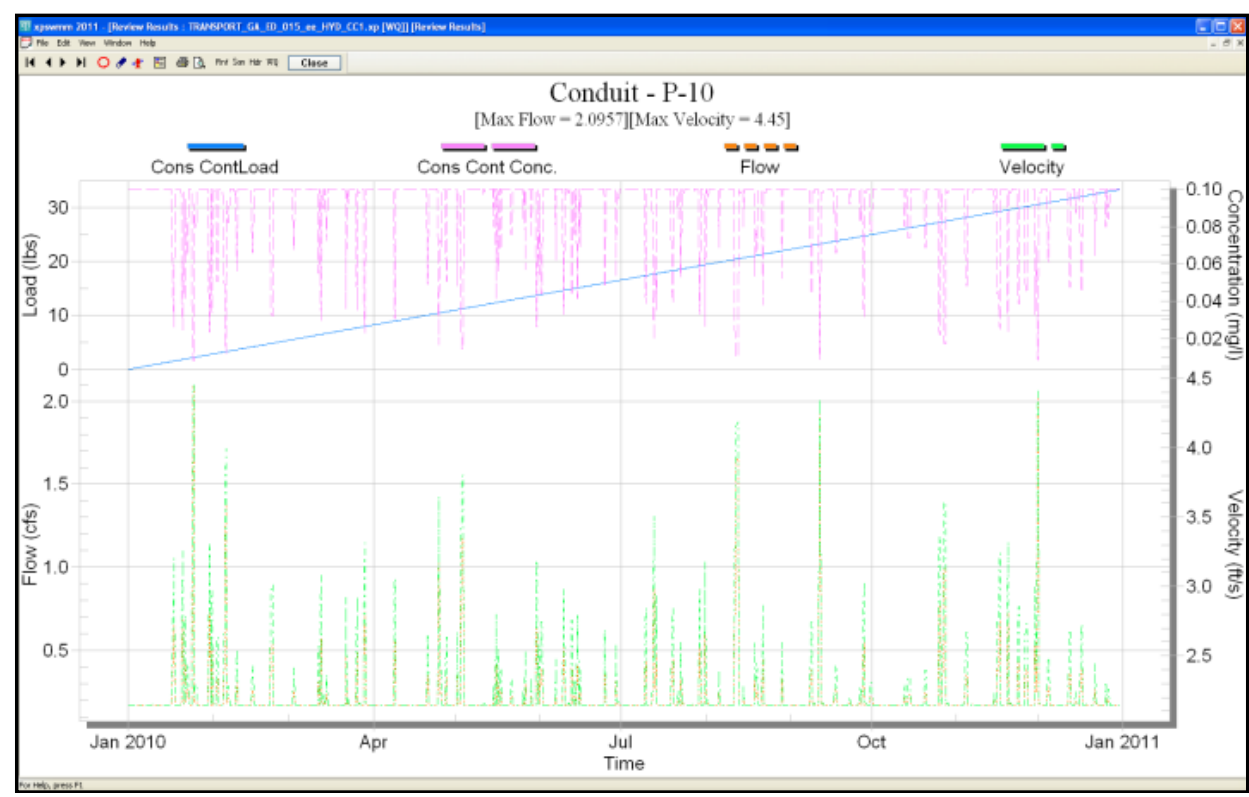

Figure 43 XPSWMM Scenario 1 P-10 Hydrograph and Pollutograph

The pollutograph for P-11, Figure 44, confirms no load was introduced to the west portion of the system as the concentration and load equal zero. Also, the hydrograph 
does not indicate a baseflow rate as none was entered. The hydrograph only indicates the runoff produces by the rainfall. The peak flow rate is $1.5 \mathrm{cfs}$.

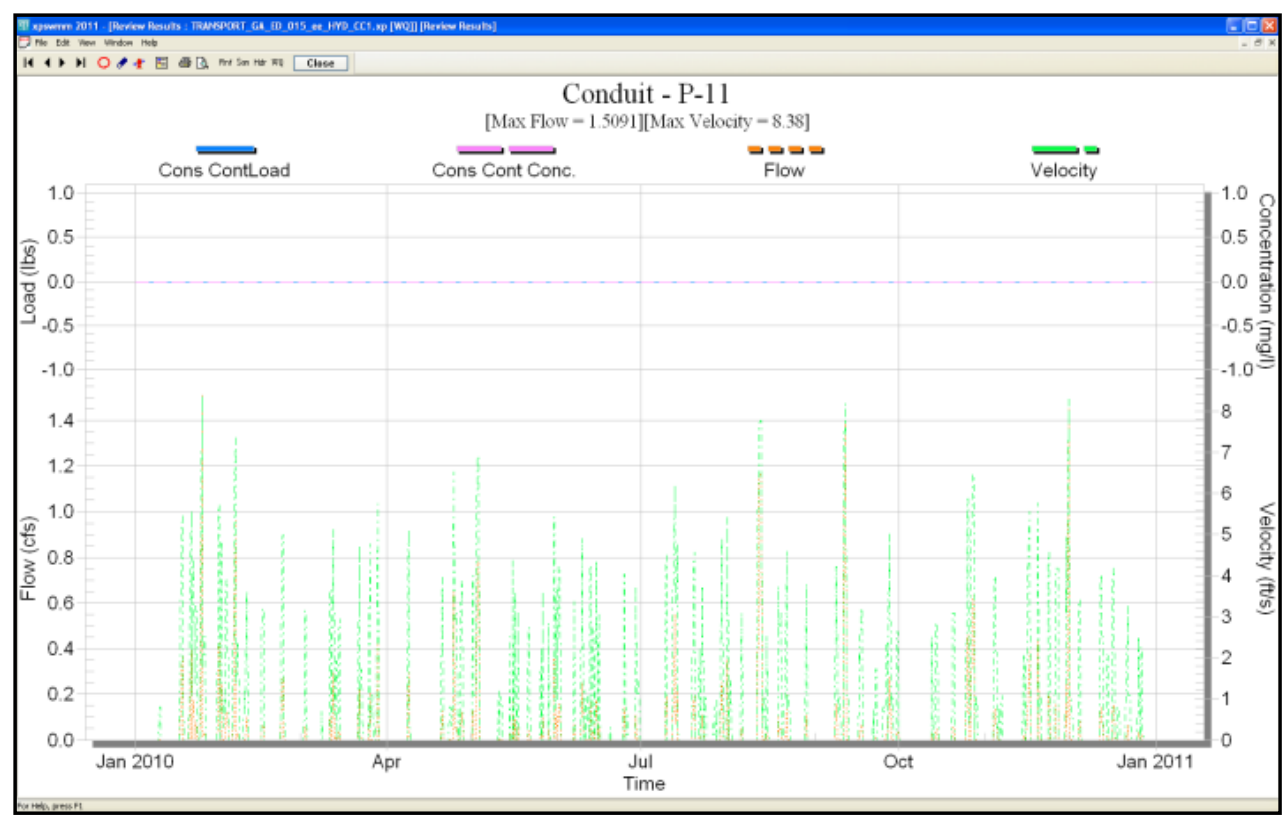

Figure 44 XPSWMM Scenario 1 P-11 Hydrograph and Pollutograph

P-15's corresponding hydrograph, Figure 45 is also consistent to the steady flow rate timeseries entered indicating a baseflow rate of $0.17 \mathrm{cfs}$. The peak flow rate is 10.5 cfs which is the cumulative flow from the north, east, and west quadrants of the system. P-15's pollutograph also indicates a maximum contaminant concentration of $0.1 \mathrm{mg} / \mathrm{L}$ and decreases as flows are encountered. The total load conveyed through P-15 is 66.75 lb. This quantity is consistent with the $33.38 \mathrm{lb}$ load conveyed through $\mathrm{P}-10$, from the north quadrant of the system, and P-27, from the east quadrant of the system, both upstream of P-15. 


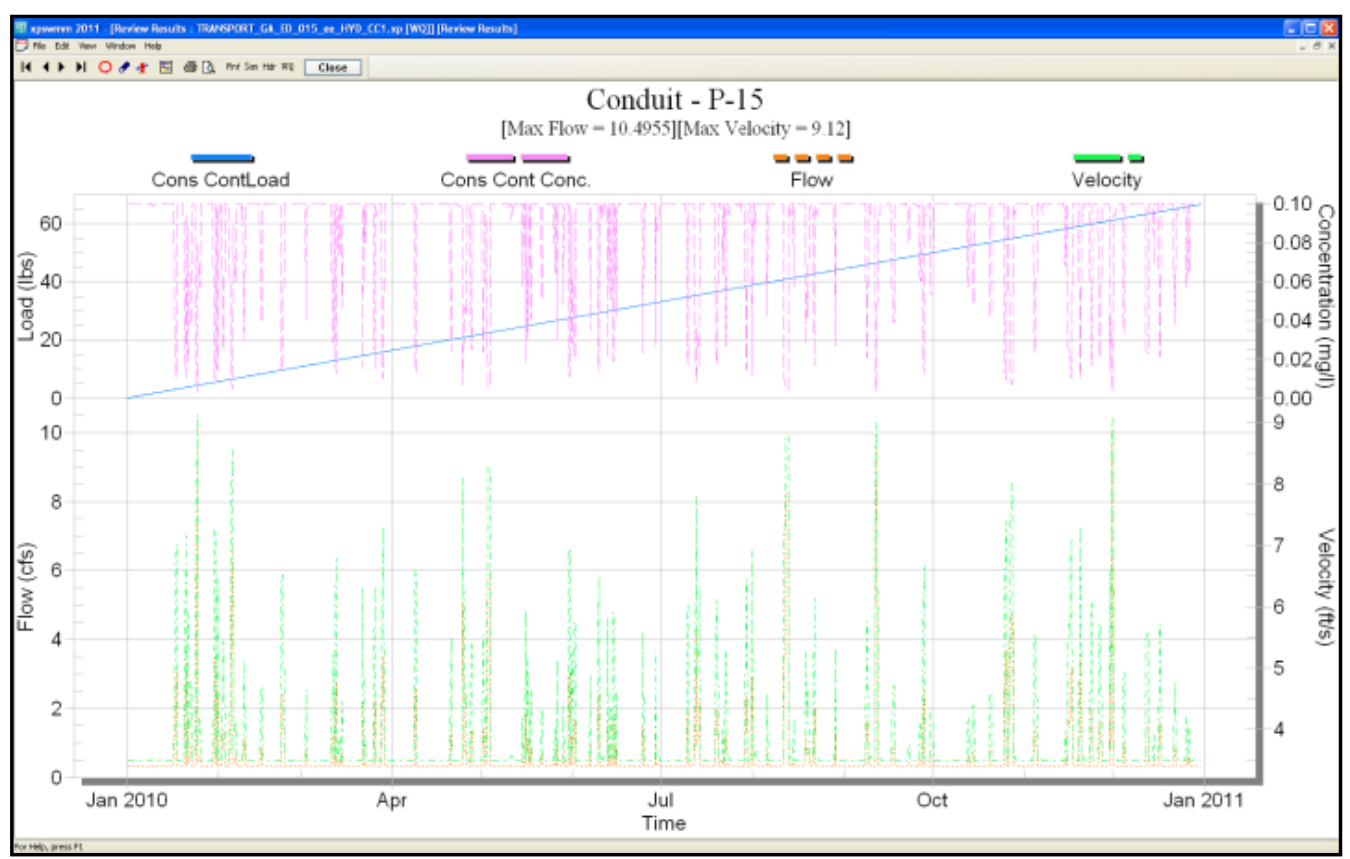

Figure 45 XPSWMM Scenario 1 P-15 Hydrograph and Pollutograph

Similarly, to P-15 the corresponding hydrograph for P-26, Figure 46, is consistent to the steady flow rate timeseries entered indicating a baseflow rate of $0.17 \mathrm{cfs}$. The peak flow rate is $12.14 \mathrm{cfs}$ which is the cumulative flow from the north, east, and west quadrants of the system. P-15's pollutograph also indicates a maximum contaminant concentration of $0.1 \mathrm{mg} / \mathrm{L}$ and decreases as flows are encountered. The total load conveyed through P-15 is $66.75 \mathrm{lb}$. This quantity is consistent with the $33.38 \mathrm{lb}$ load conveyed through P-10, from the north quadrant of the system, and P-27, from the east quadrant of the system, both upstream of P-15.

The cumulative load in P-26 is estimated to be $66.75 \mathrm{lb}$. 


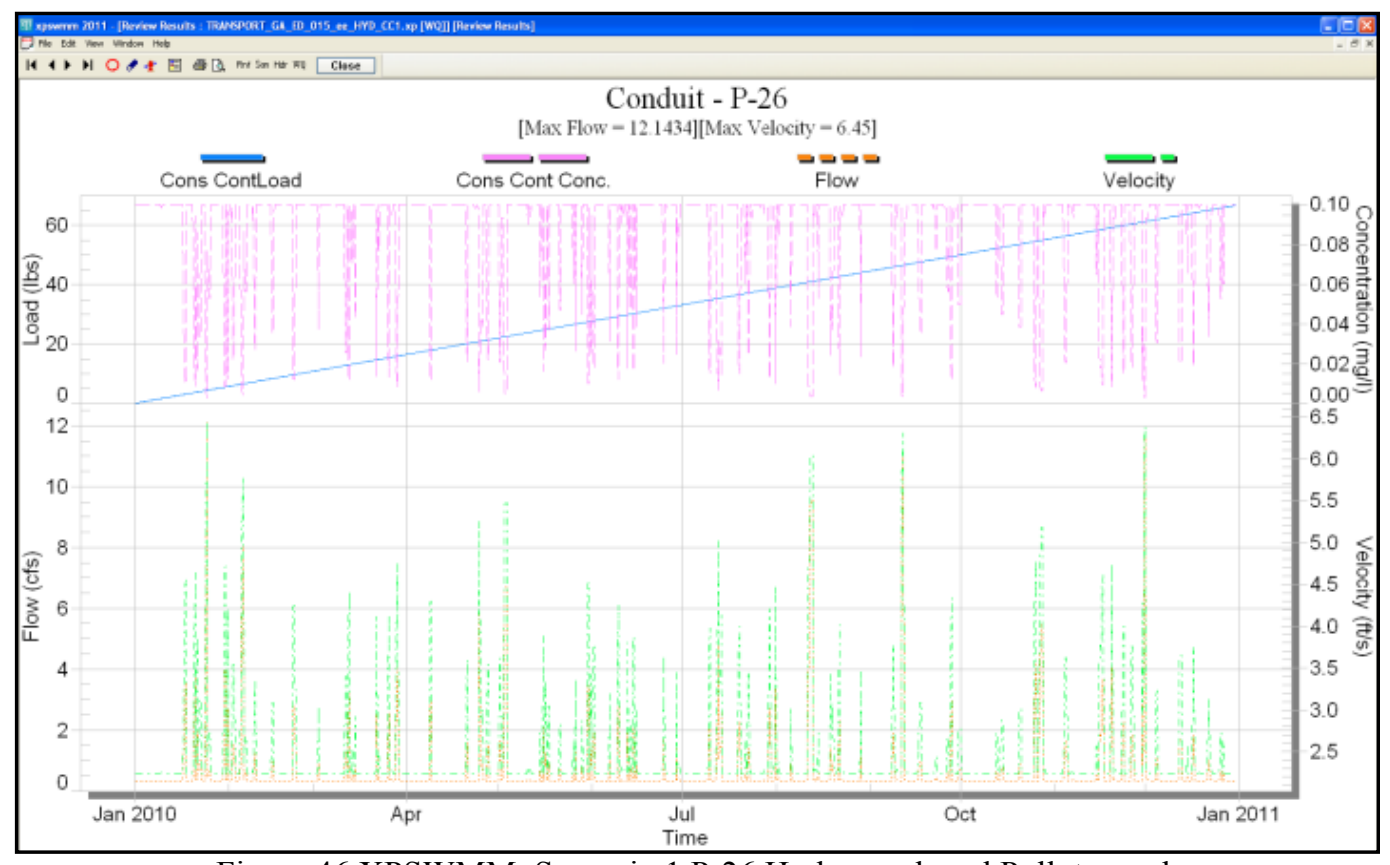

Figure 46 XPSWMM Scenario 1 P-26 Hydrograph and Pollutograph

The hydrograph below for P-27 represents the flow and concentration from the east portion of the system. Similarly with P-10, a baseflow rate of $0.17 \mathrm{cfs}$ is indicated, peak concentration of $0.10 \mathrm{mg} / \mathrm{L}$, and a total load of $33.38 \mathrm{lb}$.

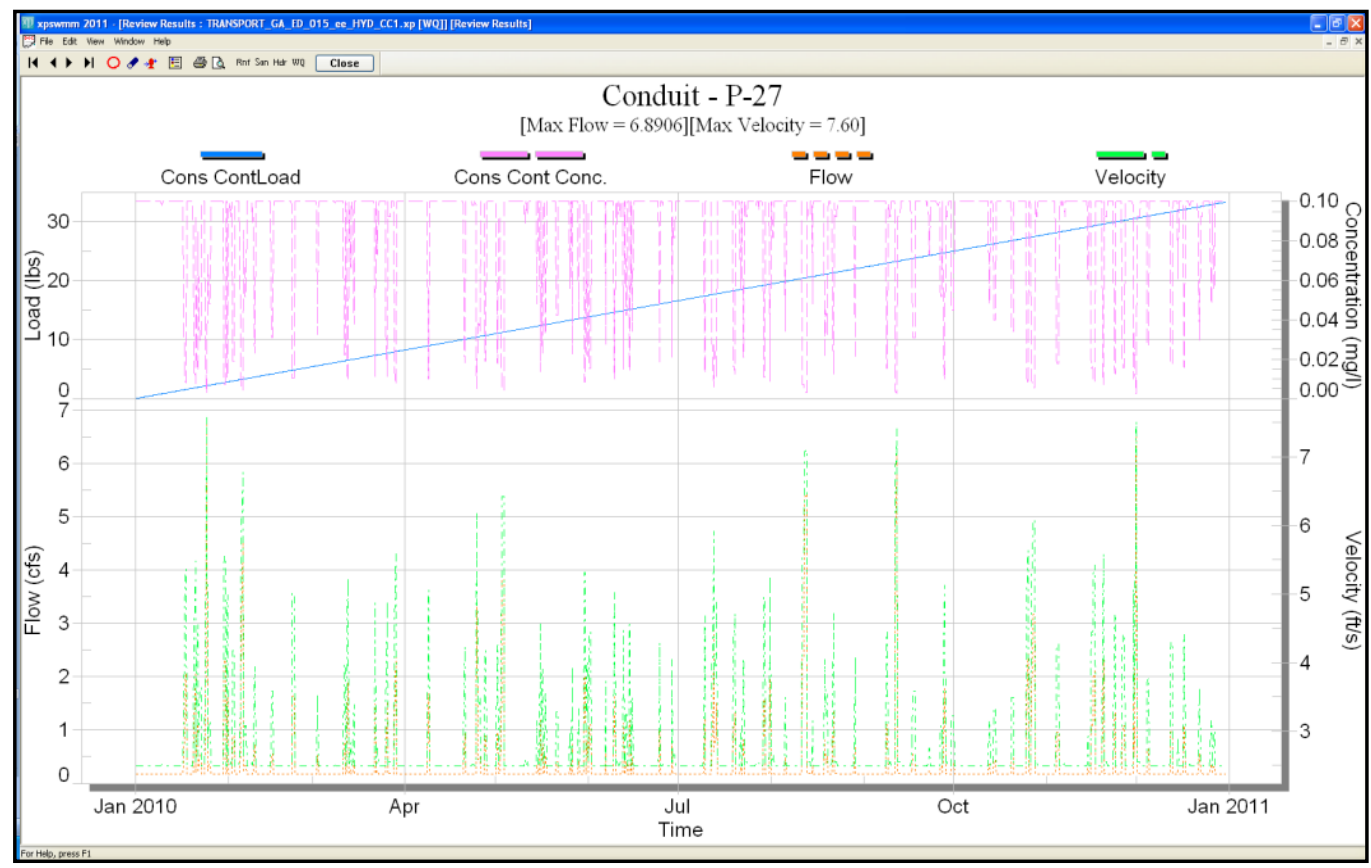

Figure 47 XPSWMM Scenario 1 P-27 Hydrograph and Pollutograph 


\subsubsection{Transport Analysis Scenario 2}

The second simulation introduces a steady timeseries flow and concentration into node B-4556 and a varied timeseries in node I-5. A pollutant load is expected to occur from the east within P-11 due to the introduction of the steady timeseries into node B4556. Similarly, a pollutant load is expected to occur from the west within P-27 due to the introduction of the steady timeseries into node I-5.

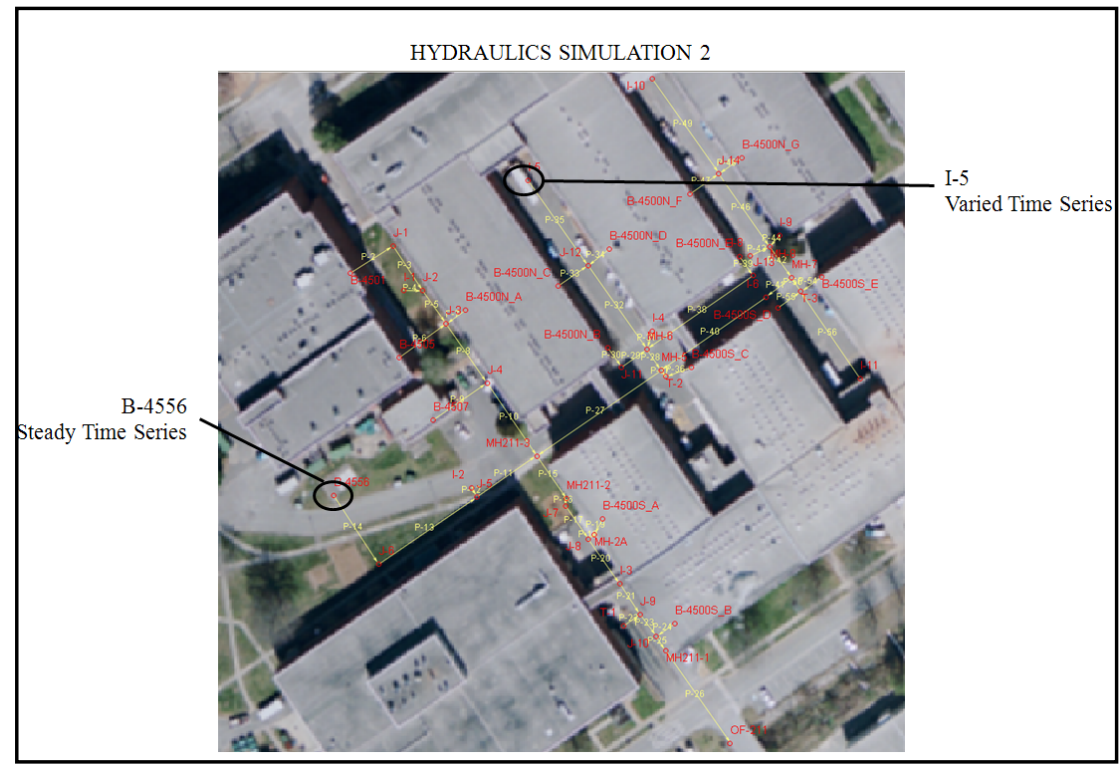

Figure 48 Transport Analysis Scenario 2 Pollutant Entrance Locations

The second scenario introduces steady timeseries into node B-4556 and varied timeseries into inlet I-5.

In the second simulation no additional flow rates and concentrations were entered into the system north of P-10; thus, P-10's flow rates represent the rainfall runoff that accumulated up to P-10. P-10's concentration is and should be zero as no concentrations were presented to the north. Similar to scenario 1, steady flow rate and concentration timeseries was introduced to the system, but to the west portion of the system represented by P-11. P-11's flow rate in the table represents the $0.17 \mathrm{cfs}$ plus the runoff encountered 
up to $\mathrm{P}-11$. The maximum concentration is $0.10 \mathrm{mg} / \mathrm{L}$ as determined by the timeseries entered.

Varied flow rates and concentrations, represented by timeseries data (B), was introduced upstream of P-27. P-27's resulting peak flow rate represents the baseflow rates in (B) and the runoff from the 2010 rainfall events up to P-27. The peak concentration entered was $0.7 \mathrm{mg} / \mathrm{L}$ and is confirmed by the results. P-15's flow rate is a sum of the runoff and baseflow rates encoutered up to MH211-3. Notice that P-15's peak concentration is $0.39 \mathrm{mg} / \mathrm{L}$.

Table 14 XPSWMM Scenario 2 Results

\begin{tabular}{|c|c|c|c|}
\hline \multicolumn{4}{|c|}{ Scenario 2 Link Results } \\
\hline Link & $\begin{array}{c}\text { Max } \\
\text { Flow } \\
\text { (cfs) }\end{array}$ & $\begin{array}{c}\text { Peak } \\
\text { Concentration } \\
(\mathbf{m g} / \mathbf{L})\end{array}$ & $\begin{array}{c}\text { Total } \\
\text { Load } \\
\text { (lb) }\end{array}$ \\
\hline P-10 & 1.93 & 0.00 & 0.00 \\
\hline P-11 & 1.68 & 0.10 & 33.38 \\
\hline P-15 & 10.48 & 0.39 & 131.11 \\
\hline P-26 & 12.12 & 0.39 & 131.11 \\
\hline P-27 & 6.90 & 0.70 & 97.73 \\
\hline
\end{tabular}

As expected, P-10 does not indicate a pollutant load and P-11, P-15, P-26, and P27 do indicate a pollutant load. Similar to the first scenario, a constant concentration of $0.1 \mathrm{mg} / \mathrm{L}$ is entered into the system to the west and varied (B) timeseries to the east. P11's pollutograph indicates a maximum concentration of $0.1 \mathrm{mg} / \mathrm{L}$ as does the timeseries entered. The concentration remains constant during the event except when runoff is encountered then the concentration is decreased. Link P-27 corresponds to the timeseries (B) data and this is spikes at the concentration of $0.70 \mathrm{mg} / \mathrm{L}$ near June, which also corresponds to the varied timeseries entered. The timeseries (B) ends with a 
concentration of $0.1 \mathrm{mg} / \mathrm{L}$. The model holds the concentration constant at $0.1 \mathrm{mg} / \mathrm{L}$ throughout the remaining storm event except when runoff is encountered, and then the concentration is decreased. A baseflow rate of $0.17 \mathrm{cfs}$ is represented in P-11 and a varied baseflow rate in P-27 due to the varying flow rate timeseries. P-15 and P-26 indicates a varied baseflow but it is not as defined as P-27 hydrograph due to the runoff accumulation upstream from the yearly rainfall.

In the link P-10 hydrograph, Figure 49 confirms that no concentration or load is present. Also, confirms that only rainfall is simulated through the network as no baseflow is present.

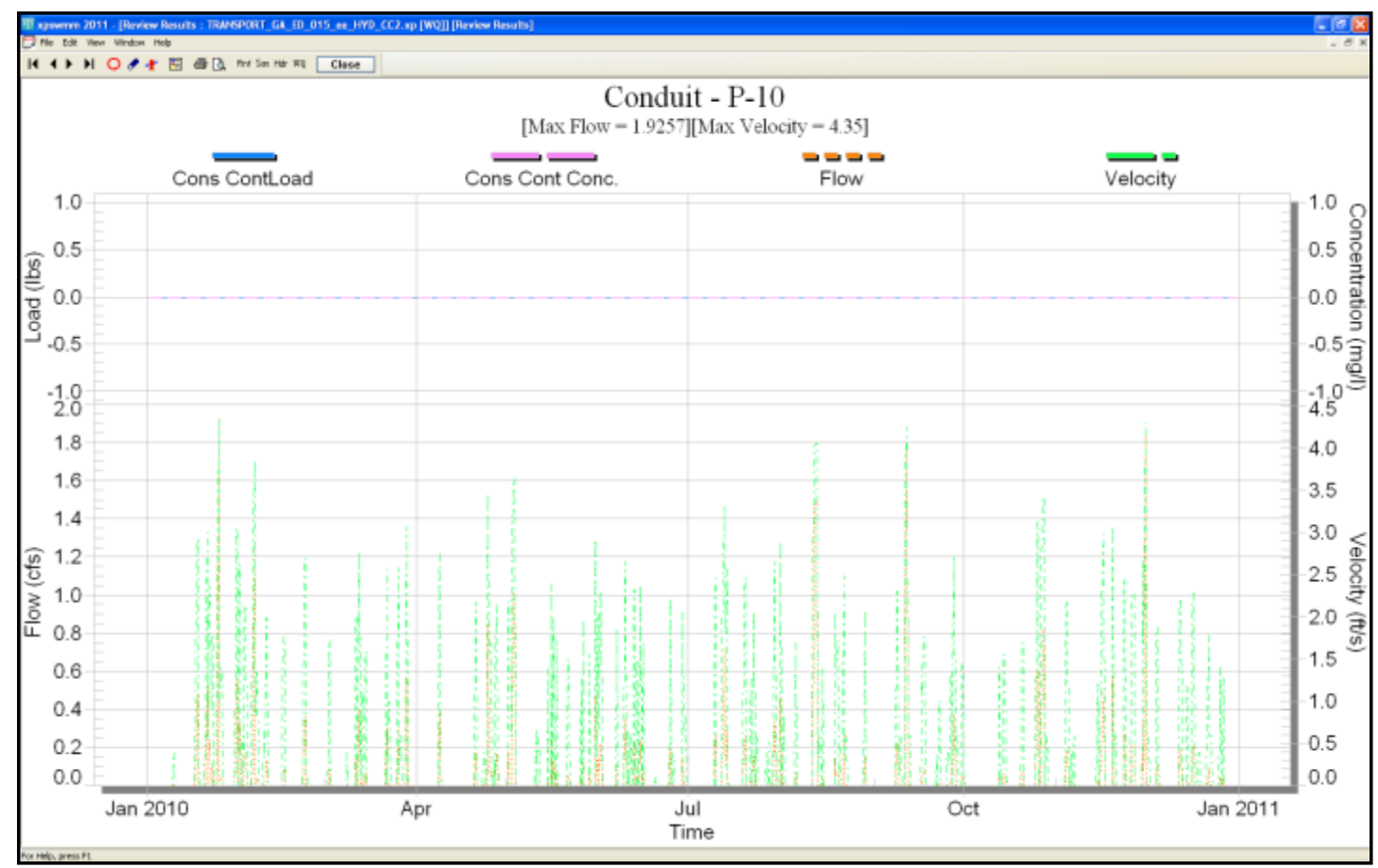

Figure 49 XPSWMM Scenario 2 P-10 Hydrograph and Pollutograph 
The P-11 hydrograph and pollutograph below correlates with the steady timeseries data entered as it depicts a baseflow rate of $0.17 \mathrm{cfs}$ and a maximum concentration of $0.1 \mathrm{mg} / \mathrm{L}$. The total load accumualted up to P-11 is $33.38 \mathrm{lb}$.

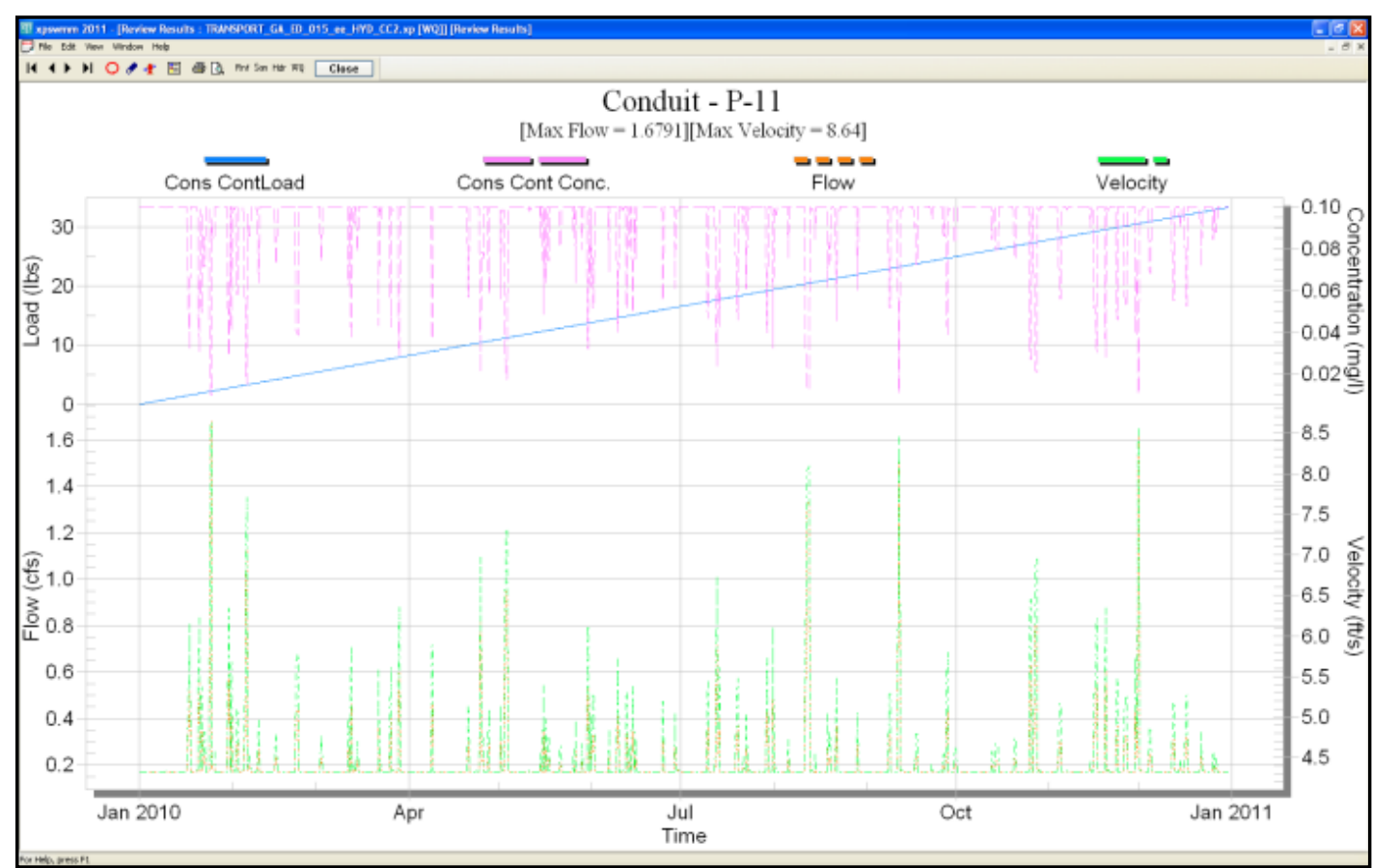

Figure 50 XPSWMM Scenario 2 P-11 Hydrograph and Pollutograph

The hydrograph for P-15 represent the summation of flow from P-11 and P-27., shown in Figure 51. The hydrograph does indicate the baseflow entered. The pollutograph also responds to the varied concentration data entered and is similar in shape to P-27 as the concentration is conveyed through P-15. This is shown by its shape where peak concentration in P-27 is $0.07 \mathrm{mg} / \mathrm{L}$. The total load accumulated up to P-15 is $131.11 \mathrm{lb}$. 


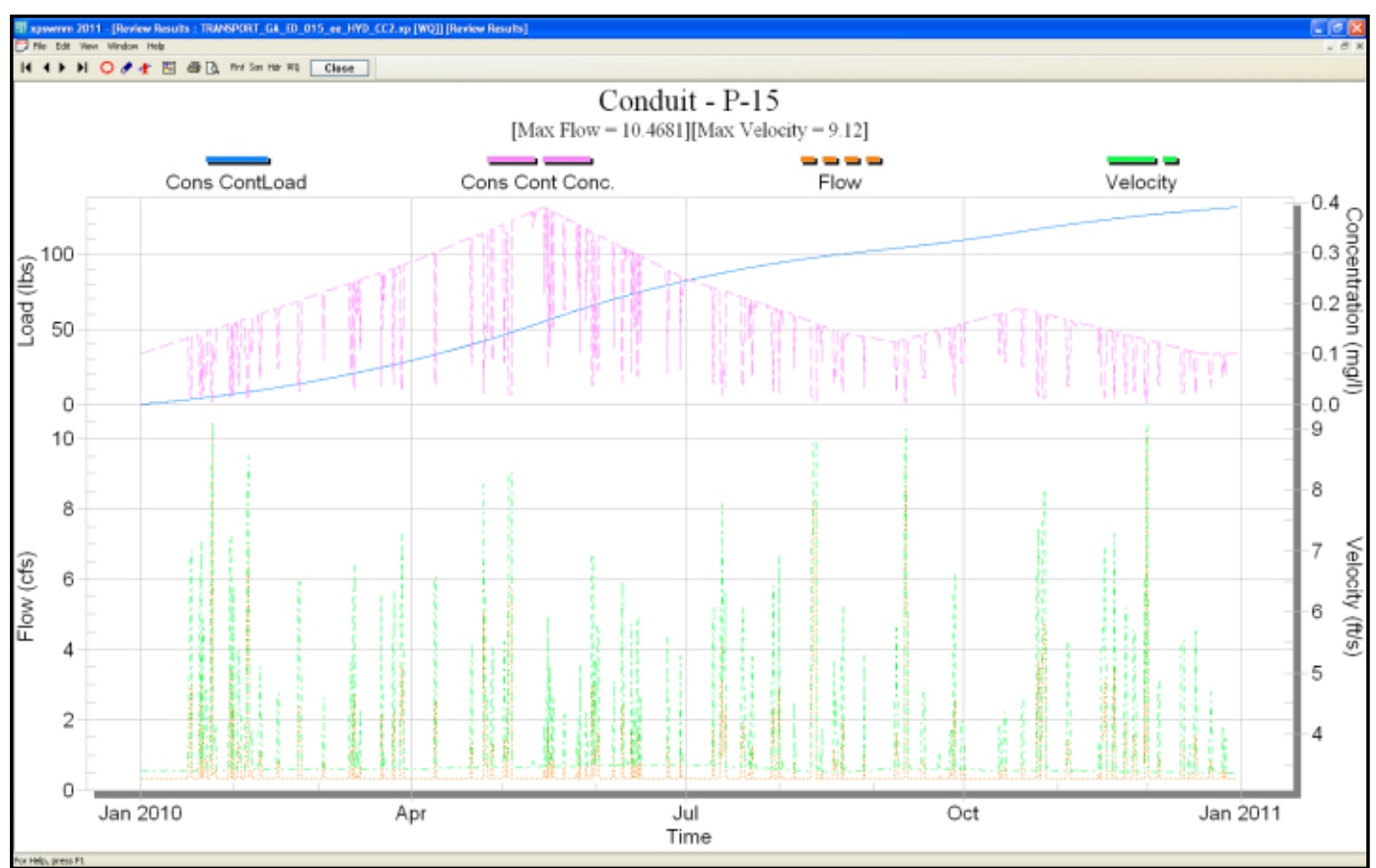

Figure 51 XPSWMM Scenario 2 P-15 Hydrograph and Pollutograph

The maximum flow rate within link P-26 is $12.12 \mathrm{cfs}$ and the maximum elevation in node OF-211 is $781.8 \mathrm{ft}$, NAD. The shape of the pollutograph shown in Figure 52 also mimics P-15 and P-27 as the contaminant is conveyed through P-26. The peak load in P26 resulted in $131.11 \mathrm{lb}$. 


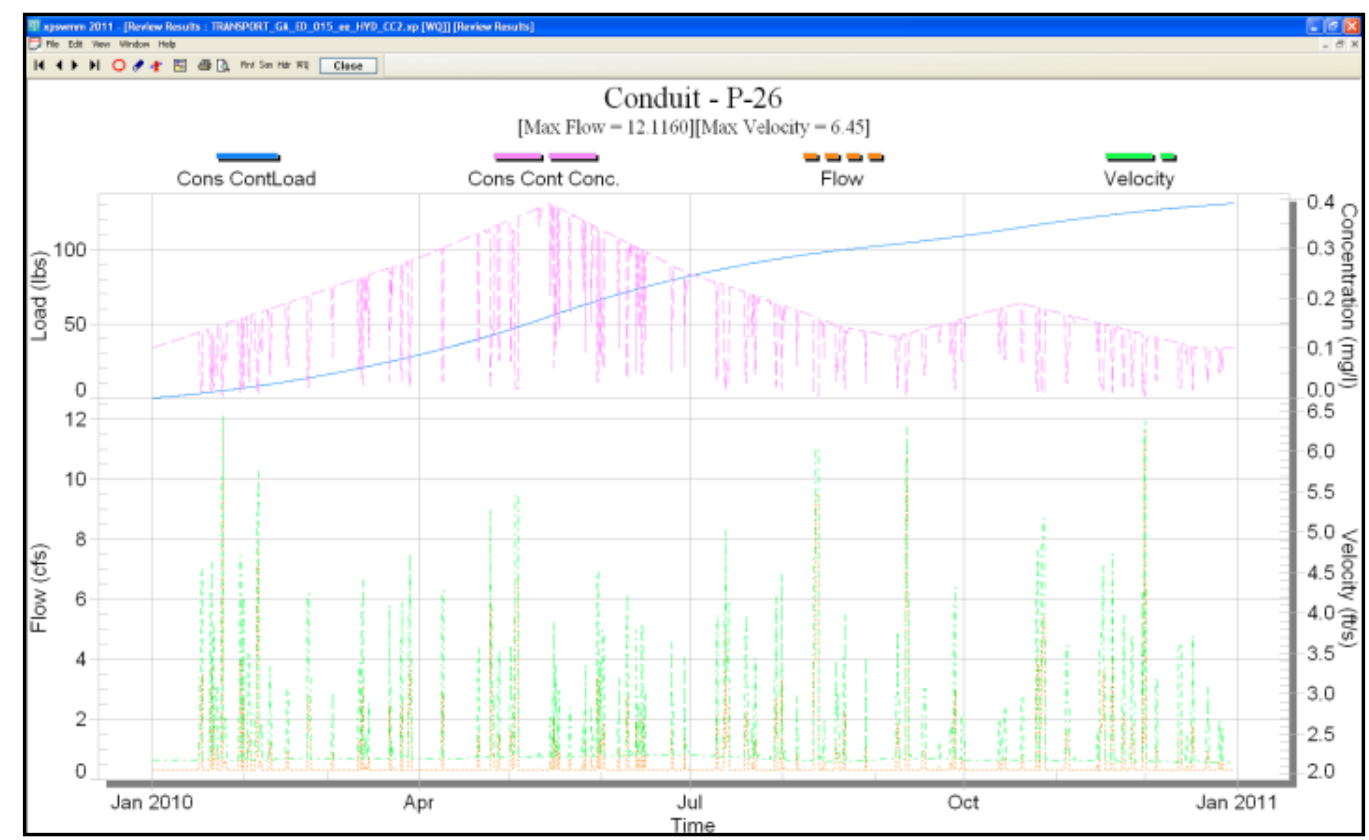

Figure 52 XPSWMM Scenario 2 P-26 Hydrograph and Pollutograph

The hydrograph for P-27 represents the baseflow rates entered and the stormwater

runoff. The peak flow rate is $6.90 \mathrm{cfs}$. The pollutograph indicates a peak concentration of $0.70 \mathrm{mg} / \mathrm{L}$. The cumulative produced up to $\mathrm{P}-27$ load is $97.73 \mathrm{lb}$

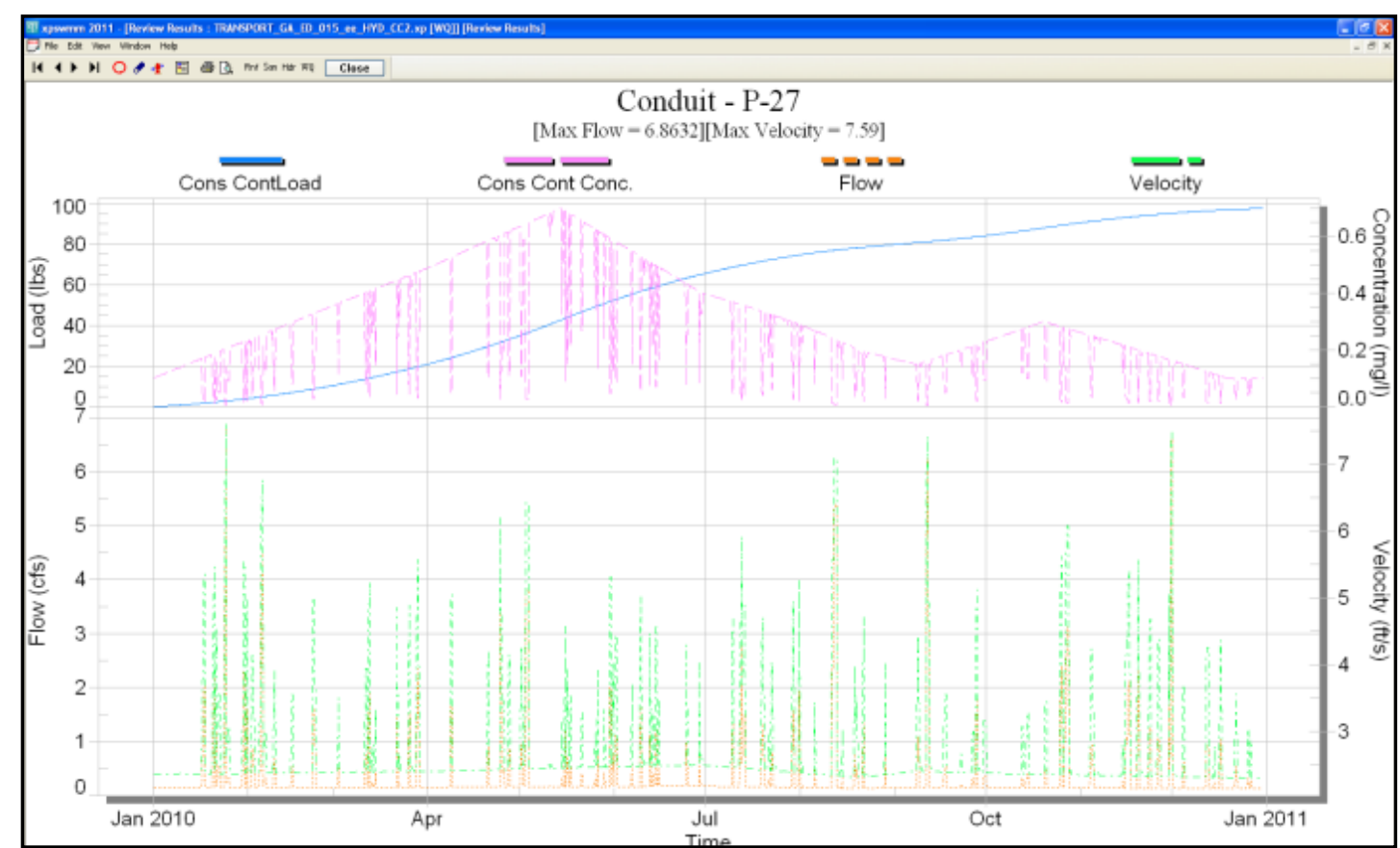

Figure 53 XPSWMM Scenario 2 P-27 Hydrograph and Pollutograph 


\subsubsection{Transport Analysis Scenario 3}

Scenario 3 introduces varied flow and concentration timeseries (B) into node I-11 and varied flow and concentration data $(\mathrm{C})$ into node I-10. No pollutant was introduced into the north and west wings of the system; therefore, no pollutant load should appear in links P-10 and P-11.

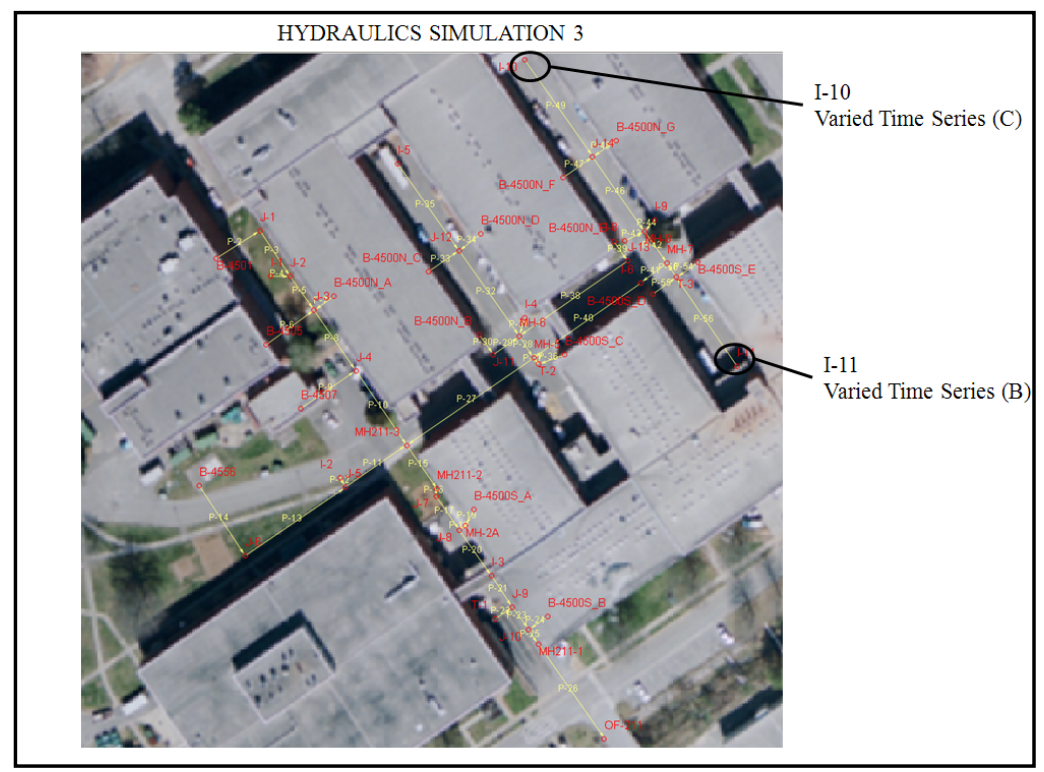

Figure 54 Transport Analysis Scenario 3 Entrance of Pollutant

The third scenario focuses on the system to the west and south of MH211-3. No timeseries (see Figure 54); data was entered into Links P-10 and P-11; thus, only contribute the runoff produced from the north and east portions of the sytem. The results are not as apparent as the first and second scenario because of the introduction of the two varied flow and concentration timeseries. Link P-27 represents the combination of the two varied timeseries (B) and (C) in I-11 and I-10. 
Table 15 XPSWMM Scenario 3 Results

\begin{tabular}{|c|c|c|c|}
\hline \multicolumn{4}{|c|}{ Scenario 3 Link Results } \\
\hline Link & $\begin{array}{c}\text { Max Flow } \\
\text { (cfs) }\end{array}$ & $\begin{array}{c}\text { Peak } \\
\text { Concentration } \\
\text { (mg/L) }\end{array}$ & $\begin{array}{c}\text { Total } \\
\text { Load } \\
\text { (lb) }\end{array}$ \\
\hline P-10 & 1.93 & 0.00 & 0.00 \\
\hline P-11 & 1.51 & 0.00 & 0.00 \\
\hline P-15 & 10.43 & 0.48 & 176.48 \\
\hline P-26 & 12.08 & 0.48 & 176.48 \\
\hline P-27 & 6.99 & 0.48 & 176.48 \\
\hline
\end{tabular}

The hydrograph for P-15 in Figure 55 portrays the cumulative varied baseflow rates and the water runoff from the north, east, and west. The peak flow rate is $10.43 \mathrm{cfs}$. The pollutograph peak concentration is $0.48 \mathrm{mg} / \mathrm{L}$. The total load accumulated from the north, east, and west is $176.48 \mathrm{lb}$.

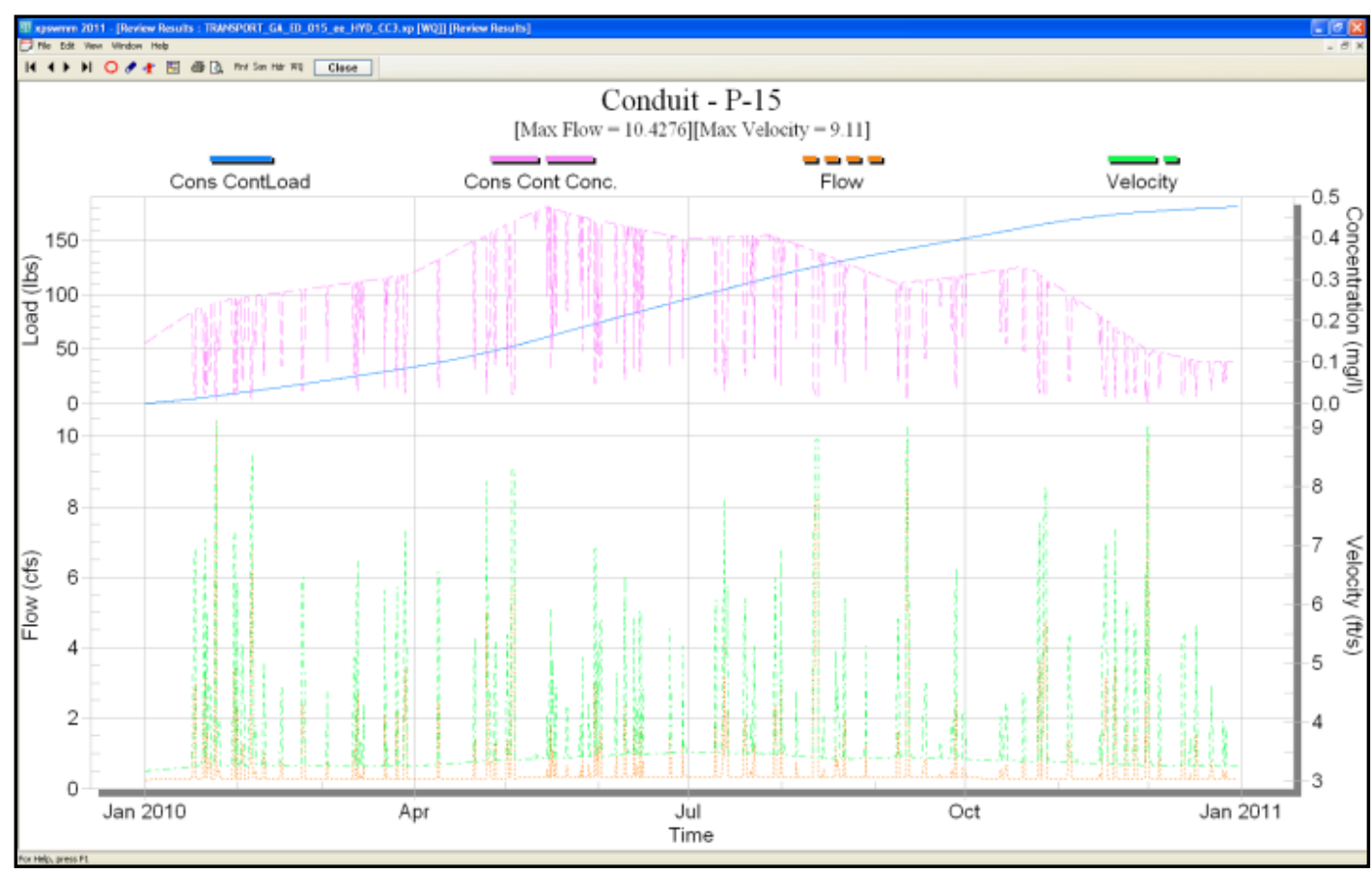

Figure 55 XPSWMM Scenario 3 P-15 Hydrograph and Pollutograph 
The P-26 hydrograph in Figure 56 indicates the baseflow and runoff up to P-26 which is the link prior to OF-211. The peak flow rate encountered within P-26 is 12.08 cfs. The pollutograph indicates a peak concentration of $0.48 \mathrm{mg} / \mathrm{L}$. The total load of $176.48 \mathrm{lb}$ is the accumulation from varied timeseries (C) and (D).

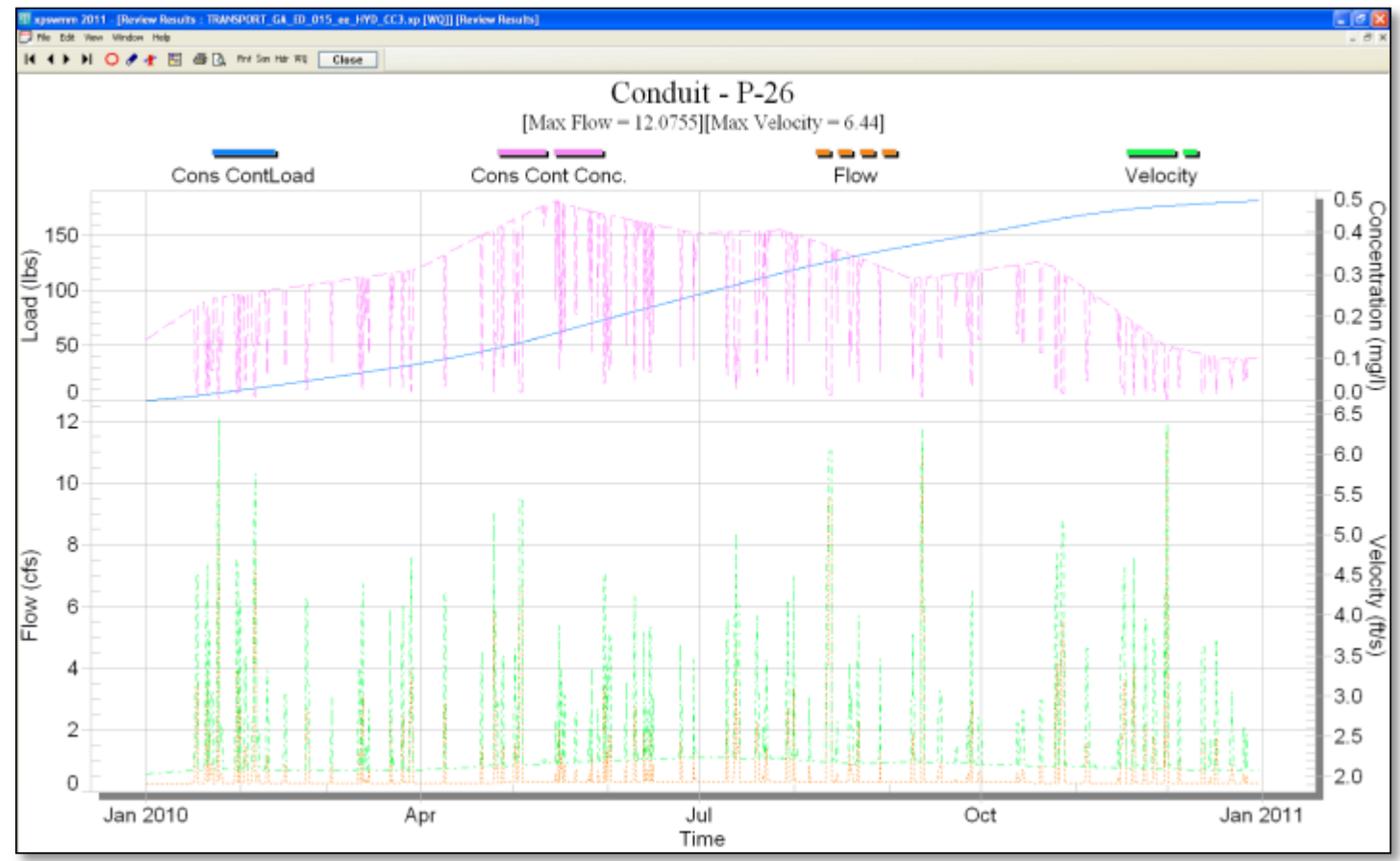

Figure 56 XPSWMM Scenario 3 P-26 Hydrograph and Pollutograph

The maximum flow rate within link P-27 is $6.99 \mathrm{cfs}$. P-27 represents the combination of the two varied timeseries data, as they were entered upstream of P-27, plus the stormwater runoff. The peak concentration encountered is $0.48 \mathrm{mgL}$. The total load resulted in $176.48 \mathrm{mg} / \mathrm{L}$. 


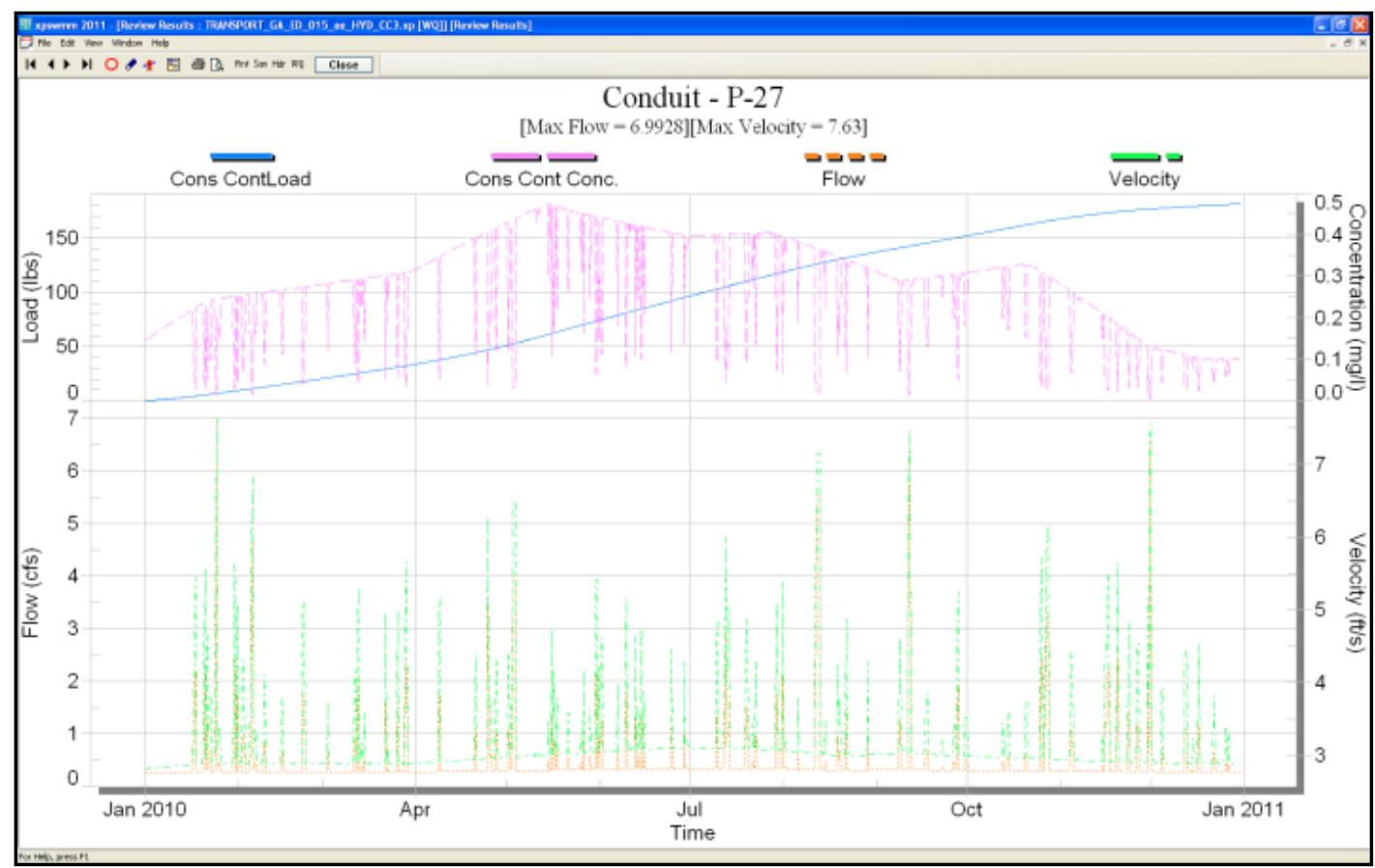

Figure 57 XPSWMM Scenario 3 P-27 Hydrograph and Pollutograph

\subsubsection{Transport Analysis Scenario 4}

The last scenario for the transport analysis introduces varied flow and concentration timeseries $(\mathrm{C})$ into node B-4500S_C, and varied flow and concentration (D) data into node T-1. B-4500S_C is a roof drain from the building upstream of P-27. The two are relatively close to each other, thus, the P-27 pollutograph should resemble the $(\mathrm{C})$ timeseries entered. $\mathrm{T}-1$ is a trench drain located downstream of $\mathrm{P}-15$ and upstream of P-26; thus, P-26 should indicate flow rate and loads from (C) and (D) timeseries. Similar to simulation 3, no pollutant was introduced into the north and west wings of the system; therefore, pollutant load should appear in links P-10 and P-11, nor the contribution to the P-15 and P-26 hydrographs and pollutographs. 


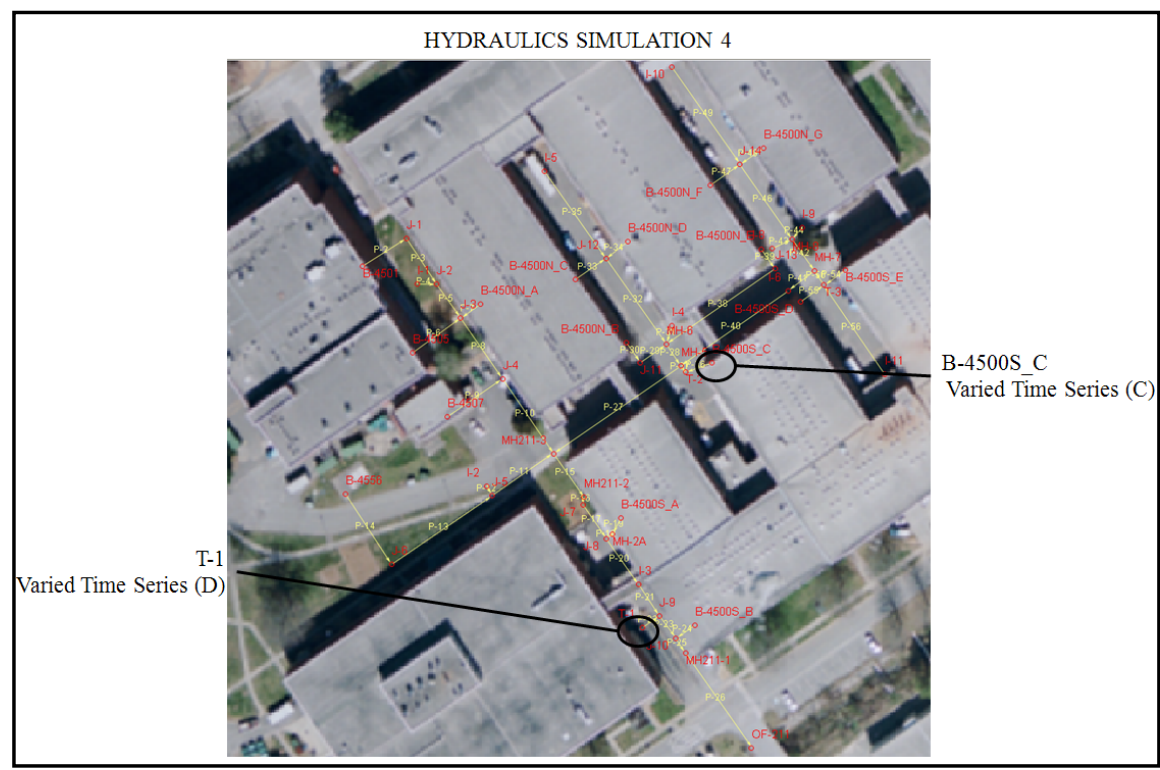

Figure 58 Transport Analysis Scenario 4 Pollutant Entrance Locations

The peak concentrations for $\mathrm{P}-10$ and $\mathrm{P}-11$ below properly responded as no baseflow or concentration data was entered. The flow rates for P-10 and P-11 are the response to the stormwater runoff up to the links. P-15 flow rate is a combination of the flows in P-10, P-11, and P-27. P-26 represents an accumulation of stormwater runoff and the hypothetical timeseries data.

Table 16 XPSWMM CC4 Scenario 4 Results

\begin{tabular}{|c|c|c|c|}
\hline \multicolumn{4}{|c|}{ Scenario 4 Link Results } \\
\hline Link & $\begin{array}{c}\text { Max Flow } \\
\text { (cfs) }\end{array}$ & $\begin{array}{c}\text { Peak } \\
\text { Concentration } \\
(\mathbf{m g} / \mathbf{L})\end{array}$ & $\begin{array}{c}\text { Total } \\
\text { Load } \\
\text { (lb) }\end{array}$ \\
\hline P-10 & 1.93 & 0.00 & 0.00 \\
\hline P-11 & 1.51 & 0.00 & 0.00 \\
\hline P-15 & 10.30 & 0.50 & 83.98 \\
\hline P-26 & 12.10 & 0.51 & 175.52 \\
\hline P-27 & 6.85 & 0.50 & 83.98 \\
\hline
\end{tabular}

Similar to scenario 3 , scenario 4 introduces varied timeseries in two different locations shown in Figure 58. One is introduced upstream of P-27 and one is introduced 
upstream of P-26. Thus, P-15 pollutograph shape shown in Figure 59 should resemble that of P-27. A $0.5 \mathrm{mg} / \mathrm{L}$ peak concentration is indicated to occur around August which correlates to the hypothetical timeseries entered. The total load produced up to P-15 is $83.98 \mathrm{lb}$.

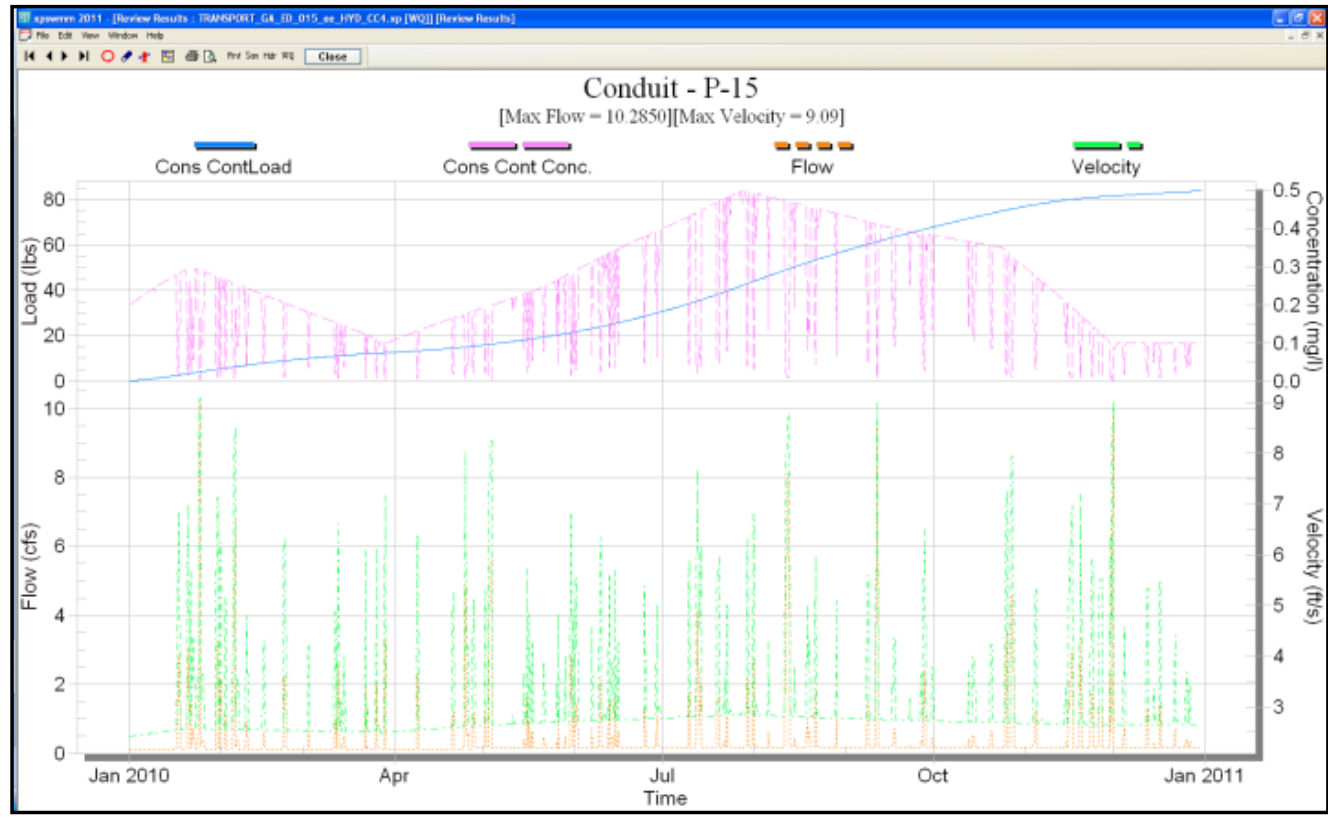

Figure 59 XPSWMM Scenario 4 P-15 Hydrograph and Pollutograph

There is a $0.51 \mathrm{mg} / \mathrm{L}$ peak concentration around July which confirms that the concentrations were entered around that time. The hydrograph P-26 has a different shape indicating a response from the varied timeseries (D). The peak flow rate is $12.10 \mathrm{cfs}$. The total load accumulated during the simulation is $175.52 \mathrm{lb}$. 


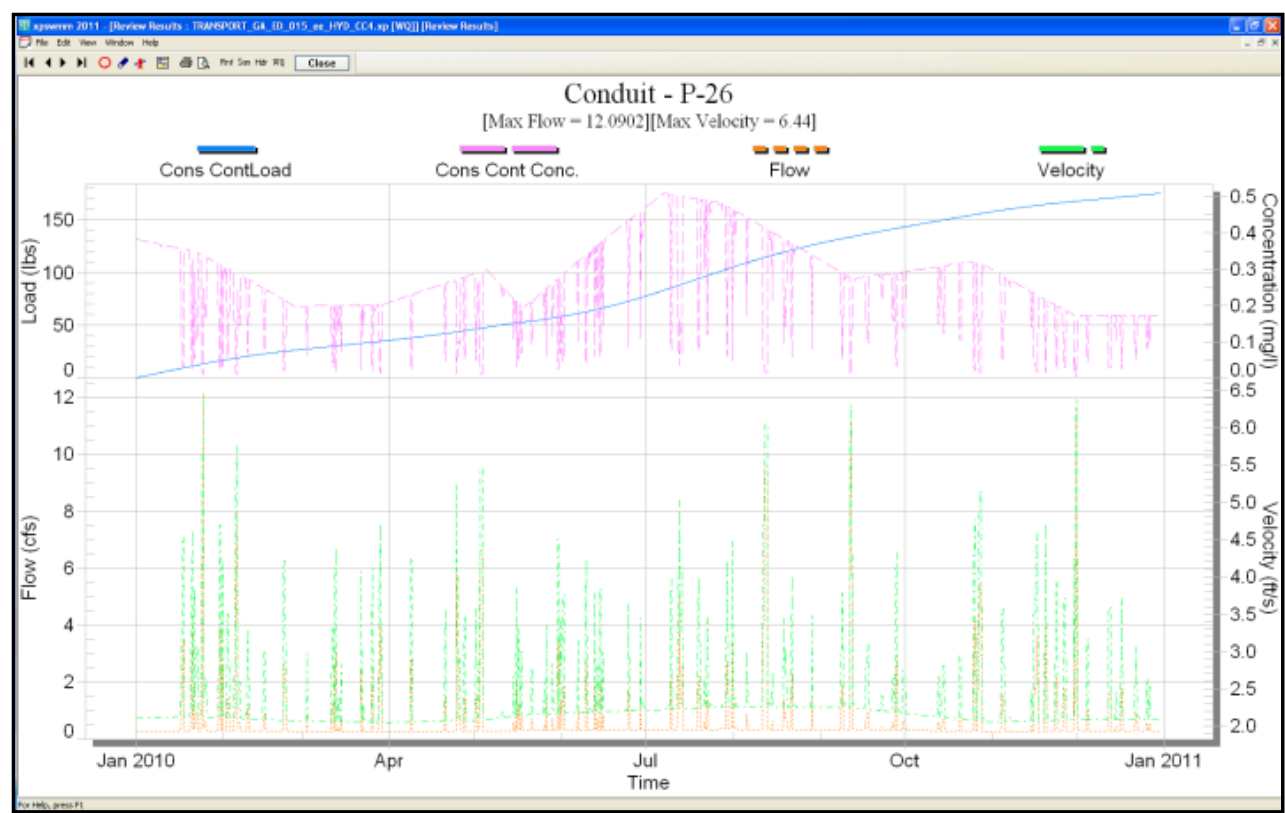

Figure 60 XPSWMM Scenario 4 P-26 Hydrograph and Pollutograph

There is a $0.5 \mathrm{cfs}$ peak around August which confirms that the concentrations were entered around that time. Similarly, the first peak is in response to the data entered. The peak flow rate is $6.85 \mathrm{cfs}$. Peak concentration is $0.50 \mathrm{mg} / \mathrm{L}$ and total load of 83.98 lb.

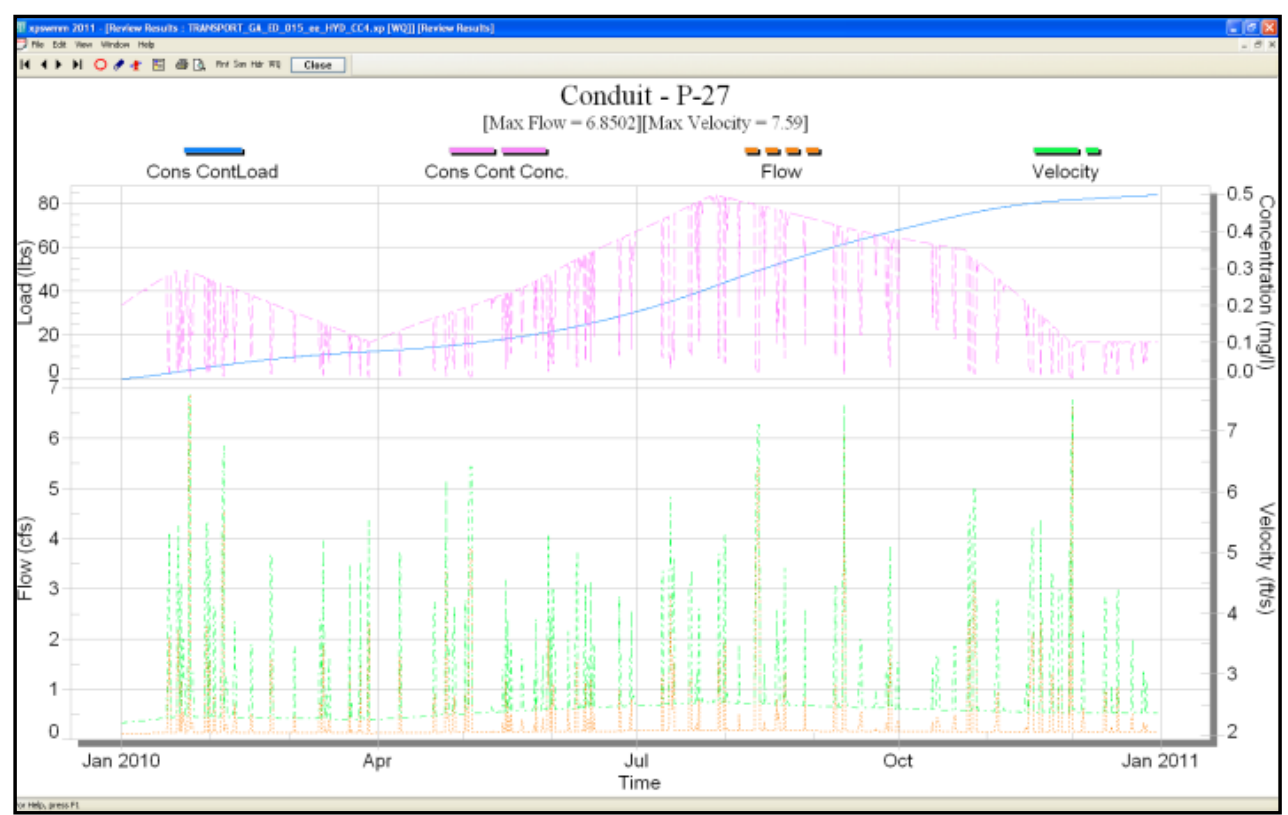

Figure 61 XPSWMM Scenario 4 P-27 Hydrograph and Pollutograph 


\subsection{Accuracy of the Model}

The model's accuracy is indicated by the convergence of the numerical calculations which is demonstrated by continuity checks. The model provides continuity errors for the overall efficiency of the model. The continuity check is performed for each simulation and is displayed to the user after each simulation completion. The model provides results as a cumulative depth for each simulation for precipitation, infiltration, evaporation, surface runoff from watersheds, and water in surface storage. These numbers are consistent for all four simulations as the same rainfall events were simulated and the timeseries flow rates introduced were of similar magnitude. Table 17 represents the continuity results from the model for the transport scenarios.

Table 17 Continuity Results

\begin{tabular}{|l|c|}
\hline \multicolumn{2}{|c|}{ Continuity Results over Entire Basin for Transport Simulations } \\
\hline \multicolumn{1}{|c|}{ Surface Water } & $\begin{array}{c}\text { Depth } \\
\text { (in.) }\end{array}$ \\
\hline Total Precipitation & 603.798 \\
\hline Total Infiltration & 33.725 \\
\hline Total Evaporation & 16.988 \\
\hline Surface Runoff from Watersheds & 553.096 \\
\hline Total Water remaining in Surface Storage & - \\
\hline Infiltration over the Pervious Area & 415.946 \\
\hline
\end{tabular}

The continuity check for surface water is calculated by the following equations:

Error in Continuity $=$ Precipitation - Infiltration - Evaporation - Surface Runoff from Watersheds - Water in Surface Storage

where the losses are equal to the last four terms in the above equation

$$
((1-(\text { Precipitation / Losses })) * 100)
$$


XPSWMM provides a continuity check for each simulation. XPSWMM considers simulation errors under $1 \%$ as excellent concluding that the equations converged and few errors occurred. All simulations produced for this study were under $1 \%$ error. Thus, the main objectives of this study was met which were to develop a reliable hydraulichydrologic surface water model where it accurately represents the simulation of the rainfall and the routing of the runoff through the network as well as to provide detailed information about flow rate and stage timeseries during various stormwater events via hydrogpraphs.

\subsection{Probability Exceedance Analysis of Hydrologic Events}

The simulations run for the sensitivity and transport analysis generate a large amount of data due to the fact that there are 52 nodes and 51 links in the network. XPSWMM generates six variables for each simulation run for the hydrology analysis node depth, node elevation, link velocity, link upstream elevation and link downstream elevation. However, this study focuses on the flow rates of MH211-3 and OF-211 and the links P-10, P-11, P-15, P-26, and P-27 as shown in the Figure 62 for both the hydrology and transport analyses. Thus, there is a need for a program to read the results and plot the data in a timely manner for data analysis. MATLAB was chosen for the task. MATLAB produced plots for each variable versus time and their probability exceedance curves (PEC).

The simulations were run where the data was saved every 300 minutes throughout the yearly simulation. Thus, 1 year saved every 300 minute interval gives 1748 intervals. When analyzing a peak flow rate for a specified pipe it may be difficult to sort through the 1748 intervals of flow rates for that single pipe. Thus, the PE has been calculated for 
all pipes and nodes within the remaining simulations in order to find the maximum flow rate within a pipe and for what percent of the time it remains at that flow rate. For instance, if a node meets or exceeds its link flow rate for $95 \%$ of the duration of the storm event, then it may be necessary for improvements to be considered. When producing PEC time is not a factor and the PEC is calculated as follows, where the rank data of the elevation from largest to smallest and the number of intervals which equals 1748 for the sensitivity analysis and transport analysis, are considered:

$$
\text { Probability Exceedance }=\text { Rank } /(\text { Total Number of Values }+1)
$$

The following figures are hydrographs representing the four scenarios and their PEC. Link P-10 shows a larger variance in PE compared to the other links. The hydrograph results indicate the difference in baseflows presented into the system. In the first transport scenario a $0.17 \mathrm{cfs}$ flow rate was introduced and the remaining flow rates began at zero and varied throughout. This is accurately portrayed in the hydrograph above. The PEC also indicates a substantial difference between the first scenario and the fourth where the flow rate remains at $0.5 \mathrm{cfs}$ or below for approximately $96 \%$ of the time when the constant timeseries was entered and at $0.5 \mathrm{cfs}$ or below for approximately $97 \%$ of the time when varied timeseries data was entered. It is important to note that P-10 is above MH211-3, a major junction point, so only the timeseries data entered is represented. If it were after the MH211-3 additional flows would be encountered and the input convoluted. 


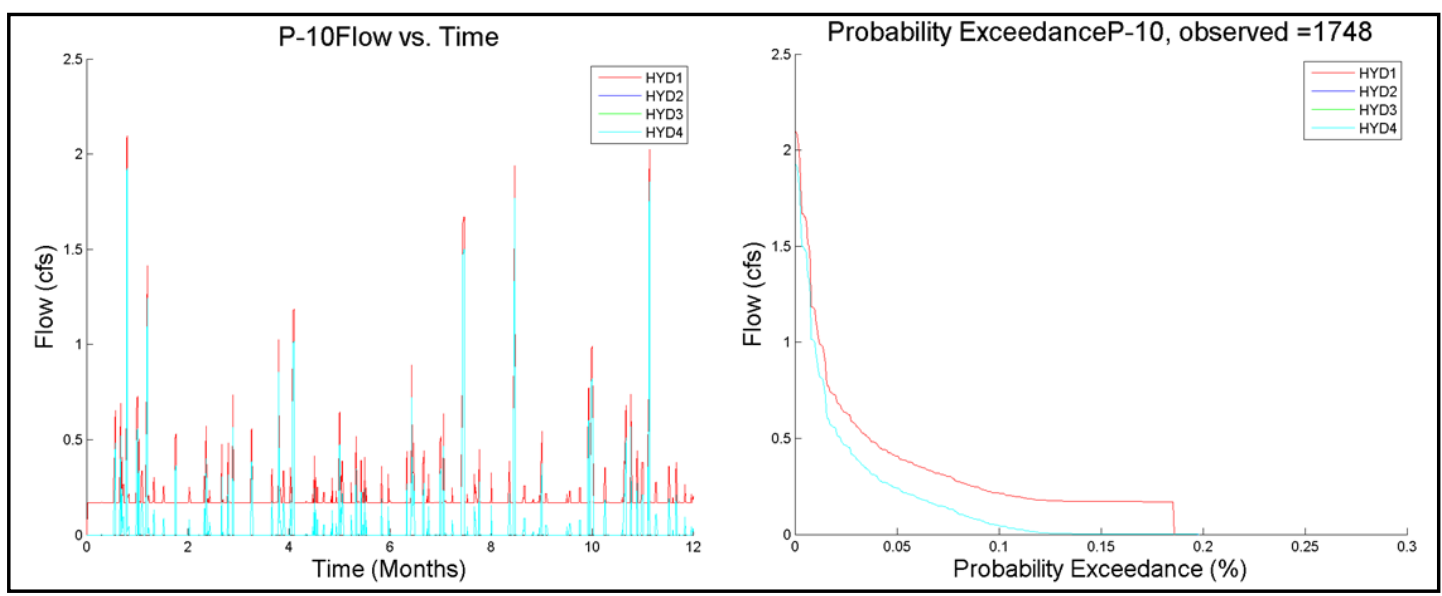

Figure 62 P-10 Hydrographs Indicating Scenarios 1-4 and their PE Curves

P-26, the link prior to OF-211, conveys the flows accumulated by the entire system so it is a combination of the timeseries data entered. The timeseries entered were upstream of P-26 for the four scenarios. Notice the flow rates begin at approximately 0.15 cfs which represents a combination of the flow rates entered for the four scenarios. Also, the PEC are closer together indicating less variation in flow rates.

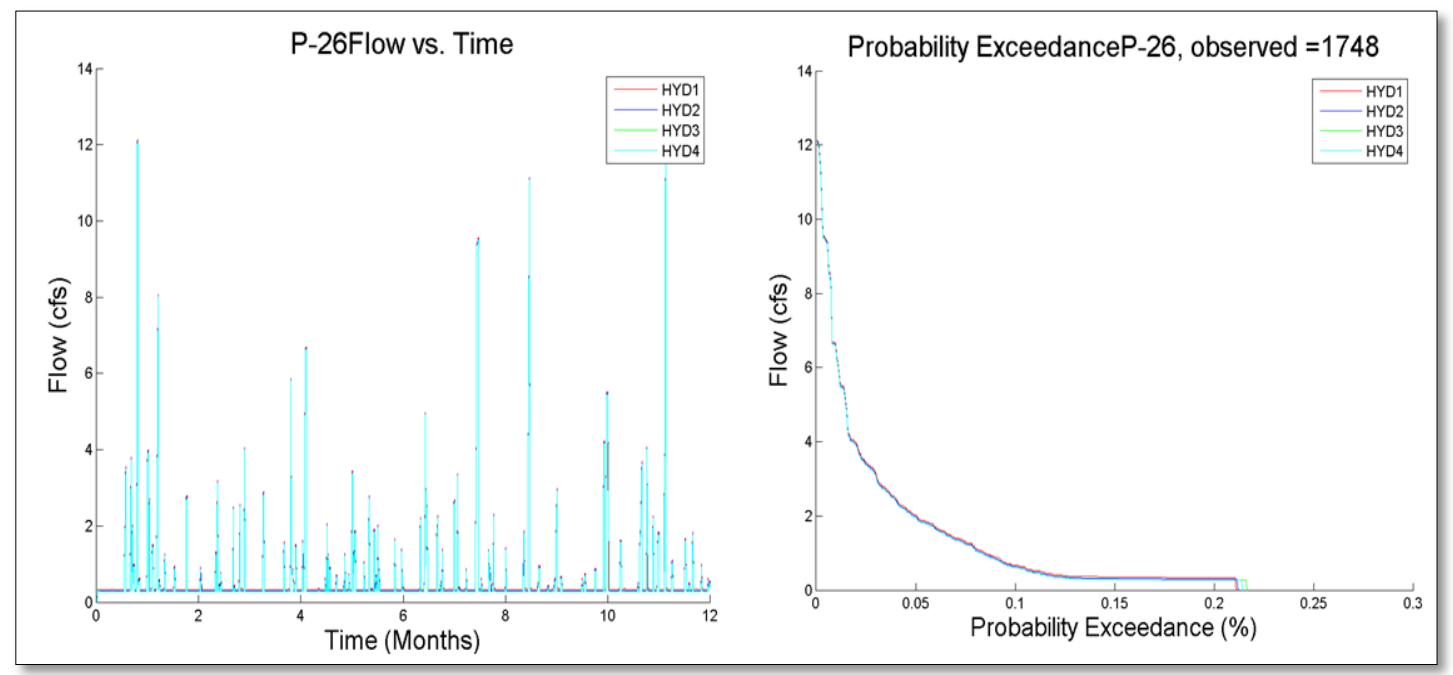

Figure 63 P-26 Hydrographs Indicating Scenarios 1-4 and their PE Curves 


\subsection{Probability Distribution of Hydrologic and Transport Data}

It is known that hydrological data follows a pattern (Hanson, 2008; Kroll, 2002; Mahdavi, 2010; Vogel, 1996). More specifically, low stream flow and rainfall depth are two hydrological data types that are continually analyzed and fit to probability distributions (PDs) to better understand their patterns and understand the underlying trend that the quantities follow. (Hanson, 2008; Kroll, 2002; Vogel, 2002). Hydrological timeseries data can be lengthy and numerous; thus, fitting the data to a PD allows the data to be characterized by its high and low distributions, which reduces the level of risk and uncertainty of results and allows for better understanding of data parameters when they are analyzed as a whole and fitted to a PD. This permits the extrapolation of data, for example in special situations such as defective monitoring equipment, on the assumption that the hydrological parameters at that given location are consistent with nearby outfalls, and may permit an educated guess with some certainty that the data may be a realistic solution. Thus, the hydrograph and pollutograph timeseries data from the transport simulations were entered into the EasyFit 5.5 tool where it fit the data to numerous probability distribution functions and ranked them according to Komogorov Smirnov, Anderson Darling, and Chi-Squared methods. The distribution fits were ranked highest by the Komogorov Smirnov method for this study.

The first ranked distributions were chosen for the majority of the parameters, but were not chosen for all due to the fact that the best fit distributions were not widely known. For instance, for Scenario 1, P-11 concentration was best fit to the generalized gamma (4P) distribution. Thus, for the purpose of this study the following widely used 
PDs were chosen for analysis: Lognormal, Log-logistic, Logistic, Generalized Extreme Value (GEV), Inverse Gaussian, and Exponential.

The following tables 18 through 21, display the resulting distributions out of the six chosen probabiilty distributions from the 'goodness of fit' test for the four scenarios. The not applicable (N/A) is indicated where no contaminant or load should be found due to the fact that it was not introduced into the system upstream of that location.

Scenario 1 flow rates do not follow one but all vary between the distributions. The contamination concentration data fit the log-logistic distribution. The load contaminant concentration data is split in half between Log-logistic and Logistic.

Table 18 Scenario1 'Goodness of Fit' Results

\begin{tabular}{|c|c|c|c|}
\hline \multicolumn{4}{|c|}{ HYDRAULICS SCENARIO 1 } \\
GOODNESS OF FIT RESULTS \\
\hline Pipe & FLOW & CONCENTRATION & LOAD \\
\hline P-10 & Lognormal & Log-Logistic & Log-Logistic \\
\hline P-11 & Logistic & N/A & N/A \\
\hline P-15 & Exponential & Log-Logistic & Logistic \\
\hline P-26 & Log-Logistic & Log-Logistic & Logistic \\
\hline P-27 & GEV & GEV & Log-Logistic \\
\hline
\end{tabular}

Scenario 2's 'goodness of fit' results shown in Table 19 conclude that the flow rate and contaminate concentration may be characterized by the GEV and the contaminant load is represented by the lognormal distribution.

Table 19 Scenario 2 'Goodness of Fit' Results

\begin{tabular}{|c|c|c|c|}
\hline \multicolumn{4}{c|}{ HYDRAULICS SCENARIO 2 } \\
GOODNESS OF FIT RESULTS \\
\hline Pipe & FLOW & CONCENTRATION & LOAD \\
\hline P-10 & Logistic & N/A & N/A \\
\hline P-11 & Lognormal & GEV & Logistic \\
\hline P-15 & GEV & GEV & Lognormal \\
\hline P-26 & GEV & Log-Logistic & Lognormal \\
\hline P-27 & GEV & GEV & Lognormal \\
\hline
\end{tabular}


Scenario 3 links, P-10 and P-11, contain runoff only and share the Logistic distribution fit; however, three out of five links share the generalized extreme value distribution. The concentration data and contaminant load is characterized by the generalized extreme value distribution.

Table 20 Scenario 3 'Goodness of Fit' Results

\begin{tabular}{|c|c|c|c|}
\hline \multicolumn{4}{|c|}{ HYDRAULICS SCENARIO 3 } \\
GOODNESS OF FIT RESULTS \\
\hline Pipe & Q & C & L \\
\hline P-10 & Logistic & N/A & N/A \\
\hline P-11 & Logistic & N/A & N/A \\
\hline P-15 & GEV & GEV & GEV \\
\hline P-26 & GEV & GEV & GEV \\
\hline P-27 & GEV & Lognormal & GEV \\
\hline
\end{tabular}

Lastly, scenario 4 indicates the combination of runoff and additional flow rate is characterized by the generalized extreme value distribution as shown in links P-15 and P27. The contaminant concentration also fits the generalized extreme value distribution, and lastly, the contaminant load the log-logistic distribution.

Table 21 Scenario 4 'Goodness of Fit' Results

\begin{tabular}{|c|c|c|c|}
\hline \multicolumn{4}{|c|}{ HYDRAULICS SCENARIO 4 } \\
GOODNESS OF FIT RESULTS \\
\hline Pipe & Q & C & L \\
\hline P-10 & Logistic & N/A & N/A \\
\hline P-11 & Logistic & N/A & N/A \\
\hline P-15 & GEV & GEV & Log-Logistic \\
\hline P-26 & Log-Logistic & GEV & Log-Logistic \\
\hline P-27 & GEV & GEV & Log-Logistic \\
\hline
\end{tabular}




\section{ASSUMPTIONS}

Although data was obtained for the development of the model, the following assumptions were made:

1. The network is an isolated system and only includes surface water runoff from the 4500 Area discharging into WOC via Outfall 211;

2. There are various pipe inverts, manhole rim elevations, and inlet elevations throughout the system;

3. Delineation of the roof area contributing to the roof drains for surface water routing;

4. Delineation of the sub-drainage areas;

5. Percent impervious of each sub-drainage area;

6. Evaporation of $0.1 \% /$ day over impervious area for yearly simulations;

7. OF-211 does not encounter backflow; however, during large storm events backflow conditions would apply.

\section{LIMITATIONS}

A limitation of the study, that must be noted, is that the impervious area for each sub-catchment area was estimated. The impervious area directly affects the quantity of contaminant transport through the system; the greater the percent impervious, the greater the mobility of the contaminant. Thus, it is highly recommended to investigate the actual percent impervious of each sub-catchment area. In addition, the infiltration method, Green Ampt, chosen for the majority of the simulations should be further analyzed. 
EPA developed XPSWMM in 1971 and has been improved upon since. It is a reliable computer model that is capable of providing hydraulic-hydrologic insight in minutes. One major utility company, Miami-Dade County Water and Sewer Department, utilizes the software to determine flow rates and water stages of their stormwater and wastewater systems when and where necessary.

However, there were a few areas in which the model could have performed more effectively. First, extraction of concentration data was inaccurate. The program does export data into excel; however, if the resulting value is less than a hundredth then it is considered zero. This was time consuming, to have to manually transfer the vast amount of resulting velocity, flow, contamination concentrations, loads, etc. manually during the transport analysis for multiple the simulations. In addition, XPSWMM did not provide accurate concentration timeseries. This may be related to the fact it has difficulty processing numbers smaller than a hundredth.

Finally, ORNL's main concern is mercury contamination remaining from the production of nuclear weapons. However, XPSWMM cannot accurately model contamination that transforms within soil, water, and air phases. For instance, when elemental mercury is released into the environment it encounters anaerobic organisms within sediments and aquatic systems that transform the elemental mercury into methyl mercury. XPSWMM is not equipped to calculate the absorption of mercury.

\section{CONCLUSIONS}

The results of this study achieved the stated objectives of producing a calibrated surface water model for ORNL's future use, providing a transport analysis of 
contaminants, and provided a method of characterizing transport data and to understand flows and trends.

\subsection{Calibration of Surface Water Model}

The first objective was to produce a calibrated surface water model that encompassed multiple simulations through the sensitivity analysis of the model, simulation of design storms, and model calibration.

\subsubsection{Sensitivity Analysis}

A sensitivity analysis of the model was conducted to determine how a change in variables impact model results. Minor variations in Manning's coefficients and infiltration parameters were introduced. The model indicated it was stable in that it accurately portrayed the minor variations presented. If greater variation in results is desired then greater variation in parameter is recommended.

\subsubsection{Design Storms Conclusions}

The hydraulic grade line (HGL), flow rates, and capacities were analyzed for the 5, 10, 25, and 100 design storms. The HGL rose higher for the 10 year storm event than the 5 year storm event, due to the amount of precipitation simulated over the site, but did not cause ponding as the capacity of the stormwater pipes did not reach capacity. During the 25 year storm event, pipes downstream of MH211-3 to I-3 encountered ponding and flow rates were estimated around 22.2 cfs. Downstream of I-3, higher flow rates up to $28.2 \mathrm{cfs}$ were encountered. There were areas where HGL was above the ground elevation downstream of I-3indicating ponding within the system. As expected, the 100 year storm produced a larger runoff excess than the 25 year storm event. MH211-3 to I-3 
encountered ponding and flow rates around $27.6 \mathrm{cfs}$. Downstream of I-3 flow rates up to $35.1 \mathrm{cfs}$ were encountered as well as flooding which is indicated by the rise of the HGL above the ground elevation.

The model proved to be robust as it accurately responded to the design storms. Flow rates and water stages increased as expected with an increase in the amount of precipitation over the site.

\subsubsection{Model Calibration}

The first calibration exercise simulated steady uniform flow. The runoff from the two sub-drainage areas were routed through the network and a) compared to the XPSWMM OF-211 flow rate results and b) compared to the rational method calculation for the sub-drainage areas and OF-211. The model's results for both sub-drainage areas were consistent with the rational method and indicate that the model accurately simulated steady uniform flow.

The next set of calibration exercises was conducted for the routing of unsteady non-uniform rainfall through the system. This consisted of simulating actual rainfall events and comparing the model results to ORNL's OF-211 monitored flow rate data. Precipitation in general is unsteady and non-uniform; thus, producing unsteady nonuniform runoff and flow rate within the pipes. ORNL provided monitored flow rate data at OF-211, specifically for the calibration of the model. The monitored flow rate data was taken during the timeframe of November 12, 2012 ending on December 17, 2012. During this time four rainfall events occurred. Each rainfall event was routed separately and comparisons between the actual rainfall data and the XPSWMM results were made. Trial 
1 rainfall event produced the most accurate results differing only $0.5 \mathrm{cfs}$, trial 2 by 0.9 cfs, trial 3 by $7.1 \mathrm{cfs}$, and trial 4 by $9.1 \mathrm{cfs}$. Thus, the model demonstrated to be an effective tool as it accurately responds to rainfall data as shown by the calibration.

It is known that the system has a baseflow rate of once-through $\mathrm{AC}$ unit condensate water from the buildings within the area of interest; however, the quantity was unknown. It was determined from the calibration exercises that the baseflow rate quantity is estimated at $0.17 \mathrm{cfs}$.

\subsection{Transport Analysis}

The second objective was to provide a transport analysis by introducing a conservative contaminant into the system at various locations in order to examine the peak concentrations downstream where existing contamination may be located within the system. This was done by using the model to introduce a contaminant and examine the resulting hydrographs and pollutographs showing contamination within the system

These results provide valuable insight. Under the conditions assumed, peak concentrations were examined throughout the system. Contaminants will bind themselves with suspended or dissolved solids and transport themselves when runoff occurs. The peak concentrations indicate where contaminant mobility occurs under the given circumstances.

\subsection{Characterize Transport Data and Show Trends}

The third objective, to fit the transport data to PEC and PDFs in order to characterize the data and understand the underlying trend of the flow rates, concentrations, and loads, was met. This was achieved by utilizing two additional programs, MATLAB and Easy Fit Tool. 
PEC determined the duration peak flow rates and water stages exist during single or continuous storm events. MATLAB was used to produce hydrographs and PEC for the sensitivity analysis and design storms. The PECs provide information about the variation in flow rates and water stages for the specified period of time.

The flow rates and water stages were fit to PDFs using Easy Fit. The flow rates and concentrations produced by the transport analysis were best described by the Generalized Extreme Value, while the loading rates were best described by Log-logistic distribution.

Ultimately, ORNL is concerned with residual contamination within the 4500 Area. This model has proved to be an effective tool in understanding the flow characteristics within the study area. Coupling the flow rate data provided by this study with contaminant concentrations will provide possible areas where existing contaminant loads occur within the system. These areas may be located and remediation may be applied.

\section{RECOMMENDATIONS}

The parameters of the model developed for this study can be used to develop a second model that is capable of accurately routing mercury transport. The sensitivity analysis and calibration trials run for this study should also be conducted on the second model to compare the output. The model results should be consistent with that of OF211's data. If it is not, then the model's parameters must be further explored.

This study reviewed the Green Ampt and Horton's methods. Variations in elevations were noted between the two methods. For the purposes of this study, suggested 
regeneration and decay rates were chosen for the Horton's regeneration method. However, further analysis of the Horton's regeneration and decay rates could be analyzed to ensure proper infiltration methods are used for future simulations such as simulating the Horton's infiltration method but varying $\mathrm{k}$, the decay coefficient.

XPSWMM simulated rainfall over the area of interest and estimated high and low flow rates via hydrographs for continuous yearly simulations for each outfall. Resulting flow rates may be entered along with concentration samples at the outfalls within the area of interest provided by ORNL. Simulating rainfall over the area of interest will provide insight into the dispersion of the mercury contamination within the area. The necessary path for remediation will be dependent upon on the range of concentration and the proximity of the contamination plumes. 


\section{REFERENCES}

Bonnin, D. M., Lin, B., Parzybok, T., Riley, D. and Yekta, M. (2006). PrecipitationFrequency Atlas of the United States. National Oceanic Atmospheric Administration Atlas 14, 2, 3.0., National Weather Service, Silver Spring, Maryland.

Brooks, S. C., Southworth, G. R. (2011). History of mercury use and environmental contamination at the Oak Ridge Y-12 Plant. Environmental Pollution 159(1), 219-228.

Chanson, H. (2004). Environmental Hydraulics of Open Channel Flows. Burlington, MA: Elsevier Butterworth-Heinemann.

ChemRisk. (1999). Radionuclide Releases to the Clinch River from WOC on the Oak Ridge Reservation-An Assessment of Historical Quantities Released, Off-site Radiation Doses, and Health Risks, Task 4. Reports of the Oak Ridge Dose Reconstruction, Volume 4. Tennessee Department of Health.

Chow, V. T., Maidment, D. R., and Mays, L. W. (1988). Applied Hydrology. McGrawHill, New York City.

City of Knoxville. (2005). Land Development Manual, Chapter 22.5 Stormwater and Street Ordinance. 20.

Elliott, A. H. and Trowsdale, S. A. (2007). Environmental Modelling and Software, 22(3), 394-405.

Fiuzat, A. A. (1991). Functional Requirements for Waste Area Grouping 6 Monitoring Station 3 Upgrade. Oak Ridge National Laboratory, TN.

Franzetti, S. M. (2005). Background and History of Stormwater Regulations. Franzetti Law Firm P.C. Oak Brook, Illinois.

Hanson, L. S. and Vogel, R. (2008). The Probability Distribution of Daily Rainfall in the United States, World Environmental and Water Resources Congress 2008, 1-10.

Hossein, E., Rottle, N., and Batten, L. (2012). Stormwater Estimation For Management In Urban Watersheds: A Landuse-Based GIS Model. 2012 AWRA Spring Specialty Conference.

Jacobson, C. R. (2011). Identification and Quantification of the Hydrological Impacts of Impervious in Urban Catchments: A Review, Journal of Environmental Management, 92, 1438-1448. 
Kroll, C. N. and Vogel, R. M. (2002). Probality distribution of low streamflow series in the United States, Journal of Hydrologic Engineering, 7, 137-146.

Lindeburg, M. R. (2006). Civil Engineering Refernce Manual. Tenth Edition. Professional Publications, Inc., Belmont, CA.

MATLAB. (2008). Mathworks Help Files, Cambridge MA.

Mahdavi, M., Osati, K., Sadeghi, S. A. N., Bakhtiar, K., and Mobaraki, J. (2010). Determining Suitable Probability Distribution Models for Annual Precipitation Data (A Case Study of Mazandaran and Golestan Provinces), Journal of Sustainable Development 3, No.1, 159-168.

Mein, R. G. and Larson, C. L. (1973). Modelling Infiltration during a steady rain, Water Resource Research, 9(2), 384-394.

Morss, R. E., Downton, M. W., Wilhelmi, O. V., Gruntfest, E. (2005). Flood Risk, Uncertainty, and Scientific Information for Decision Making: Lessons from an Interdisciplinary Project. Bull. Amer. Meteor. Soc., 86, 1593-1601.

Oak Ridge National Laboratory (ORNL). (2008). Oak Ridge Reservation Annual Site Environmental Report 2007: Chapter 1 Introduction to the Oak Ridge Reservation. Home of the Oak Ridge Reservation Annual Site Environmental Report. Oak Ridge National Laboratory September 2008. UT-Battelle, LLC, for the Department of Energy.

Ravichandran, M. (2003). Interactions between mercury and dissolved organic matter-a review. Chemosphere 55 (2004) 319-331.

Risse, L. M., Nearing, M. A., and Savabi, M. R. (1994). Determing the Green Ampt Effective Hydraulic Conductivity From Rainfall-Runoff Data For the WEPP Model. Journal of the American Society of Agricultural Engineers, 37(2), 411418.

Taylor, F. G., Jr. (1989). Mercury Monitoring of Water and Sediment in Oak Ridge National Laboratory Streams During 1989. ORNL Environmental and Health Protection Operated by Martin Marietta Energy Systems, Inc. for the United States Department of Energy.

United States Department of Energy (USDOE). (1999). Remedial Investigation/Feasibility Study for Bethel Valley Watershed at Oak Ridge National Laboratory. Report\# DOE/OR/01-1748/V1\&D2. 
United States Environmental Protection Agency (USEPA). (2004). Health Assessment: Y-12 Uranium Releases. Federal Facilities Assessment Branch Division of Health Assessment and Consultation Agency for Toxic Substances and Disease Registry. USDOE Oak Ridge, Tennessee.

USEPA. (2006). Public Health Assessment White Oak Creek Radionuclide Releases Oak Ridge Reservation. Federal Facilities Assessment Branch Division of Health Assessment and Consultation Agency for Toxic Substances and Disease Registry. USDOE Oak Ridge, Tennessee.

Verma, S. C. (1982). Modified Horton's Infiltration Equation. Journal of Hydrology. Burlington, Elsevier, 58, 383-388.

Vogel, R. M., and Wilson, I. (1996). Probability distribution of annual maximum, mean, and minimum streamflows in the United States. Journal of Hydrologic Engineering. American Society of Civil Engineers, 1 (2), 69-76.

Yang W, Gan J., Hunter W, Spurlock F. (2006). Effect of suspended solids on bioavailability of pyrethroid insecticides. Environ Toxicol Chem. 2006 Jun; 25(6):1585-91. 